\title{
AN ALTERNATIVE TO DEVELOPMENT FRAMEWORK: A STUDY OF PERMACULTURE AND ANARCHISM IN GLOBAL JUSTICE MOVEMENTS IN NEW ZEALAND
}

By

\author{
Tazia Gaisford
}

A thesis

submitted to the Victoria University of Wellington

in partial fulfilment of the requirements for the degree of

Master of Development Studies

Victoria University of Wellington

2011 


\begin{abstract}
This study is a response to calls for alternatives to development by postdevelopment authors and critics of post-development alike. It asks "can the praxis of permaculture and anarchism provide an alternative to development?" Although alternatives to development arguably do not exist untouched by the dominant development paradigm, it is possible to imagine and to create the different possible organisations based on principles of mutual aid, direct action and self-management. Anarchism as a politically focused social philosophy and permaculture as an ecologically focused design philosophy are mutually beneficial in strengthening each other. The combined analysis of alternatives to development uses case studies in the Wellington Region, primarily Climate Camp Aotearoa, with permaculture and anarchist principles, and contributes another perspective to the post-development debate. The two approaches share converging central ethics, principles and struggles of praxis. They recognise that transformative change is necessary. Whether it is called a cultural revolution, transition or paradigm shift, the underlying recognition is that we need to live more harmoniously with each other and the natural environment by creating diverse post-industrial societies. Many tools, principles and processes advocated by alternative development and post-development are the same. However, the combination of those tools, principles and processes, and how they are designed and applied in relation to each other systemically, are significant in determining whether or not the intent is that of an alternative to development. Solidarity and stewardship, decentralisation and autonomy, tight multiple feedback mechanisms and a whole system design approach are some of the alternative people-focused solutions proposed by anarchism and permaculture. Fieldwork research was conducted using the qualitative ethnographic and action research methods of participant observation from a constructionist and post-development perspective. Global justice networks are given importance as examples of the anarchistic intent of alternatives to development.
\end{abstract}




\section{Acknowledgements}

Firstly I'd like to thank my supervisor, John Overton, for his guidance and enthusiasm, and for introducing me to anarchism as "an interesting theory to do a thesis on." I am grateful to Gary Williams, my Permaculture Design Course (PDC) teacher, for his valuable insights and for his support of this project from the start. A big thanks to all the Climate Camp Aotearoa local groups, particularly those in the North Island who I got to know most in 2009 and to the individuals within them who have been inspirational in so many ways. Thanks for being part of my personal paradigm shift. There are also many other individuals who have contributed intellectually in some way to this thesis or at least helped me through some difficult thought processes however briefly at different times. These conversations have been invaluable. I'd like to also thank my mother for laboriously trawling through drafts when I needed it most. 


\section{Table of Contents}

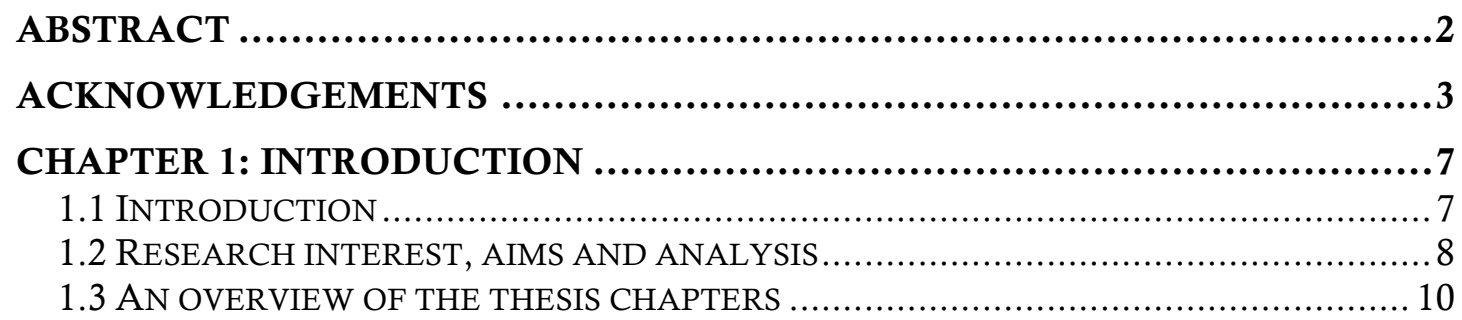

CHAPTER 2: POST-DEVELOPMENT THEORY, ANARCHISM, PERMACULTURE AND THE GLOBAL JUSTICE MOVEMENT ............... 11

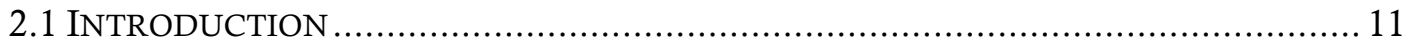

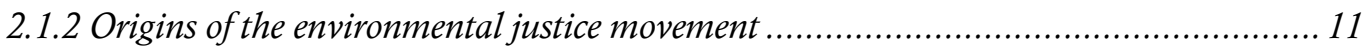

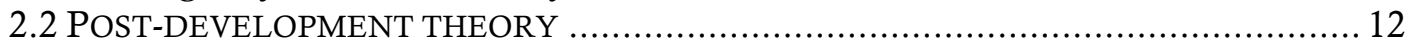

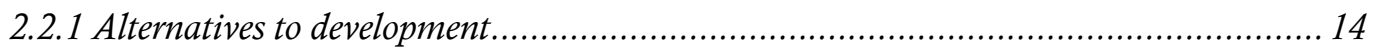

2.2.2 Global justice movements and alternatives to neo-liberalism................................... 15

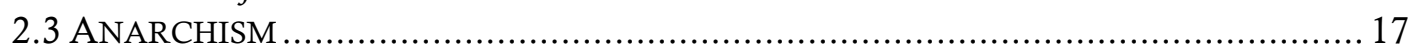

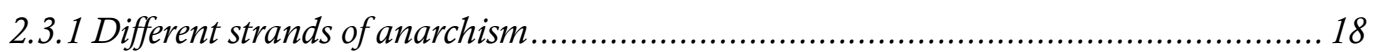

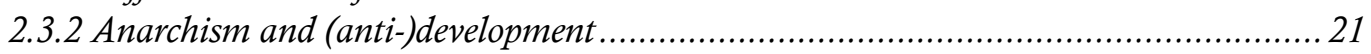

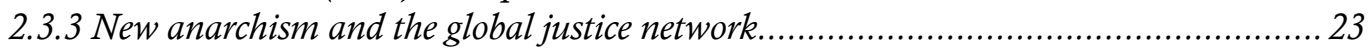

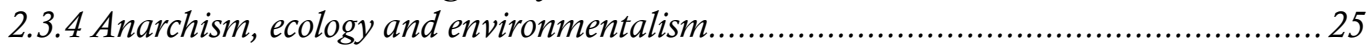

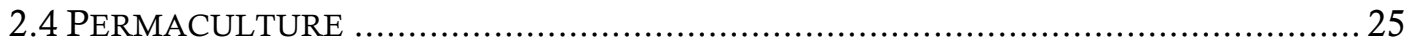

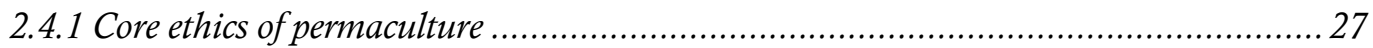

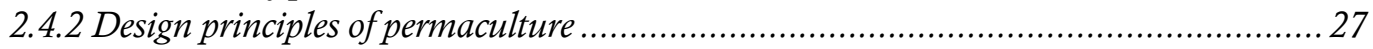

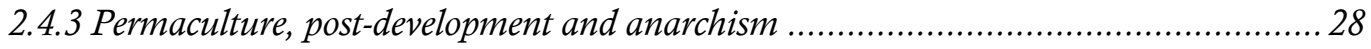

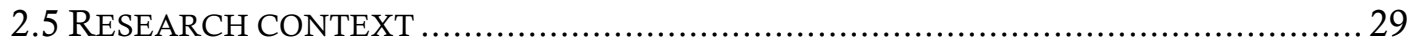

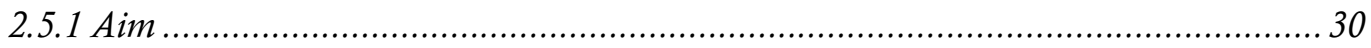

CHAPTER 3: RESEARCH APPROACH .......................................... 32

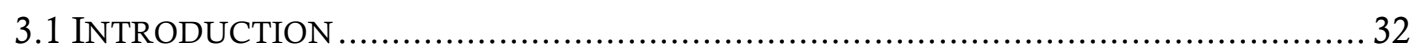

3.2 POST-DEVELOPMENT THEORY AND THE CALL FOR ALTERNATIVES ........................ 32

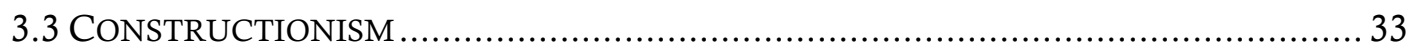

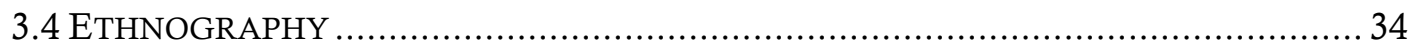

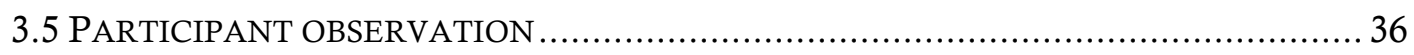

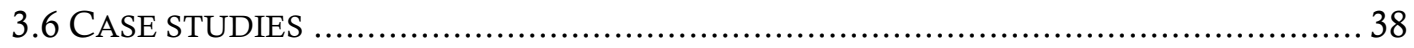

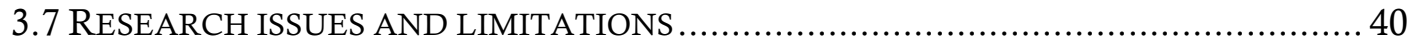

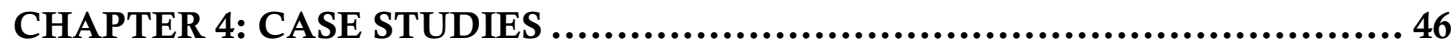

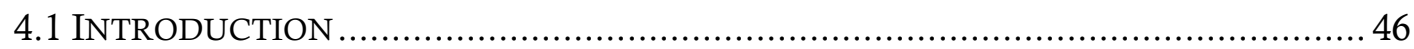

4.2 CAMP FOR CLIMATE ACTION AOTEAROA ….............................................. 46

4.3 PARIHAKA AND THE BEGINNINGS OF MY INVOLVEMENT .............................. 49

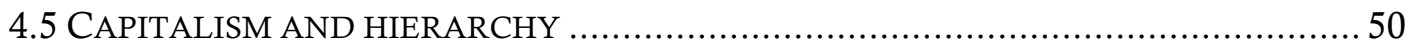

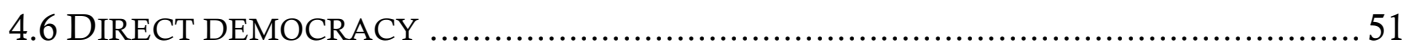

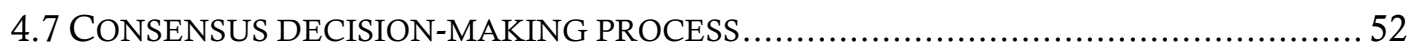

4.7.1 Key roles in the consensus decision-making process............................................. 53

4.7.2 Hand signals for communication in the consensus process....................................... 54

4.8 ORGANISING AND DECISION-MAKING STRUCTURES (AND PROCESSES) .................56

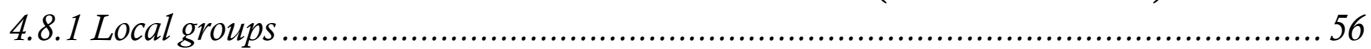

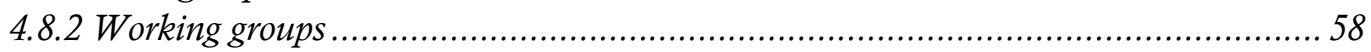

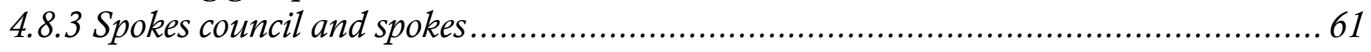

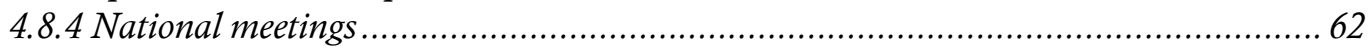

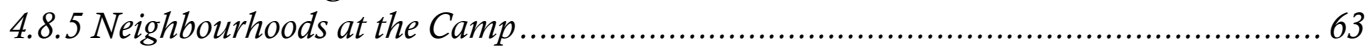

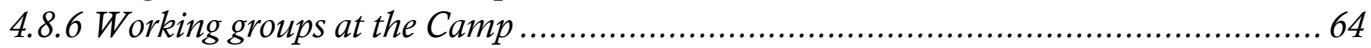




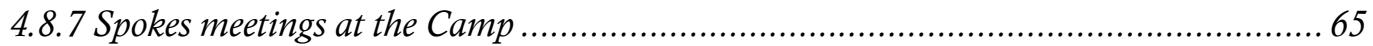

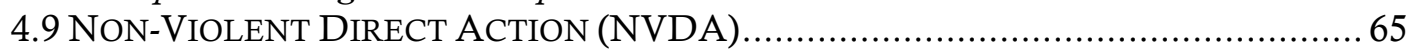

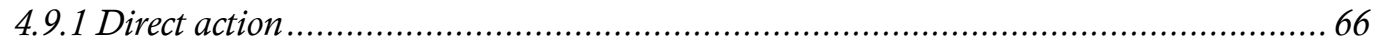

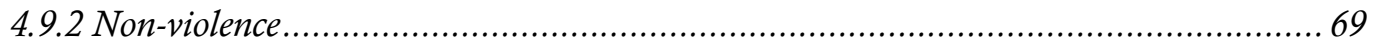

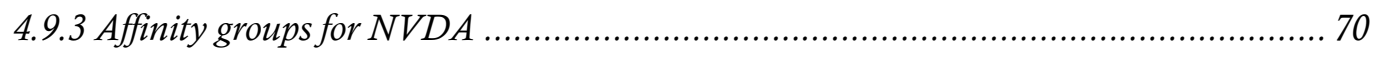

4.10 ELEMENTS OF THE CAMP REFLECTING PERMACULTURE …........................... 71

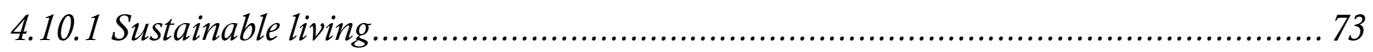

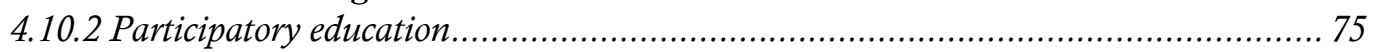

4.11 PERMACULTURE HUI PARTICIPATORY TOOLS FOR LEARNING …..................... 75

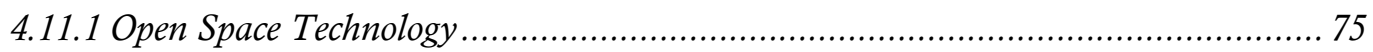

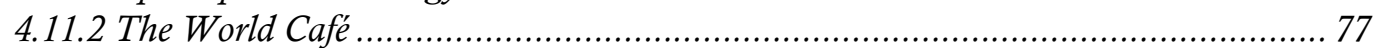

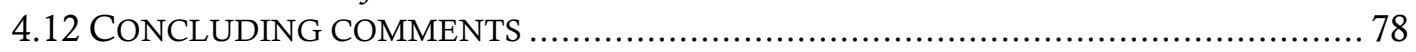

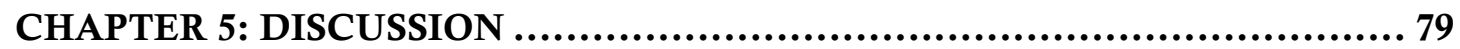

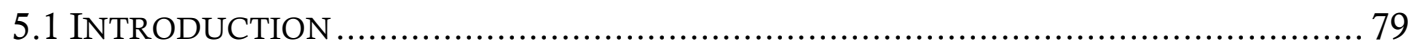

5.2 PERMACULTURE ETHICS AND DESIGN PRINCIPLES ..................................... 79

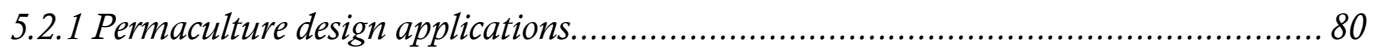

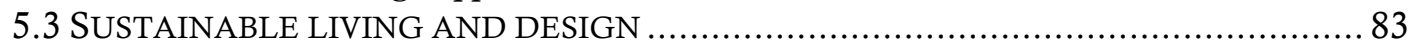

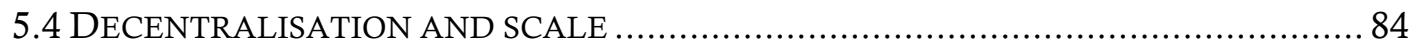

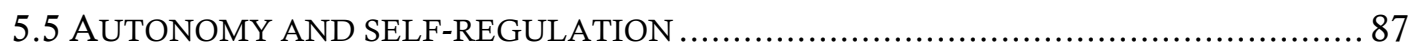

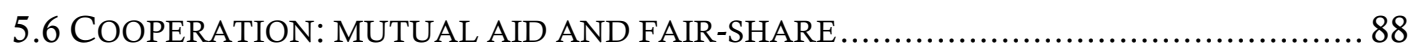

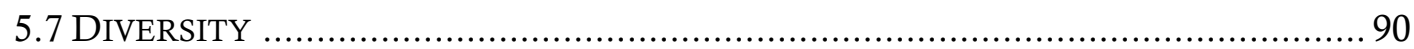

5.8 TAKING ACTION: DIRECT ACTION AND SELF-RELIANCE ................................. 91

5.9 DIRECT DEMOCRACY, COMMUNITY GOVERNANCE AND INVISIBLE STRUCTURES 92

5.9.1 Inequalities, conflict and informal hierarchies................................................. 95

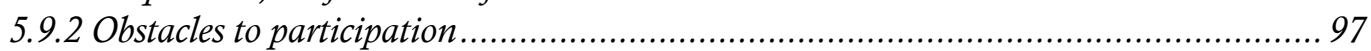

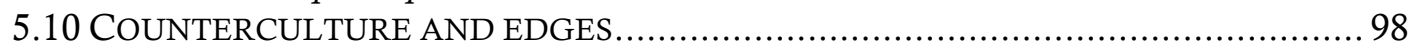

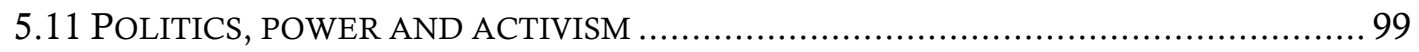

5.12 VARIATION BETWEEN PERMACULTURE AND ANARCHISM .......................... 101

5.13 TACTICS: CONFRONTATION AND 'UNDER THE RADAR' ................................ 103

5.14 ALTERNATIVE SYSTEMIC PRINCIPLES AND SOLUTIONS ............................... 105

5.15 CONCLUSION: ANARCHISM AND PERMACULTURE IN MUTUAL SOLIDARITY ... 106

CHAPTER 6: CONCLUSION ...................................................... 108

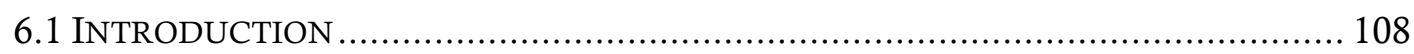

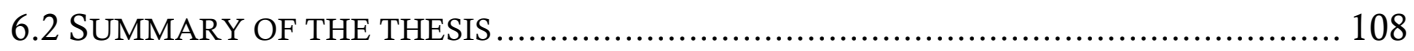

6.3 AN ALTERNATIVE TO DEVELOPMENT FRAMEWORK ..................................... 113

6.4 ALTERNATIVE DEVELOPMENT AND DEVELOPMENT INTENT ......................... 117

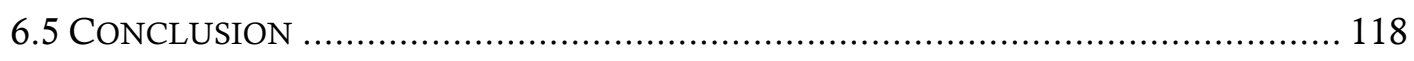

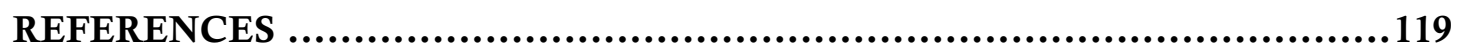




\section{List of Figures}

\section{CHAPTER 4}

Figure 4.1 CAMP FOR Climate Action Aotearoa Principles AND

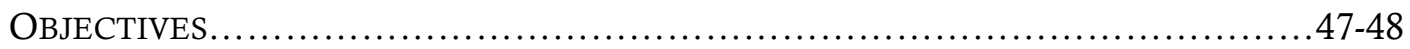

Figure 4.2 The 'CAPitAlism RePresents AcCePtable Policy' (C.R.A.P) AFFINITY GROUP ................................................................ 50

FIGURE 4.3 DIAGRAM SHOWING THE RELATIONSHIP BETWEEN LOCAL GROUPS AND

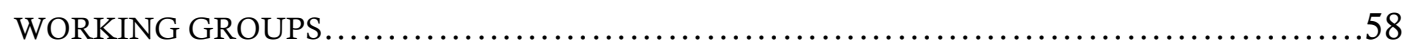

FIGURE 4.4 HORIZONTAL DECISION-MAKING STRUCTURES AND PROCESSES.........60

FIGURE 4.5 DIAGRAM OF THE SPOKES COUNCIL ....................................62

FigURE 4.6 CLIMATE CAMPERS MARCH ALONG LAMBTON QUAY....................67

Figure 4.7 Setting up the entrance to the Climate Camp at Moonshine

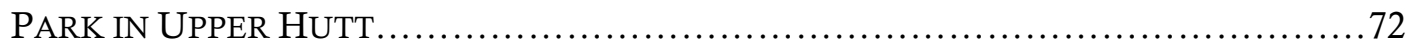

FIGURE 4.8 SETTING UP THE SITE .............................................. 73

FIGURE 4.9 'DOING IT OURSELVES’ SUSTAINABILITY................................ 74

\section{CHAPTER 5}

Figure 5.1 DAVID HOLMGREN's TwElve PERMACUlture Design PRINCIPLES...80

Figure 5.2 THE PERMACUltURE Flower........................................ 81 


\section{Chapter 1: Introduction}

\subsection{Introduction}

We live in a world of great disparity and suffering caused by human activities. Ecological exploitation and degradation, increasing climate change, poverty and hunger, species extinction, the endless pursuit of profits and material wealth, fossil fuel dependence and exponential growth are all aspects of a dominant economic development mindset and its practices.

What are the alternatives? How can we live cooperatively with each other and include our ecological environment in how we organise ourselves? This thesis seeks to answer the above questions through the theoretical perspective of the post-development call for alternatives to development (e.g. Escobar, 1995; Gibson-Graham, 2005; Sidaway, 2007). More specifically, the thesis asks whether the principles and practices of anarchism and permaculture can provide an alternative to development framework? The anarchistic nature of postdevelopment has not, to my knowledge, been explored in detail, although the sentiment has been recognised (e.g. Nederveen Pieterse, 2001, p. 117).

Post-development has looked to 'new social movements' as leading the search for alternatives and going beyond development (e.g. Bullard, 2005; Escobar, 1999). These movements have been described as anarchistic in principle and practice, although this 'new' (Graeber, 2002) or 'post-ideological' (Curran, 2006) anarchism holds a broad global justice perspective and addresses all manifestations of domination and oppression, including green issues, and not just those pertaining to state and industry.

Permaculture is another practical and ethical philosophy that, like anarchism, seeks to create alternatives to the modern industrial complex and centralised systems. The design approach looks to nature for cooperative ways of designing and organising our environments and ourselves. Design is central to permaculture and its ethics underpin the twelve principles used in permaculture design. 
Development is seen by the post-development perspective as an interventionist and managerial strategy of hegemony (e.g. Escobar, 1999; U. Kothari, 2005; Nederveen Pieterse, 2001; Rist, 1997) and there are calls for the 'developed' world to look at its own social and ecological problems and stop interfering with the 'Third World' (e.g. Latouche, 1993; Sachs, 1997). The case studies in this thesis are thus New Zealand based and show anarchist and permaculture examples of alternatives to the dominant cultural paradigm of development. The anarcho-communalist perspective is the most widespread strand of anarchism in New Zealand and most complementary to permaculture and post-development approaches. It is this strand that is emphasised in this thesis.

The recent trend in post-development is towards a more hopeful approach to the implications of the post-development critique for development practice (GibsonGraham, 2005; McGregor, 2009; McKinnon, 2007; Simon, 2007). The search for alternatives to development has included grassroots community supported economies such as complementary currencies and Community Supported Agriculture (CSA) (e.g. Gibson-Graham, 2005; Seyfang \& Pearson, 2000) and radical democratic processes and movements (e.g. Boron, 2005; De Angelis, 2005; Ziai, 2004). These tools are significant in the praxis of alternatives. This thesis focuses on the complementary social decision-making structures and processes and learning tools utilised by the Camp for Climate Action Aotearoa and Permaculture in New Zealand (PiNZ) and their corresponding principles. Although tools such as complementary currencies, community gardens and social centres are necessary for the facilitation of sustainable living and are advocated by permaculture and anarchism, they are beyond the scope of this thesis. Similarly, poststructuralist discourse analysis is not explored herein. The focus is on exploring the principles and participatory democratic practices of an alternative to development framework.

\subsection{Research interest, aims and analysis}

My interest in the topic of this project stemmed from participating in a permaculture design course (PDC) and more broadly from an ecological and social concern arising from multiple associated crises, including climate change and peak oil, exacerbated by the global economic system (e.g. Goldring, 2007; 
Holmgren, 2002; Kent, 2005; Murphy, 2008; G. Williams, 2006). Out of this began a deep questioning of what is to be done to create more harmonious relationships. The ethical and design principles of permaculture based on the notion of cooperation, and the rejection of competitive behaviour and the growth imperative, resonated with my own concerns for the future of the earth and my search for alternative means of living.

Post-development's call for alternatives to development led me to ask whether permaculture could provide an alternative. I recognised parallels with loose principles promoted as guidelines for alternatives to development with permaculture - including the support for diversity, relocalisation, community and cooperation - and a critique of capitalist globalisation and modernity. Could cooperatives be an alternative to development? This question introduced me to anarchism as an ethical philosophy and praxis for social self-organisation with a strong critique. Could anarchism and permaculture provide an alternative to development framework? I searched for grassroots groups in Wellington that held these principles.

It was here that I came across Climate Camp which, for me, represented the marrying of anarchism and permaculture. The climate justice network also met the post-development criteria of being a 'new social movement' (Escobar, 1995) or a 'global justice network' (Routledge, 2009; Waterman, 2005).

The primary aim of this thesis is to respond to the call for alternatives to development by providing ethical and practical examples of anarchism and permaculture as a viable alternative framework. A second aim is to extend discussions surrounding praxis for both development practitioners and global justice activists. The combined analysis of alternatives to development using case studies with permaculture and anarchist principles contributes another perspective to the post-development debate. The thesis concludes that, although there is no pure alternative to development system untouched by the dominant development paradigm, there are alternative ethics and practices based on harmonious principles of self-organisation - including mutual support and solidarity, decentralisation, direct action and direct democracy - that can be utilised in imagining and creating a diversity of possibilities. 


\subsection{An overview of the thesis chapters}

Chapter Two traces the ideas and histories of post-development, the global justice network, anarchism, environmentalism and permaculture through existing literature and thus begins to thread these seemingly disparate movements together. Chapter Three outlines the research approach and methodology. It justifies the use of case studies and action-orientated ethnography as being principally in line with the philosophies being studied in the thesis, and explores the ethical issues of the fieldwork. Chapter Four describes the principles and practices of the main case study, Camp for Climate Action Aotearoa, with a large focus on the decentralised decision-making structures and processes. In accordance with these anarchistic processes are the knowledge sharing tools used by Permaculture in New Zealand (PiNZ), which are also described in the chapter. Chapter Five discusses the similarities between permaculture and anarchist ethics, principles and practices, and highlights some points of contention. The final chapter concludes by relating the discussed concepts to those of post-development and the call for alternatives to development, and of their implications for development practice. 


\section{Chapter 2: Post-development theory, anarchism, permaculture and the global justice movement}

\subsection{Introduction}

This chapter examines, from existing literature, the key concepts central to the dissertation, namely post-development, anarchism and permaculture. It also aims to draw attention to some of the similarities shared by these concepts, by looking at the ideas and history of the "new social movements" (Escobar, 1999) more recently referred to as "global justice networks" (Routledge, 2009) that postdevelopment holds as being in line with the 'alternative to development' trajectory (e.g. Escobar, 1999). The chapter ends by outlining the research context and aim of the thesis.

\subsubsection{Origins of the environmental justice movement}

Global justice networks are characteristic of third wave environmentalism. Environmentalism as a political ideology is concerned with the relationship between humans and nature, and is to a large extent a reaction against the process of industrialisation (Heywood, 1992). In the seventies, the so-called 'first wave' of environmentalism emerged as a response to the energy crisis, a growing awareness of the ecological crisis and the Club of Rome 'Limits to Growth' report (Holmgren, 2002, p. xvii). The environmental justice movement rejects the notion of limitless economic growth and views the relationship between humankind and the natural world in ecological terms. Therefore, humans are viewed as part of the natural ecology and need to cooperate within it, particularly in light of declining resource availability.

The 'second wave' of environmentalism began in the eighties and centred around the principles of sustainable development, whilst mainstreaming environmental issues from the first wave (Arvanitakis \& Healy, 2000, p. 25). This second wave was triggered by public awareness of global warming (Holmgren, 2002). Unlike

\footnotetext{
${ }^{1}$ Other terms include the 'movement of movements', the 'network of networks' and the 'antiglobalisation' movement.
} 
the first wave, this second wave was pro- rather than anti-development and antibusiness. Sustainable development insisted that economic growth is compatible with protection of the environment and that no radical change to the current economic and social systems is required (Arvanitakis \& Healy, 2000).

This view is contested. A debate exists regarding the meaning of "sustainable development". Starr (2000) distinguishes two distinct types of sustainable development: grassroots sustainable development (in which permaculture stands as an anti-corporate movement and a "delinking" mode of resistance and relocalisation) and the co-opted version associated with the Brundtland Report and corporate sustainability. "The idea that [ecological] sustainability can coexist with growth-style economic development co-opts the radical political economy proposed by the grassroots movement" (Starr, 2000, p. 126).

The current third wave of environmental justice is identified as emerging at the end of the nineties, with the 1999 Seattle WTO protests signifying a major watershed event (Arvanitakis \& Healy, 2000; Holmgren, 2002). It challenges the assumptions of the previous wave as well as mainstreaming some of its innovations (Holmgren, 2002). The current environmental movement is characterised by "a new coalition of diverse groups committed to radical change" and "demonstrates the diversity of the global protest movement that is emerging" (Arvanitakis \& Healy, 2000, p. 25). The environmental movement today addresses a far broader range of issues than just pertaining to environmental impacts, extending to issues of social justice (Heywood, 1992). "These new coalitions are being formed to protest against a wide range of injustices that emerge from continued economic globalisation" (Arvanitakis \& Healy, 2000, pp. 25-26). Starr (2000) has identified environmentalism as a form of 'globalization from below', 'people's globalism' or 'global civil society' which works in solidarity with local and national organisations to create a global politics of resistance against neoliberal exploitation.

\subsection{Post-development theory}

The post-development critique emerged as a theoretical framework in the 1990s, as an attempt to break through the current development impasse between 
modernisation and dependency theory (Escobar, 1999). It was an outright rejection of 'development' as a discourse and ideology from a post-structuralist view. Development is seen as a failed project in terms of alleviating poverty, while succeeding in what is its underlying real agenda - that of using its doctrines to strengthen the global hegemonic neoliberal order.

Development ideology has been interpreted by post-development writers as a capitalist, neo-liberal agenda which uses discourses such as 'progress', 'underdevelopment' and 'scarcity' to promote Western-style modernity (industrialisation), economic growth and excessive consumption and production (Escobar, 1995; Esteva, 1995; Latouche, 1993, 1997; McGregor, 2009; Rahnema \& Bawtree, 1997; Rist, 1997; Sachs, 1995, 1997; Sen, 2002)2. This in turn has created massive debt, a growing disparity between rich and poor, and ecological havoc (e.g. Escobar, 1995; Esteva, 1995; Korten, 2006; Murphy, 2008; Rahnema \& Bawtree, 1997; Rist, 1997; Sachs, 1997; Sen, 2002)³.

Post-development sees 'development' as an interventionist mode of domination through the exploitation of the Third World by the First World (Escobar, 1997, 1999). Similarly, the 'have-nots' are seen as exploited by the 'haves' through the language of 'development', and for the extension and retention of power (Crush, 1999a). This exploitation and domination is manifested in the form of neoliberalism and state self-interest, often on an international scale, and often is played out in the development industry.

Post-development authors such as Ziai (2004) and Escobar (1999) regard development as merely promoting modernity and capitalism, and highlight the political crisis of development (see also Crush, 1999b; McGregor, 2009; Routledge, 2009). It is from this perspective that a number of post-development authors have claimed that development is a failed project (e.g. Valente, 2002).

\footnotetext{
${ }^{2}$ A distinction has been made between anti-development and post-development approaches. For insight into this debate, see for example Simon (2007).

${ }^{3}$ Refer to Kent (2005) and Schumacher (1973) for an explanatory discussion on the effects of the current dominant economic system outside of the post-development school (see also Arvanitakis \& Healy, 2000; Ewoldt, 2006; Goldring, 2007; Homer-Dixon, 2007; Murphy, 2008, concerning impending multiple global crises).
} 
Post-development authors have called for a new paradigm of 'alternatives to development' (Escobar, 1995). This study fits within the post-development school's search for alternatives to development.

\subsubsection{Alternatives to development}

There has been a significant shift in post-development away from the school's original emphasis on the power of development discourse and its view that development should be discarded as a failed project. The recent trend is towards more 'hopeful geographies' by searching for examples of 'alternatives to development' via case studies (Cavanagh \& Mander, 2004; Gibson-Graham, 2005; McGregor, 2009; Sidaway, 2007). Nustad (2001, p. 479) writes, "Postdevelopment attempts to demonstrate why development interventions do not work, and this must be kept separate from a call for alternatives." I find this statement too simplistic. Although post-development is a critique of development and has focused on the failure of development, its critique informs what are and could be considered the alternatives to development. This is particularly important when a new paradigm is being sought.

The post-development school rejects universalisation and advocates plurality. Thus the search for 'alternatives to development' consists, necessarily, of many different and particular case studies (Escobar, 1991). Post-development writers such as Gibson-Graham have pointed to pockets of people who are creating ethical spaces and returning to localism to recreate a community and ecological harmony. Examples include Community Supported Agriculture (CSA) (e.g. Esteva \& Prakash, 1997) and local community currencies (e.g. Gibson-Graham, 2005), the latter being considered a significant tool in terms of alternatives to the global economy (e.g. Seyfang \& Pearson, 2000; Starr \& Adams, 2003).

How local community groups deal with working in the global system (economic and state) is recognised as an important question. These 'communities' are diverse and do not yet act in a concerted way, but when taken together they constitute alternatives to development. Case studies need to be gathered in order to form a comprehensive body of knowledge of these specific systems, which 
cannot be fully addressed by this thesis. However, this dissertation does draw on a primary case study as well as referring to secondary case studies.

Post-development authors such as those found in The Post-Development Reader (Rahnema \& Bawtree, 1997) have supported the notion of the simple life (see Gandhi, 1997; Shi, 1997). They look to indigenous peasant societies and indigenous movements for inspiration, and reject the blueprint solution of development (Escobar, 1995). Kothari (1997) criticises the modern nation-state as repressive and abusive in what it does in the name of development. By contrast, post-development advocates radical grassroots democracy (Cavanagh \& Mander, 2004; Escobar, 1999; Ziai, 2004). Power relations involving exploitation and domination are given focus in post-development literature and writers have a tendency to see solutions in grassroots movements.

The definition of 'development' is highly contested. The post-development school has been criticised mostly for romanticising the traditional, for universalising development, and for offering nothing new and providing no concrete practical solutions - to name a few - and not without validity (see for e.g. Corbridge, 1998; Kiely, 1999; Nustad, 2001; Rapley, 2004; Storey, 2000; Ziai, 2004). The alternatives to development approach has also been critiqued for just being a form of development by authors such as Cowen and Shenton (1996) in that development is intentional practice and emerged to ameliorate the perceived chaos caused by progress. This thesis aims to focus on development from the post-development perspective, in line with the search for alternatives via case studies, as well as showing the correlation with the practical philosophies of anarchism and permaculture.

\subsubsection{Global justice movements and alternatives to neo-liberalism}

Post-development writers have turned to the global justice movements and relocalisation movements as models for 'alternatives to development'. There has been a vast amount written on the 'anti-globalisation' movement as a form of resistance and on its characteristics. The entire June 2005 issue of the journal Development was devoted to 'the movement of movements'. The Zapatistas and the World Social Forum, in particular, have been given much attention ( e.g. De 
Sousa Santos, 2005; Esteva, 1997; Guttal, 2005; Rahnema \& Bawtree, 1997; Starr, 2005).

The term 'anti-globalisation movement' is a misnomer as it defines the 'network of networks' by a highly contested term (globalisation) and by what it is against (Graeber, 2002; Routledge, 2009; Sen, 2002; Starr, 2005). Like the postdevelopment perspective, the "global justice network" (Routledge, 2009) rejects any economic development or 'corporate globalisation' that is characterised by the exploitation of the poor masses (particularly in the Global South) for the benefit of a few elites (particularly in the Global North) through profits, privatisation, commodification or through the economic growth imperative.

The 'global justice network' or 'alternative globalisation movement' rejects the notion that 'there is no alternative' and seeks to create alternatives whilst resisting capitalism or 'free trade' and all forms of imperialism. Some argue for "another world" while others argue for a world with different perspectives and systems (Starr \& Adams, 2003). The 'alternative globalisation movement' has demonstrated the 'developing' world's struggle in anarchist and post-development discourses.

Routledge (2009) writes that the characteristics of the movements in the global justice networks are recognised by their (1) diversity, (2) creativity, (3) political vision and practice of autonomy, (4) convergence, (5) spatially extensive politics, (6) their attempt to create spaces for participatory democracy, and (7) their attempt to forge solidarities through the making of connections grounded in place and face-to-face- based moments of articulation. The strategy of "delinking" from the global economy and relocalisation (which includes permaculture and community currencies), and the creation of convergence spaces of temporary autonomy as both resistance and prefigurative politics (such as the World Social Forum) are significant characteristics (Routledge, 2009; Starr, 2005; Starr \& Adams, 2003). Hakim Bey (1991), a contemporary anarchist writer, originally coined the term Temporary Autonomous Zones (T.A.Z.) to describe spaces of convergence where one is temporarily free from formal structures of control and where moments of autonomy open up and widen the cracks for other non- 
hierarchical relationships and ways of existing (see also Starr, 2005, pp. 121-124). Here we can begin to see the direct influence of anarchism on the global justice network.

\subsection{Anarchism}

Anarchism is a diverse political theory concerned with the metaphysics of practice (Curran, 2006; Graeber, 2004; L. Williams, 2007). Historically, anarchism came to the fore at the end of the nineteenth century with the rise of industrialisation and the nation-state in Europe, although its ideas can be traced back much earlier to the Stoics and Cynics of Ancient Greece and the Diggers and Levellers of the English Revolution (Heywood, 1992; Starr, 2005, p. 114). The First International saw the split between Marxists and anarchists (the latter led by Bakunin) due to their fundamentally different understandings of the nature of power (Heywood, 1992; Highleyman, 1988; Morland, 2004). Anarchism rejected the Marxist view that the working class would rise up to overthrow the capitalist elite and that an interim proletarian state was necessary to assist the transition to socialism. For anarchism, the state structure itself is corrupt and any proletariat state would only take the place of an existing elite to form the new elite without addressing the systemic basis of domination and control.

A major difference between anarchism and Marxism surrounds the issue of vanguardism, and relates to what Cowen and Shenton (1996) have called 'trusteeship' in development. For anarchism, the idea of a 'vanguard party' is authoritarian and is thus oppressive as well as prescriptive (Graeber, 2009; Morland, 2004). Instead, anarchism holds that living by one's principles in the present, and thus making the means consistent with the ends, is vital for the process of creating a just world (Graeber, 2004). Moreover, the growing 'do it yourself' (DIY) culture is naturally anarchistic and resists hierarchies and vanguards (Starr, 2005; The Trapese Collective, 2007).

Anarchism is commonly misrepresented as synonymous with chaos. Linked to this is the misconception that without rulers there will be chaos or disorder. Anarchism seeks order "without rule" but not without organisation (Carter, 2000; Heywood, 1992, p. 193). It has been heavily criticised and negatively 
characterised by those in positions of power because it naturally threatens their power (Highleyman, 1988).

From the perspective of anarchism, people know what is best for them and are able to self-organise without rulers. The philosophy advocates a mutually supportive approach of solidarity or mutual aid, and respect for the autonomy of communities and individuals. This anti-authoritarian philosophy critiques all forms of hierarchy and centralisation as oppressive, domineering and the root of injustice - although initially its focus was primarily on the state (Highleyman, 1988; L. Williams, 2007). A perspective that calls for autonomy, participatory democracy, direct action, diversity, individual freedom and collective responsibility, non-violence, voluntary association, cooperation, mutual benefit and non-profit is the antithesis of that of the state and of capitalism. Anarchism emphasises the practice of horizontally decentralised systems and selforganisation (Graeber, 2002, 2004; Starr, 2005). Kropotkin (1904) described the Kalahari Bushmen as a pre-modern anarchist society.

\subsubsection{Different strands of anarchism}

There are various strands of anarchism that address different hierarchical aspects of society. For example, anarcho-syndicalism is mainly concerned with the industrial workplace and was a movement led by Emiliano Zapata in Latin America in the early twentieth century ${ }^{4}$ (Heywood, 1992, p. 194). Green anarchism - of which eco-anarchism and social ecology are a part, is mostly concerned with the relationship between humans and nature. Primitivism is concerned with the effects of modernity and anarcha-feminism focuses on gender relations from a feminist perspective.

Within anarchism there is a diversity of ideas on what exactly an anarchist society might look like. For example there is tremendous diversity around the role of technology and on the strategies and tactics to achieve a just society (Highleyman, 1988). This includes differing views on what constitutes violence and how to foster transformative change. Consistent within anarchism, however,

\footnotetext{
${ }^{4}$ Anarcho-syndicalism had originated in the late nineteenth century in Europe and Russia.
} 
are the general principles of non-hierarchy including direct democracy, selfgovernance, decentralisation, voluntary association, solidarity and direct action.

The different strands also vary in emphasis on the importance of the individual versus the collective. Individualist anarchism has been most popular in the United States (Curran, 2006, p. 25; Heywood, 1992, p. 201). This perspective emphasises individual autonomy and self-interest. Although closely resembling liberalism, individualist anarchism differs in that it rejects the state outright as an impingement on individual liberty and believes that free individuals can work together constructively without authority (Heywood, 1992, p. 202). Individualism and self-interest can be regarded as capitalist values (Knoll, 2009) and have been adopted by the strands of anarchism that have a rational and economic emphasis, such as anarcho-capitalism (Heywood, 1992).

There is debate around whether anarcho-capitalism is an anarchist strand or a reinvention of right-wing libertarianism (e.g. Curran, 2006; Heywood, 1992, p. 50; Highleyman, 1988; Meltzer, 1996). Authors such as Meltzer (1996, p. 50) state that anarchism proper understands capitalism as an exploitative and hierarchical system that relies on law to uphold the position of elites, in contrast to the more social nature of anarchism (see also Bookchin, 1971, p. 18; Highleyman, 1988). ${ }^{5}$

Collectivist anarchism, on the other hand, stresses collective freedom and the cooperative and social nature of humans, resembling a more socialist and communalist perspective. It is concerned with creating systems of reciprocity, collective ownership and small human-scale self-governing face-to-face communities (Graeber, 2004). Collectivist anarchist strands include libertarian socialism (Chomsky) and anarcho-communism (Kropotkin and Bookchin). This thesis addresses the more collectivist or socialist anarchist leaning, which is also

\footnotetext{
${ }^{5}$ Additionally for Bookchin (1995), individualistic anarchism including Zerzan's primitivism, the Global Justice Network (GJN) and Temporary Autonomous Zones (Bey, 1991) that the movements create are what he pejoratively called 'lifestyle anarchism'.
} 
the most common strand (Curran, 2006, p. 23). The thesis will also demonstrate that it is also in line with permaculture, ecology, and the 'global justice network'.

Starr (2005, p. 117) emphasises that the diverse anarchist approaches are not incompatible but that they "highlight aspects of anarchist theory." Anarchism today (discussed below) shows how much these different aspects of anarchism are being increasingly interwoven. Anarchism's principles and its organisation of decentralisation and egalitarianism have not changed (L. Williams, 2007, p. 307). Its ethics promote individual responsibility and collective action in the form of direct action and DIY.

Classical anarchism highlighted the cooperative characteristic of human nature. In Mutual Aid (1904), anarcho-communalist Kropotkin demonstrated that in nature that animals worked together for mutual benefit and generally avoided competition by adapting their diets or migrating. This was in response to social Darwinism's 'survival of the fittest', which viewed human nature as competitive and inherently self-interested (see also Heywood, 1992, p. 206; Knoll, 2009). Kropotkin, in opposition to Darwin, showed that, in nature, cooperation or what he called 'mutual aid' was more common for species' survival than competition.

Kropotkin argued that humans, as social creatures, have been concerned with looking after each other for the benefit of all, more so than being individualistically concerned with selfish profit (Knoll, 2009; Kropotkin, 1904). Anarchism today tends to view human nature as both cooperative and competitive, and therefore - as shown by Kropotkin - that there is no 'human nature' as such. "Humans are neither inherently good or bad, but both. The question therefore is if they are more good than bad and how to deal with conflict, poverty and other problems arising in our society today" (Knoll, 2009, p. $11)$.

According to anarchism, the modern industrial paradigm plays on the Darwinist notion of human nature, giving privilege to the individual as a self-interested

\footnotetext{
${ }^{6}$ However, not all authors share this view, particularly those from classical anarchism and capital'A' Anarchists (see Bookchin, 1995; Graeber, 2002).
} 
being and providing a perception of scarcity. Murray Bookchin, the founder of social ecology, writes on the idea of post-scarcity and its relation to ecology:

"For one thing, scarcity is more than a condition of scarce resources: the word, if it is to mean anything in human terms, must encompass the social relations and cultural apparatus that foster insecurity in the psyche. In organic societies this insecurity may be a function of the oppressive limits established by the natural world; in a hierarchical society it is a function of the repressive limits established by an exploitative class structure. By the same token, the word "post-scarcity" means fundamentally more than a mere abundance of these means of life: it decidedly includes the kind of life these means support" (Bookchin, 1971, p. 11).

The above perspective corresponds with post-development, both in the poststructuralist tradition of language critique and in its environmental concern (e.g. Latouche, 1993; Sachs, 1997).

\subsubsection{Anarchism and (anti-)development}

In Profit Over People, influential linguist and libertarian socialist scholar Noam Chomsky (1999) reflects, in line with post-development thinking, that agreedupon economic development policies are not conventionally understood, have very little basis, usually turn out to be "bad ideas", and in fact serve the growth doctrine. "The "bad ideas" may not serve their "expressed goals," but they typically turn out to be very good ideas for their principle architects" (Chomsky, 1999 , p. 26, italics in original). He further argues that capitalist state (representative) democracy, as we have now and which has been spread through the world by the neoliberal doctrine via economic development policies, does not allow the majority of people to be involved in decision-making processes or to control the means of production. Thus, from this perspective, global hegemonic power exists only in the hands of a few and at the expense of many. Chomsky equates the usage of the term 'democracy' as really meaning 'free trade' and this really refers to neo-liberalism or 'corporate globalisation' (see also Morse, 2007). Neo-liberalism relies on the state apparatus, through laws and regulations, to 
protect corporate interests and their existence albeit laisse faire (see also Morse, 2007; Starr, 2005).

Morse (2007) adds to this perspective of how development is used as a strategy to promote this free market agenda (which she states is also the real agenda behind the 'war on terror'), through subversion of the language of development and terms such as 'good governance' and 'security', and through how development aid primarily serves the neoliberal self-interest of the donor country. Starr (2000, 2005) agrees with post-development and anarchist authors of the failure of Western development and its promise really being a lie for privatisation.

Like post-development, anarchism rejects universal blueprints and expertism (e.g. U. Kothari, 2005). Post-development has been described as "anti-managerial", having "anti-authoritarian sensibilities" and an "anarchist streak" (Nederveen Pieterse, 2001, p. 117). The paragraph is worth quoting in full:

"Development thinking is steeped in social engineering and the ambition to shape economies and societies, which makes it an interventionist and managerialist discipline. It involves telling other people what to do - in the name of modernization, nation building, progress, mobilization, sustainable development, human rights, poverty alleviation, and even empowerment and participation (participatory management). Through post-development runs an anti-authoritarian sensibility, an aversion to control and perhaps an anarchist streak. Poststructuralism too involves an 'anti-political' sensibility as a late-modern scepticism. If the public sphere is constructed through discourse and if any discourse is another claim to truth and therefore a claim to power, what would follow is political agnosticism. This also arises from the preoccupation with autonomy, the problem of representation and the indignity of representing others." (Nederveen Pieterse, 2001, p. 117) 


\subsubsection{New anarchism and the global justice network}

Williams (2007) writes that anarchism has been recently revived ${ }^{7}$, or at least that it is being increasingly noticed and studied in the realm of academia (Purkis \& Bowen, 2004; L. Williams, 2007, p. 297). The 'new anarchism' (Graeber, 2002) rejects any form of domination and oppression, not just state authoritarianism and uses an eclectic mix of ideas without conforming to one ideology (Curran, 2006). These "small 'a' anarchists" (Curran, 2006) show an eclectic assortment of ideas and practices and do not necessarily identify themselves as anarchist (Curran, 2006; Graeber, 2002; Highleyman, 1988; Starr, 2005). This anarchism also does not anticipate a revolution coming from any particular group, and does not anticipate necessarily a revolution at all, but instead visualises a transition to a world where there exists a diversity of autonomous groups working in solidarity on issues that they share a common interest in. "Anarchism's core values remain autonomy, liberty, anti-statism and anti-authoritarianism" (Curran, 2006, p. 2).

New anarchism, particularly symbolised by the global justice network, has hybridised from classical anarchism (Curran, 2006, p. 32). The global justice network has been shown to share characteristics with anarchism including voluntary/ free association, DIY, mutual aid, non/anti-hierarchical practices, direct action and autonomy/ autonomous zones (Graeber, 2002; Knoll, 2009; Starr, 2005).

Anarchist influences in the global justice movements are strongly notable in the forms of horizontal organisational principles used by these movements primarily direct democracy, consensus decision-making, self-organisation, and direct action (Graeber, 2002; Routledge, 2009; Starr, 2005). The diversity in these movements is also reflective of the anarchist perspective and shared by postdevelopment writers and permaculture. Solidarity amongst diverse groups transcending borders to support a common cause is an anarchist tactic. "However you choose to trace their origins, these [creative and peaceful] new tactics are perfectly in accord with the general anarchistic inspiration of the movement, which is less about seizing state power than about exposing, delegitimizing and

\footnotetext{
${ }^{7}$ Post-structuralism has been particularly influential (see Curran, 2006; Morland, 2004; Mueller, 2003; L. Williams, 2007).
} 
dismantling mechanisms of rule while winning ever-larger spaces of autonomy from it" (Graeber, 2002, p. 68).

Curran (2006), in her book 21st Century Dissent: Anarchism, Anti-Globalization and Environmentalism, refers to a reluctance of governments to act against the current path of global development and away from the 'business as usual' approach. Anarchism has played an important part in the 'new global agenda' and for the communities being created in response to the loss of faith in the current path to 'progress'. Williams (2007) points to a loss of sense of community, place and belonging in the current neo-liberal paradigm where relationships lose their privilege. "In the absence of faith in government, faith in people - that is, faith in the like-minded souls found in neighborhoods, face-to-face communities, and interpersonal relations - seems like a natural alternative" (L. Williams, 2007, p. 310).

Curran describes the new anarchism, influenced by the anti-globalisation movement and radical ecology, as "post-ideological anarchism".

\footnotetext{
"Post-ideological anarchists are inspired by anarchism's principles and ideas [and strategies], drawing from them freely and openly to construct their own autonomous politics. They reject doctrinaire positions and sectarian politics, preferring to mix their anarchism with an eclectic assortment of other political ideas and traditions. Post-ideological anarchism is also primarily green" (Curran, 2006, p. 2).
}

The new anarchism rejects all forms of hierarchy or authoritarianism, not just the state. It is a political ideology which seeks out all forms of domination and strives to dismantle them and build more inclusive and just organisational structures and relationships (L. Williams, 2007). This includes economic and social as well as political exploitation and even extends to ecological domination. "As anarchists are beginning to understand, the next struggle for humanity in the $21^{\text {st }}$ century is a struggle for survival. Call it what you will - post-industrial survival movements, post-oil, post-neoliberal eco-communitarian anarcho-urban survivalism - this is a movement in opposition to a capitalist system, global in scale, that can only 
reproduce in the presence of capital accumulation and surplus labor, in other words, profit" (Polk, 2008, p. 14). The anarchist ethics drawn upon in this thesis include those of cooperation, mutual aid, direct democracy and direct action as the basis for organisation in radical political opposition.

\subsubsection{Anarchism, ecology and environmentalism}

Classical anarchist authors particularly Bookchin and Kropotkin have emphasised the need for ecological principles. Heywood (1992, p. 259) describes anarchism as being the most environmentally sensitive ideology and many in the green movement recognise the influence of Kropotkin and Bookchin in the environmentalist origins. Bookchin (1971) has suggested a correspondence between anarchism and ecology. "Anarchists believe in a stateless society, in which harmony develops out of mutual respect and social solidarity amongst human beings. The richness of such a society is founded upon its variety and diversity. Ecologists also believe that a balance or harmony spontaneously develops within nature, in the form of ecosystems, and that these, like anarchist communities, require no external authority or control" (Heywood, 1992, p. 259). Anarchism is concerned with creating a cooperative and decentralised society, based on ethic of mutual aid and the principles of direct action, direct democracy, autonomy and free (voluntary) association.

\subsection{Permaculture}

Permaculture is an ethical design philosophy, which seeks to create low energy systems and environmental sustainability by mimicking patterns and relationships found in nature. It is also "an applied science in that it is essentially concerned with improving the long-term material well-being of people" (Holmgren, 2002, p. 2). The term "permaculture" was coined by Bill Mollison and David Holmgren in the 1970s with the first wave of environmentalism, and was initially a contraction of 'permanent agriculture', since it focused mostly on food production for selfreliance. The Australian co-founders stressed the disastrous ecological effects for which humans are responsible and the need to redesign our mode of living and 
production towards self-reliance and bioregional self-sufficiency ${ }^{8}$. This is significant for understanding the basis of the permaculture worldview. Mollison and Holmgren (1987) identified modern agricultural practice and its high use of petroleum-based products as an important issue.

The meaning of permaculture has extended over time to encompass 'permanent culture', as it has been applied to the relationships between people, nature and the built environment to create resilient communities. The limits to growth, the need to limit our own behaviour and to break away from the global economy's high energy dependence on fossil fuels, requires a decentralisation of the means of production. Like anarchism, the way people organise themselves is central to permaculture in order to create a more environmentally sustainable culture. "More precisely, permaculture as the use of systems thinking and design principles that provide the organising framework for implementing the above vision ... draws together the diverse ideas, skills and ways of living which need to be rediscovered and developed in order to empower us to move from being dependent consumers to becoming responsible and productive citizens" (Holmgren, 2002, p. xix).

Significantly, permaculture activists advocate a holistic approach to systems. They stress the need to understand whole processes, and the relationships between elements, in order to successfully change a dysfunctional system. This holistic position and rejection of reductionism, de-compartmentalising and narrow thinking (that pervades the world today and prevents people from understanding the wider implications of their actions) has led to criticism. Mollison (1994) has commented on permaculture having been criticised by purists due to its multi- disciplinary position. Permaculture ethics reflect the notion that we are part of nature and that our current paradigm of Cartesian logic has led us to see ourselves as separate from nature and that this logic is the foundation of the environmental crisis.

\footnotetext{
${ }^{8}$ For the history and critique of the term 'self-sufficiency' from a post-development perspective see In the Wake of the Affluent Society (Latouche, 1993, p. 161). There is also debate within permaculture on self-sufficiency. It is generally agreed that on an individual level self-sufficiency is not possible or desirable. Rather, bioregional self-sufficiency is advocated as a means of closing economic gaps to tighten feedback (see Hopkins, 2008).
} 


\subsubsection{Core ethics of permaculture}

The three core ethics in permaculture are 'care for the earth' (earth-care), 'care for the people' (people-care) and 'limit consumption and distribute surplus' (fairshare). The exact wording and emphasis of meaning varies through permaculture texts (see for example Holmgren, 2002; Mollison, 1988). Each ethic draws on the previous ethic.

Permaculture emphasises the need to change the way we think and move towards an earth stewardship position inherent in the first permaculture ethic 'care for the earth' to create "harmonious integration of landscape and people" (Mollison \& Slay, 1994, p. 2). Humans are understood as being a part of nature, not superior to nature and don't need to dominate through control of nature.

Similarly, we need to change our way of thinking about human nature. "Cooperation, not competition, is the key" (italics in original; Mollison \& Slay, 1994, p. 3). 'Care for the people' extends from the first ethic and emphasises the importance of looking after others and working with people as opposed to the competitive, individualistic approach presently valued by modern society. This second ethic draws attention to the provision of access to resources for existence (Mollison, 1988, p. 2). Similarly, in thinking about energy descent for a more sustainable world 'fair-share' is important. This ethic looks at issues including greed, self-governance and the need to share resources in order to satisfy needs and minimise our ecological footprint.

\subsubsection{Design principles of permaculture}

In his significant book, Permaculture: Principles and Pathways Beyond Sustainability (2002) co-founder David Holmgren has provided twelve principles to be utilised in any design system. They can be applied to land, technology, education, health, community governance, economics and the built environment. These design principles are explored below in the case studies and discussion chapters of the thesis.

Holmgren's permaculture design flower (see Figure 5.2 below) illustrates the various aspects of society in its seven petals: land and nature stewardship; built 
environment; tools and technology; culture and education; health and spiritual wellbeing; finance and economics; and land tenure and community governance, with the ethics and principle at the centre of the flower. Next to each petal is are the different practical applications from different fields that have been adopted into the permaculture design system (Holmgren, 2002, p. xx).

\subsubsection{Permaculture, post-development and anarchism}

Applications of permaculture principles are included in a number of what the post-development school has termed 'alternatives to development' such as Community Supported Agriculture (CSA), Local Trade and Exchange Systems (LETS), grassroots democratic processes and other local and community-based cooperative systems (e.g. Esteva \& Prakash, 1997; Gibson-Graham, 2005; Starr \& Adams, 2003).

Permaculture holds a "vision of separation from, rather than collaboration with, existing political economic systems" (Starr \& Adams, 2003, p. 3; see also Goaman, 2004). Like post-development and anarchism, permaculture sees decentralisation as a necessary alternative to the dominant centralised power structures. Permaculture, post-development and anarchism also promote human scale 'do it yourself' (DIY) technologies for ecologically and socially just lifestyles (e.g. Heywood, 1992; Holmgren, 2002; Sachs, 1997; Schumacher, 1973; Starr, 2000).

Ball (2007) describes permaculture as "inherently political" and "fundamentally radical in challenging dominant economic discourses." Polk (2008, pp. 19-20) states that permaculture is gaining popularity in anarchist circles and that it "presents a method of social and ecological reproduction antithetical to capitalism" (see also Purkis \& Bowen, 2004, p. 2). Permaculture does not sit comfortably either with representative democratic systems and party politics, and instead it favours decentralisation, local control and affinity-building (Ball, 2007; Polk, 2008), a stance compatible with (libertarian socialist) anarchism.

Post-development, anarchism and permaculture correspond in their rejection of growth as sustainable and good, their view of traditional peasant societies as 
models for alternatives, their distain for hierarchy and domination and their promotion of a DIY culture of self-organisation that exist in harmony with nature. They also advocate local small-scale societies and means of production. These exhibit some idea as to solutions to the problem of development and indicate something of what may constitute an 'alternative to development' framework.

\subsection{Research context}

The concern of this thesis is that of ecological and social ethics, looking at the philosophies of permaculture and anarchism and their praxis in the search for alternatives to development. This study therefore fits broadly within the global struggle for political, social and environmental justice. From this perspective, there is a need to reassess the current ethics and values upheld in the modern paradigm in order to create an ecologically sound existence (Holmgren, 2002). This thesis shows some similarity to the work of Amory Starr and J.K. GibsonGraham.

Anarchism and permaculture are both practical philosophies that utilise the mode of "delinking" from economic globalisation and that seek solutions in relocalisation projects. The anarchism of which this study is concerned is that which rejects all forms of domination and hierarchy, including ecological and economic, and is characterised by the global justice networks.

Post-development scholars have studied large established movements of social resistance such as the Zapatistas, Peoples Global Action and World Social Forum extensively. There are more recent global justice movements that have sprung from these and with diverse foci. Small-scale, decentralised local projects and strategies are also increasingly being studied and documented by postdevelopment authors such as Gibson-Graham and this is important work in the search for alternatives. This thesis fits within this academic framework of postdevelopment theory and the call for alternatives to development.

Attention has focused on grassroots empowerment groups in the 'Third World' but the 'First World' is a significant site for post-development study, particularly 
in regard to the post-development call for the 'West' to stop interfering with the rest and to look at itself, its own (environmental and social) problems and to sort itself out locally. Specificity and variety of case studies are equally significant principles for alternatives to development, anarchist and permaculture solutions. With this in mind, and in order to keep in line with permaculture's ecological concerns for low energy use of project design, the study focuses on Wellington (New Zealand) as a geographic location for research examples.

Very little has been written on post-development, anarchism and permaculture specifically. What is uncertain is what would result if you correlated these three concepts. What are the similarities? What are the differences? Would it be possible to provide an alternative to development framework using these concepts? What is going on currently in the Wellington region that may provide this 'alternative to development'? Are these things enough for post-development?

\subsubsection{Aim}

The central aim of this thesis is to answer the question 'can the praxis of anarchism and permaculture provide an alternative to development framework?'

Perhaps a simpler framing of the question of whether the principles of permaculture and anarchism can provide an alternative to development framework is 'if post-development/antidevelopment/ alternatives to development were to be put into practice, what would it look like?' It is from this perspective that this study stands. I have already drawn attention to some of the links into which this thesis will delve. "Even more than High Theory, what anarchism needs is what might be called Low Theory: a way of grappling with those real, immediate questions that emerge from a transformative project" (Graeber, 2004, p. 9). The thesis seeks to find the correlations between permaculture and anarchism, through case studies which show the praxis of such a transformative project where each of these philosophies for social change can strengthen each other in the search for alternatives to development. I wish to show to an extent that permaculture may provide design principles for anarchist practice. 
This thesis is a comparative study of the three central concepts. This is done by exploring their praxis using case studies focused in Wellington but with the intent that these cases are typical of a broader national and international context. The primary case study is a climate justice movement characterised by its anarchistic principles, objectives and organisational structures, its use of "convergence spaces" or "T.A.Z." (Temporary Autonomous Zones), and its permaculturally recognisable local solutions to climate change: Camp for Climate Action Aotearoa (abbreviated to Climate Camp). 


\section{Chapter 3: Research approach}

\subsection{Introduction}

The purpose of this chapter is to outline the research context of the study with its basis in the post-development school, and in keeping with permaculture and anarchist methodology. It does so by describing constructionist epistemology. This is followed by an explanation of ethnography and the significance of action research. Participant observation, as the primary method of information gathering, as well as other methods utilised are outlined. It also details the case studies and the research methodology. The chapter ends by pointing out some of the research limitations and ethical issues of the study.

\subsection{Post-development theory and the call for alternatives}

The post-development school has critiqued development as being a powerful and dominating Western interventionist strategy oppressively imposed on the Third World (Crush, 1999a; Escobar, 1995; Sachs, 1995). Development is viewed from this theoretical perspective as promoting the neoliberal growth agenda as the only path to progress, and modernity as desirable (Gibson-Graham, 2005; Latouche, 1993, 1997; Rist, 2007). Post-development authors point out that the result of this agenda is social and environmental catastrophe (Escobar, 1995; Rist, 1997, 2007; Sachs, 1995). This is the theoretical starting point of the thesis. The study is a response to calls for alternatives to development by post-development writers, such as Escobar and Gibson-Graham. It is also a response to the critique of postdevelopment not proposing any solutions and leaving very little room for "forward politics" or the construction of alternatives due to its "imaginary of power" (Nederveen Pieterse, 2001, p. 109). Hence, the goal of this thesis is to find an alternative to development framework, to be achieved by using case studies and through comparative analysis of anarchism and permaculture. The central question is 'can anarchism and permaculture provide an alternative to development framework?' 


\subsection{Constructionism}

The role of anthropology in the search for alternatives to development is significant. Anthropology, characterised by ethnography ${ }^{9}$, has taken a reflexive turn by questioning and criticising its role in the colonial process. Escobar (1991) has extended this critical stance to international development and the unwitting role of the anthropologist in assisting the postcolonial global hegemonic system of oppression and domination (see also Keesing \& Strathern, 1998, p. 473). "It has been realized that not taking a political position, not making a moral commitment, is not neutral: it is making a commitment - to the support and continuation of the system of which one is part and within which one is working anthropologically" (Keesing \& Strathern, 1998, p. 474). Critical reflexivity of human assumptions and issues of representation and power are central to the ethnographic approach as well as post-development and anarchism.

Epistemologically, objectivity and subjectivity are perceived in ethnography as intertwined. The basis of constructionism is that there is a reality in which objects exist but the meanings associated with the objects are socially constructed and culturally relative. Constructionism is the view that "all knowledge, and therefore all meaningful reality as such, is contingent upon human practices, being constructed in and out of interaction between human beings and their world, and developed and transmitted within an essentially social context" (Crotty, 1998, p. 42).

Culture is important in anthropology and constructionism since culture is a system of shared meaning in social processes and provides a framework of expected behaviour (Keesing \& Strathern, 1998). Thus, by interacting with communities firsthand through fieldwork, the researcher is concerned with understanding and explaining the meanings constructed by cultures or subcultures (communities) as they engage with, relate to and interpret the world and objects in the world. An ethical extension of social constructionism is significant in terms of the relationship between the researcher and the people being studied. Since there is no such thing as an objective truth or neutrality, the

\footnotetext{
${ }^{9}$ A discussion of ethnography will follow in the 'Ethnography' section of this chapter.
} 
researcher needs to make her values and assumptions - or bias and prejudice explicit in the research (Clegg \& Slife, 2009).

Transformative research seeks to contribute to social justice and human rights, to privilege the reality of the oppressed and challenging perceived realities that sustain an oppressive system and asks how we can collect data about the reality of a concept in such a way that one feels confident that one has indeed captured that reality and done so in an ethical manner (Mertens, Holmes, \& Harris, 2009, p. 88). This is one route that a decolonised anthropology (Keesing \& Strathern, 1998) may pursue and can be seen in the flexible approaches of militant ethnography (Juris, 2007; Scheper-Hughes, 1995) and autoethnography (Butz \& Besio, 2009; see also Tedlock, 1991 on narrative ethnography) in anthropology, and action research in radical activist geography (Brydon-Miller, 2009; Pain, 2003). My methodological approach fits broadly within these frameworks and relates more specifically to the key ethnographic method of participant observation.

\subsection{Ethnography}

Ethnography has been promoted by post-development anthropologist Arturo Escobar (1991, p. 678, 1995) and anarchist anthropologist David Graeber (2004) as a significant source of case studies. Ethnography is a significant methodology for providing records of and contributing to the collective re-envisioning of practical examples of different "ways of organizing societies and economies, ways of relating to nature and to one another that have a better chance of life" (see also chapter 22 of Keesing \& Strathern, 1998). For anarchism, anthropology holds a wealth of knowledge of examples of egalitarian, non-capitalist societies for the creation of anarchist societies (Graeber, 2004), while for post-development, reenvisioning the way we organise potentially provides an important process for discovering other ways of caring and healing the ravages brought about by development in the Third World (Escobar, 1991). Both anarchism (Graeber) and post-development (Escobar) look to social movements as arenas of resistance to capitalism and inspiration for the creation of alternatives. My chosen case studies fit within this framework and align with the post-development emphasis of using concrete particular accounts rather than a universal set of truths or expertise 
(Esteva, 1995; U. Kothari, 2005; McGregor, 2009; Rahnema, 1997; Sidaway, 2007). ${ }^{10}$

The process of ethnography entails a holistic approach. Anthropology studies different ways of living and organising society, which is unique to the discipline and important when looking at how anarchist societies might be organised for holistic solutions. The holistic perspective is also utilised in permaculture and is significant in understanding a system as a whole, how it functions and the power underlying those processes. "If we do not have the power to see beneath the surfaces of things, to see processes rather than symptoms, to see whole systems rather than separate parts, then our individual efforts and energies will be dissipated; our voices will add to the confusion that surrounds us" (Keesing \& Strathern, 1998, p. 483).

What this means, in anthropology, is that behaviour is best understood in context of a community or society's everyday activities and also in relation to the wider social context ${ }^{11}$. Hence, to study people in their natural settings, or local situations, is significant. ${ }^{12}$ "The underlying assumption here is that to learn about a world you don't understand you must encounter it firsthand" (Blomberg, et al., 1993, p. 125). Fieldwork also is important for ethnography as a means of observing the (in)consistencies of what people say they do or believe (their principles in theory) and what people do (their behaviour in practice). The underlying assumption is that the truth about reality can be found by observing people's everyday behaviour.

An ethnography is descriptive - it seeks to describe how people actually behave and organise (not the way they ought to behave) in a nonjudgmental, culturally relative manner (Blomberg, et al., 1993). Ethnography seeks to understand the point of view of the insider in order to explain how they make sense of the world.

\footnotetext{
${ }^{10}$ See also (Clegg \& Slife, 2009) on the particular in the postmodern context.

${ }^{11}$ What constitutes a community or society is not clear-cut. Within anthropology, it is generally now agreed that these are dynamic relationships and not bounded static entities that can be completely isolated from the broader regional or transnational context (see for example Keesing \& Strathern, 1998, p. 10).

${ }^{12}$ I was not able to observe and record everyday activities in the traditional sense. My concern was with the organisation of groups that could be described as alternative to development and so I was interested in the interactions with people within the groups and in relation to others.
} 
This has thrown up debates about the emic/etic ${ }^{13}$ or insider/outsider dialogue and questions about whether one can ever be truly objective or neutral, particularly with the advent of growing interest in anthropology of studying one's own culture and a focus on power relations (Keesing \& Strathern, 1998).

'Cultural activism' (Verson, 2007) is important for both permaculture and anarchism to directly bring about transformative cultural change (see also Holmgren, 2006; G. Williams, 2006). Militant ethnography ${ }^{14}$ can be viewed as a form of action research. This type of research blurs the boundary between the insider/ outsider and academic/activist binaries (Brydon-Miller, 2009; Butz \& Besio, 2009; Pain, 2003; Routledge, 1996; Tedlock, 1991), where the researcher becomes a politically engaged and critically reflexive insider within the grassroots movements. "In order to grasp the concrete logic generating specific practice, researchers have to become active practitioners" (Juris, 2007, p. 165). This ethically and politically grounded action-orientated research seeks to "not only comment on but get directly involved in seeking solutions to social problems and inequalities" (Pain, 2003, p. 655). Building relationships and trust is an important part of this socially engaged and immersive research strategy.

I chose this action-orientated approach to participant observation as a means of practicing permaculture and anarchist ethics of care (i.e. mutual aid and earth and people care) and principles of practice (i.e. direct action and practical interaction) that I was exploring. These are reflected in the core values of action research as "commitment to open and transparent participation, respect for people's knowledge, democratic and nonhierarchical practices, and positive and sustainable change" (Brydon-Miller, 2009, p. 245).

\subsection{Participant observation}

The methods I used for data collection were qualitative. From my own undergraduate anthropology background and from an interest in how organisations function, I chose to use the ethnographic method of participant

\footnotetext{
13 'Emic' refers to the insider view of a culture and 'etic' refers to the outsider view of a culture.

${ }^{14}$ My usage of the term 'militant ethnography' is not identical to how it is used in the specific contexts of Scheper-Hughes or Juris but its core meaning for the researcher as political activist and value-laden participant in the field - unable to be passive bystander or neutral observer - is of significance.
} 
observation with informal interviews through conversation and with the idea of becoming as fully immersed in the relevant activities in the 'field' as was possible. "Participant observation is learning by doing to generate what one anthropologist termed a "living understanding" of the culture." (Nolan, 2002, p. 8) This also complemented the first permaculture design principle of 'observe and interact' (Holmgren, 2002).

Holmgren (2002, p. 13) explains that: "A process of continuous observation in order to recognise patterns and appreciate details is the foundation of all understanding". However, he continues to say that:

"There is little value in continuous observation and interpretation unless we interact with the subject of our observations. Interaction reveals new and dynamic aspects of our subject and draws attention to our own beliefs and behaviour as instrumental to understanding. The interplay between observer and subject can be thought of as the precursor to design. The accumulation of the experiences of observation and interaction build the skill and the wisdom needed both to intervene sensitively in existing systems and to creatively design new ones" (Holmgren, 2002, p. 14; see also Blomberg, et al., 1993).

Action ethnography is important because it uses the method of participantobservation as a form of involvement and a way of seeing interactions first-hand and relates broadly to the anarchist principle of direct action as a means of bringing about political or social change through practice and taking back control (Cutler \& Bryan, 2007; The Seeds for Change Collective, 2007b; Verson, 2007).

Participant observation was chosen as it is a useful method for observing activities first-hand. It is significant that the researcher does not just rely on what she is told as being the truth in order to gain understanding. Moreover, leaning towards the participant side of the participant-observation continuum allowed for a more immersive experience, which mainly took place through meetings and conferences but also in more informal settings and situations. The significance of why I chose immersion over other forms of methods was mainly due to recognition of the importance of building relationships or rapport. In this way, 
the more extractive process of information gathering was minimised, as I was more able to participate and contribute in some way to the groups, communities and individuals. This was aided by my shared personal interest in alternative means of practice and the principles and ideas of permaculture and anarchism.

I utilised the method of reviewing the literature and attending meetings and conferences to affirm and contrast the literature by comparative analysis. I conversationally interviewed participants at hui (meetings) for the same purpose (i.e. to make sure that what I was reading and what speakers were saying were shared views and beliefs) and to add to formal meetings. Only informal interviews took place through conversation. These were not recorded and notes were not taken during conversations. Primarily the information from these discussions was used to enhance my understanding of what people thought and to gain knowledge of background information. I used secondary texts in the form of texts - including pamphlets, websites, articles, posters and stickers - produced by individuals and collectively from within the researched groups' networks as well as texts produced by other sources which were used by the 'movements' to inform my understanding of the points of view of these groups. I also kept a journal to record my own thoughts and observations in the fieldwork process.

\subsection{Case studies}

The case studies that were used in the thesis were intended to ground the study in actual practice even though the theme of this thesis is based on a theoretical framework. I found this very useful in terms of affirmation of what I was reading in academic texts in participants' comments and views, being able to participate in and observe these events and situations personally, and in that these experiences facilitated the formulation of my own ideas in relation to development theory.

I chose Wellington as the place for fieldwork as I was adopting the postdevelopment view that the West needs to look at itself and stop intervening with the rest (e.g. Latouche, 1993). I also chose the location because it was the city I was studying and living in, which meant that I did not need to travel far and could thus work on living with a lighter ecological footprint and build networks locally - in line with permaculture, post-development and anarchism. I would 
thus be acting on the solutions these philosophies suggested, where possible. Although the groups that I participated in and observed were based in the Wellington region, sometimes it was necessary to attend larger meetings outside of the Wellington region.

Unlike traditional ethnographic study, I was unable to observe the groups' everyday living and it was not my intention to do so. These groups generally had regular meetings throughout the year and it was the ideas within these groups in which I had an interest as well as how these ideas were played out in the meetings (the 'process'). Hence much of the participant observation happened within meetings, conferences and events. Since I shared a personal interest in the subject matter in some of these meetings, as well as the participation techniques used in these meetings, my role swayed throughout the fieldwork between participant and observer. I could not be the 'fly on the wall' nor did I intend to be. I engaged in discussion and actively participated in activities.

"Ethnographic field work requires the personal involvement of the investigator, a willingness to be in situations out of one's control and as such an abandonment of strict "scientific control." It also involves an iterative, improvisational approach to understanding, wherein partial and tentative formulations are revised as new observations challenge the old, and where adjustments in research strategy are made as more is learned about the particular situation at hand" (Blomberg, et al., 1993, pp. 129-130).

In the first month of the project my main concern was to make contacts and build rapport. I utilised the snowball method to find case studies and kept all options open initially. I already had contacts in the permaculture network through the Permaculture Design Certificate course I had completed in 2008, and intended to find as many activities as possible that were able to complete the permaculture design flower (see Figure 5.2 in the discussion chapter).

This list expanded as rapport was built. I attended a number of events at the anarchist run Radical Social Centre and informally interviewed some of the activists in order to verify my reading material. I attended a Sunday working bee at Common Ground, the community garden in Island Bay. I also attended an Anarchist Conference run by the Wildcat Collective at the Newtown Community 
Centre on the theme of organising, which was the first fieldwork study. The Anarchist Conference was very helpful in terms of relating what I had read with the concerns and ideas of the people within the 'movement'. I attended the first meeting of the Kelburn/Highbury Transition Town at the Kelburn School Hall and a Seed Savers day organised by Transition Towns Brooklyn at the Home of the Sisters of Compassion and Common Ground. I planned to attend the Simply Good Food CSA (a Community Supported Agriculture in the Wairarapa) Autumn Harvest Day but they were fully booked, although from enquiring what it was about and finding out the results gave me some insight into the group. I also used their website to research their mission. I attended a two day workshop hosted by Living Economies on various kinds of community currencies, namely Time Banking, Genuine Wealth System and LETS (Local Exchange and Trading Systems).

I participated in two lower North Island permaculture hui (meetings) and the Permaculture in New Zealand (PiNZ) Institute's Annual General Meeting in Te Teko in May/June 2009. For the Camp for Climate Action Aotearoa I attended the call for organisers at Parihaka in April 2009, joined the Wellington local group and participated in regular local group meetings, three national meetings, online spokes councils, up-skilling workshops at Kotare in Northland and the actual Climate Camp event at Moonshine Park in Wellington in December 2009.

\subsection{Research issues and limitations}

I had originally envisioned becoming highly involved in the community gardens, Transition Towns Kelburn/Highbury, local complementary currencies, the CSA Simply Good Food along with some other projects, recording how they were organising as case studies of alternatives (since these tools are shared by permaculture, anarchism and post-development) and interviewing key people. However, this did not eventuate.

I realised that there is an overwhelming amount of activity within Wellington that fits into the permaculture approach. Although originally I wanted to find these and in some way make up what an alternative to development looked like in the region, to do this would be a lifetime occupation. Some of the issues I found when considering these groups are pinpointed through this thesis. However it was 
just not possible to explore them all or consider in detail all those that I had some dealings with.

As an active researcher, I became unexpectedly involved in the organising of the first Climate Camp in Aotearoa New Zealand. I received an email through the Transition Towns network inviting people to attend the mini Camp for Climate Action Gathering being held at Parihaka in April 2009. I read the principles and objectives and recognised the anarchist ethics within them and the direct link with permaculture and climate change concerns. This led to a new turn in my case studies and fieldwork since it was in fact the call for people to join in organising for the Climate Camp, and not the Climate Camp itself. This meeting at the Parihaka Marae was an unplanned and exciting addition to the case studies. Initially I did not intend to get involved in large global justice groups, but to focus on the small independent groups in Wellington. However, global justice groups are revered in post-development's call for alternatives and they provide an important example of anarchist principles in action and marry these principles with global environmental issues. Consequently, Climate Camp Aotearoa became my central case study. I attended the first Aotearoa Climate Camp held at Moonshine Park in Wellington in December 2009.

The focus of my fieldwork changed further with attending the Lower North Island hui that took place at Tapu Te Ranga Marae and the PiNZ AGM hui which took place at Tu Teao Marae in Te Teko, leading to a focus on larger organisational tools and how meetings are run (the organising process) more than the community activities such as gardens, which had been included in my original proposal.

The focal case studies in this thesis are therefore somewhat different to the original focus of the study, which aimed to explore the structure and functioning of smaller community groups in Wellington which adhered to the principles of permaculture and anarchism to inform my understanding of an example of an 'alternative to development'. As my understanding transformed through the research process I came to realise that an alternative to development did not exist, in a pure sense, not only because a community currency alone was not an alternative to development from an anarchist perspective but also because there 
was not a fully functioning system that was separate from the current neoliberal paradigm, even though there were elements of it budding and blossoming in places.

Contrary to what I had envisioned as relocalisation fieldwork with a land and economics base, I began to get involved in different techniques used in groupwork and attended many meetings, a few 'conferences' and some workshops. The focus moved towards building a peoples' movement and how it could be structured.

In my original proposal, I chose to eliminate the political aspect of these examples. I was interested in the details. However, I realised that the implications of applying such methods (consensus decision making, community currencies etc.), indicated a fundamentally political result by potentially undermining the current paradigm. It was around this time that I noticed that permaculture downplayed (if not outright denied or ignored) its central political nature ${ }^{15}$ and that I came across the call to the Climate Camp Gathering at Parihaka.

I made it explicit and public wherever I could at meetings and events that I was both participating as a researcher and an activist. As the approach was action anthropology, I was not just the researcher watching and recording what the group were discussing or the group dynamics - as I got further and further involved in the 'fieldwork' and into an activist role, it became more and more difficult to detach myself as researcher from my participant role. The lines became blurred until, at one stage, the research seemed secondary to what had begun as 'fieldwork'. On occasion, I felt a tension between my researcher role and activist role, as they were at times conflicting in terms of activities and thinking. My academic role wanted to link the practice to theory while my activist role was involved with the day-to-day activities and discussions at hand at the various events or engaged in tasks for the Climate Camp. I felt the "marked contradiction between the moment of research and the moments of writing, publishing and

\footnotetext{
${ }^{15}$ Shown by the example of a Transition Town debate and it being 'apolitical' - made up of the whole spectrum of 'left'. (For insight into this debate see Hopkins, 2009; Trainer, 2009a; Trainer, 2009b)
} 
distribution" (Juris, 2007, p. 165), with working actively in solidarity with others and with writing solitarily.

Routledge (1996) writes about a 'third space' between academic and activist as 'critical engagement'. This brings in the issue of the relevance of this study to the people being studied and the personal gain associated with writing this thesis. The reason I asked the question I have that is central to this thesis ('can the principles of permaculture and anarchism provide an alternative to development?') was to learn about and get involved in grassroots activities through academic gain. It is difficult to say what indirect relevance this study will have outside of academia, unless this thesis and any publications thereafter are perceived as a form of resistance (Scheper-Hughes, 1995).

An objective of the research was to find out how these groups were organising. By using a participant observation approach, this provided an opportunity to get involved in the process and thus to experience the process of organising and decision-making. This was not a passive role. As Juris (2007) has pointed as, it meant getting involved in messy group politics and discussions. In addition and more significantly, through being actively involved and engaging as much as possible within the groups (particularly Climate Camp), my own depth of understanding and personal perspective was affected by the process and interactions with other participants.

Within the anthropological study is the debate around the insider/ outsider position. As a white, educated, middle class female immigrant native English speaker in my late twenties, I generally fitted into the groups. The ideas and values I held were similar to the majority the groups and counter to the 'mainstream'. As a South African immigrant, I did not share a common history with New Zealanders but the groups I was working with generally had some variety of nationalities and cultures and generally consisted of travelled and educated individuals.

An interesting phenomenon too was that depending on which group I was in determined how I viewed the other groups. In other words I had to take different positions. So if you imagine permaculture, anarchism and post-development each as a different character observing the other two from its own position (i.e. 
imagine three people at a table, each one representing permaculture, anarchism and post-development) I found myself at different times taking the perspective of one of these and looking at the other two from that perspective. This was very useful in figuring out the similarities and differences between the concepts and how they related to one another.

Taking on an activist role was very challenging. In Development Fieldwork, researchers are cautioned against advocacy and activist work if enough time and resources cannot be ensured and to be careful of the potential pitfalls of local involvement, even though involvement can be beneficial (Scheyvens, et al. 2003, p. 188). In the case of the Camp for Climate Action, it required participating in the functioning of the group, which involved attending regular face-to-face local meetings, travelling to and attending national meetings, administration, acting a liaison, co-ordinating, acting as 'spoke' (delegate), attending events, outreach and so on. Having full access to resources such as a computer, Internet, Skype, printing and being flexible with time aided my ability to participate more fully in the group activities and affected the researching and writing process of the thesis. Note taking proved to be a challenge when participating in discussions and decision-making processes especially in addition to the intensity of multiple day meetings and the need to be continually thinking about how these meetings related to the thesis (which was at times lost to the moment) with no time to contemplate until afterwards - by which point I was too tired to think anymore!

Doing 'fieldwork at home' and on voluntary and community projects meant that potentially there could never be an end to the fieldwork process and that I never left the field. However, an end had to be reached in order to write up and thus ended with the Climate Camp event as an ethnographic case study. The permaculture hui were two weekend long meetings and the other anecdotal case studies were not in-depth research, partially for reasons I touched on above and explain further in the discussion chapter. I have not included all of the events and cases I studied into the body of the thesis, some I have placed throughout the thesis as illustrations of ideas and in the chapter on case studies I have included only those that I felt were of particular significance and held some novelty for both the thesis and each other. Findings come from my participation and 
experience in meetings and with conversations and comments that arose in those meetings.

I applied for and gained ethics approval from the Human Ethics Committee. This process included the provision of a participant information sheet for the study and a form for consent to participation in research. While out on fieldwork, I verbally stated my position as a researcher, gave information about the research and asked for consent to participation. The ethical concerns of research in the study are significant. The consequences of naming participants could potentially be harmful, particularly due to the nature of some of the activities of the groups and individuals. I have only included information that is of relevance to the study and informed consent has been given for any source attribution. Participants remain anonymous and confidential information remains as such. I have, however, quoted myself in the study from the journal I kept during the fieldwork and research. 


\section{Chapter 4: Case Studies}

\subsection{Introduction}

The focus of this chapter is the Camp for Climate Action Aotearoa ('Climate Camp'), selected as the primary case study of anarchist and permaculture principles in practice. I describe some of my experiences as a participant in the activities of the movement leading up to the Climate Camp event itself and at the Camp. Particular attention is paid to the organising structures and processes of the Climate Camp movement are as anarchical practice. Permaculture elements of the Camp are explored to show the links between anarchist and permaculture principles. Processes experienced at permaculture groups' meetings - namely Open Space Technology and World Café - are also incorporated into this chapter as a secondary case study in accordance with participatory education processes.

\subsection{Camp for Climate Action Aotearoa}

Camp for Climate Action is a grassroots people's movement that 'seeks to actively address the root causes of climate change'. It advocates a climate justice perspective, which concentrates on the moral aspects of tackling climate change. By focusing on the (physical and political) impacts of climate change and proposals for adaptation and mitigation on human and environmental values of equality and freedom, climate justice is a political perspective with an intrinsic respect for the dignity of humans and other life forms. This position is concerned with distributive social and ecological justice issues of fairness, democratic representation, participation, legitimacy and empowerment (Comim, 2008). 


\section{CAMP FOR CLIMATE ACTION AOTEAROA}

\section{Our Principles:}

Camp for Climate Action Aotearoa working groups and local groups will work in line with the following collectively created principles:

1. We will work in a positive, inclusive and people focused manner.

2. The Camp itself will be an autonomous space for individuals to address Climate Change.

3. We wish to remain unaffiliated with any big NGOs or political parties.

4. As a Climate Justice focused initiative, we must address class divisions, oppression and how they are intertwined with the problems and possible solutions to the issues at hand.

5. We will work towards empowering people facing the threat of Climate Change and those confronting its root causes.

6. We support people based solutions as opposed to market based solutions.

7. We will have a multi cultural, Climate Justice focus with particular emphasis on Indigenous Peoples - Tangata Whenua in particular.

8. We aim to provide solutions that are relevant to people's everyday lives.

9. Any funding that we choose to receive from external sources will be strictly 'no strings attached'.

10. We will address the Climate Crisis and its root causes while acknowledging that this is not just an issue for humans but for all life on earth. 


\section{Our Objectives:}

11. First and foremost: The overarching goal is to build a peoples movement that addresses the root causes of Climate Change.

12. To identify the problem areas in Aotearoa and the root causes of Aotearoa's emissions.

13. To raise awareness of what is happening at an international level and how the New Zealand government is involved.

14. To engage with the rural community of Aotearoa on Climate Change and Climate Justice.

15. To radicalise and normalise Direct Action on Climate Change in Aotearoa.

16. To raise awareness of the Climate problem and inspire people to tackle it themselves.

17. To create a Climate Camp which serves as an example of a sustainable community.

18. To upskill the grassroots Climate Change movement \& share our existing skills.

19. To present an alternative viewpoint on Climate Change and;

20. To present an alternative viewpoint from a Pacific perspective.

21. To build an inclusive movement that is multicultural and diverse.

Figure 4.1. Camp for Climate Action Aotearoa Principles and Objectives (Camp for Climate Action Aotearoa, 2009a)

The principles and objectives of Camp for Climate Action Aotearoa (see Figure 4.1) reflect the anarchist principles of direct democracy, direct action, diversity, non-hierarchy, autonomy and anti-capitalism (a rejection of market-based solutions), free association and self-organisation. Organising structures for decision-making are decentralised, autonomous, and based on cooperation and respect.

Climate Camp as an event itself is an objective of the movement, as it serves as an example of a sustainable community, an embodiment of Camp for Climate Action Aotearoa's principles and a space in which its other objectives are acted 
upon. It is "an autonomous space for individuals to address Climate Change". (See Figure 4.1)

Camp for Climate Action grew out of the Climate Justice Movement in the United Kingdom (UK) and the movement's anarchist roots are overtly stated in recent writings from activists within the movement. "The Camp for Climate Action grew out of the radical anarchist and environmental movements, a synthesis of the organisational skills developed at the Anti-G8 protest camp at Stirling, and the ecological direct action movements such as Earth First!" (Shift Magazine/ Dysophia, 2010, p. 4).

The first Climate Camp took place in 2006 and was set up in Yorkshire, England, with Drax, the largest coal-fired power station in the UK and Europe, as the target for the day of direct action. Subsequently, Climate Camps have continued and spread throughout the UK and to other parts of the world, with at least 19 having taken place in 2009, mainly in the Global North, including various countries in Europe, the UK, different states in Australia, and one in New Zealand (Camp for Climate Action Aotearoa, 2009b).

In December 2009, the first Climate Camp in Aotearoa/ New Zealand took place for five days at Moonshine Park in Upper Hutt, Wellington. Participation in the functioning of the Camp and in decision making by everyone present was central to its principles, reflecting the anarchist principle of self-organisation. Horizontal (non-hierarchical) decision-making processes and structures were practiced at the Camp and on the Day of Direct Action on the last day. The Climate Camp democratic structures and processes and the principle of non-violent direct action are explored in this chapter.

\subsection{Parihaka and the beginnings of my involvement}

The call for individuals to participate in organising the first Camp for Climate Action in Aotearoa/ New Zealand took place in April 2009 at the Climate Camp Gathering at Parihaka in the Taranaki region, which was held on the Parihaka Marae. Although this was not the first meeting ${ }^{16}$ in New Zealand, it was the first

\footnotetext{
${ }^{16}$ There had been another meeting the year before in Wellington where the principles and objectives had been discussed and written down.
} 
time I had heard of the movement. Reading the principles and objectives, I recognised that they reflected those of anarchism, falling just short of calling themselves such, and was immediately drawn to participate even though the meeting location was not in my region of study. This significant event changed the focus of my study from the local community projects in Wellington to incorporate the more global and radical focus and more explicit principles of community organisation.

\subsection{Capitalism and hierarchy}

The rejection of capitalism and hierarchy, and the praxis of alternatives are at the heart of the Climate Camp project. The 'root causes of climate change' were discussed at the Climate Camp Gathering at Parihaka. The general agreement was that a 'root cause' is capitalism as an economic system based on infinite growth and social and ecological exploitation and control for profit. "Our climate is changing not simply because of particular polluting practices but because of the underlying logic of capitalism, which values short-term profit and perpetual growth" (Camp for Climate Action Aotearoa, 2009f, p. 20).

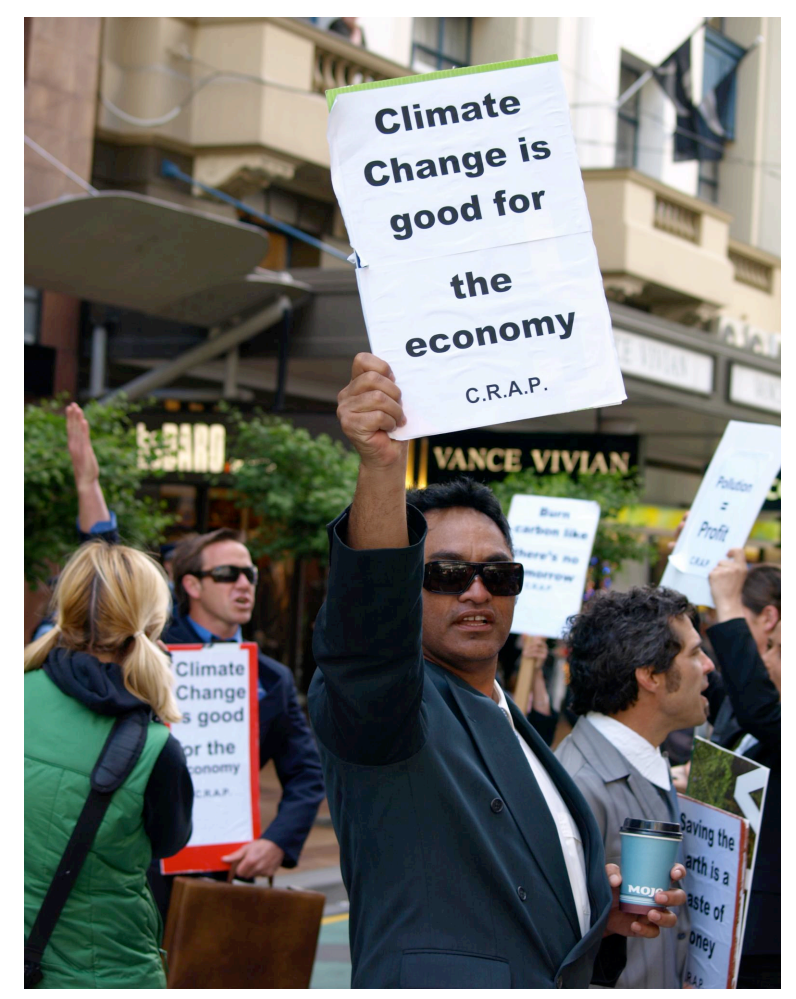

Figure 4.2. The 'Capitalism Represents Acceptable Policy' (C.R.A.P.) affinity group for the Camp for Climate Action's Day of Direct Action in Wellington 21 December 2009 (Source: www.scoop.co.nz accessed 21/12/2009) 
The Camp for Climate Action Aotearoa Handbook 2009 states that climate change is a result of the current economic system and caused by the people who promote and preserve it. "Capitalism - the pursuit of endlessly growing profit exhausts, degrades and exploits those that work under this system, just as our ecological systems are being exhausted, degraded and exploited" (Camp for Climate Action Aotearoa, 2009f, p. 20). Thus climate change is framed from a social and ecological justice perspective and with the recognition of capitalism as a competitive and undemocratic system. "We support people based solutions, not market based solutions" (Figure 4.1, see also Figure 4.2).

Camp for Climate Action Aotearoa is concerned with distributive justice and stands in solidarity with those who are most vulnerable to the effects of climate change and market-based solutions, such as carbon trading. "Not only will these 'market-based solutions' fail to solve the climate crisis, but this failure will dramatically deepen poverty and inequality, because the poorest and most vulnerable people are the primary victims of climate change - as well as the primary guinea pigs for these emissions-trading schemes" (Camp for Climate Action Aotearoa, 2009f, p. 20).

This climate justice perspective takes an ethical stance on climate negotiations and reframes the debate to focus on questions of equity, responsibility and democracy. Camp for Climate Action Aotearoa promotes a DIY democratic approach based on a rejection of hierarchy and needing leaders to take action, since the political system is tied in with the capitalist system. The lack of faith in governments' ability and the view that they are part of the problem is supported by governments' apparent inaction on stopping runaway climate change, their role in fossil fuel consumption and promotion of false market-based solutions. "Within this crisis is an opportunity to change things at a deeper level, to rethink our relationship with each other and the world, to do something radically different" (Camp for Climate Action Aotearoa, 2009f, p. 15).

\subsection{Direct democracy}

"Democracy and self-management lies in the very nature of the Camp for Climate Action Aotearoa project. We strongly believe in the human ability to maintain its own affairs without the need for politicians, managers or bosses ... 
Climate Camp is not just about the rejection of mainstream politics, it is about the celebration of a vibrant way of doing politics for ourselves" (Camp for Climate Action Aotearoa, 2009d). The Climate Camp movement is concerned with direct democracy by organising in a participatory non-hierarchical manner. This is practiced through a process of collective consensus decision-making and by local decentralised and horizontal organising structures based on cooperation, trust and respect. "Self-government is based on the ideal that every person should have control over their own destiny. This ideal requires us to find ways to organise a society in which we can coexist with each other whilst respecting people's individuality, their diverse needs and desires" (The Seeds for Change Collective, 2007b, p. 55).

\subsection{Consensus decision-making process}

'Consensus' was defined collectively by participants at the Climate Camp Gathering as "a direct democratic, inclusive and collective process that needs to be structured in a non-hierarchical way that comes up with creative solutions." The consensus decision-making process is the basis for all Climate Camp meetings. The rationale behind direct democracy is to create a process that is transparent, accountable and decentralised and empowers everyone to participate in local decision-making.

This is in opposition to the system of hierarchy created by representative democracy where power is handed over to a minority of elected representatives to make decisions and effect change on behalf of the majority through a competitive voting system, which favours the majority while marginalising and excluding the 'loser' minority (The Seeds for Change Collective, 2007b, p. 51).

"Democracy is at the heart of our beliefs ... By using consensus decision-making, everyone's views are heard, and the group tries to find a solution that addresses everyone's concerns and desires. The result is greater understanding between different individuals and groups, and usually a better decision because everyone has thought carefully about it, and because hopefully everyone who takes part in making the decision feels that they has a stake in the decision and therefore a stake in making it happen" (Camp for Climate Action Aotearoa, 2009a). 
Decentralised non-hierarchical decision-making structures are practiced by Climate Camp Aotearoa to ensure equity, empowerment, participation, transparency and accountability in these processes. This participatory model of organising is based on cooperation through open discussion and respect of differences (The Seeds for Change Collective, 2007a). Although this may be a lengthy process at times, it is perceived as an effective method of decentralising power and practicing meaningful democracy in a sustainable community.

All Camp for Climate Action meetings use this consensus process. The participants set the agenda for the meeting. Some points for the agenda (such as proposal points for discussion and decision making and outreach event planning) are usually communicated by participants to the local group or wider groups via email prior to the meeting with other announcements added to the agenda at the meeting. This is typically true for national meetings, where local groups communicate face-to-face or via spokes council using Skype. These structures are discussed in more detail later on in this chapter.

\subsubsection{Key roles in the consensus decision-making process}

The role of facilitator is a significant part of meetings and is considered vital for a meeting to run smoothly. The facilitator role includes keeping the meeting focused and on track with the agenda, watching and mediating hand signals and speaking order, reiterating points and changes to proposals, and testing for consensus. Anyone can volunteer to facilitate a meeting. They can also ask to step down at any point in the meeting and someone else can take over, or anyone can offer to take over the role during the meeting if they sense the facilitator needs to break. The facilitator may "step out of the facilitation role" if they need to add to the discussion.

Minute taker and timekeeper are other roles that may be used depending on the meeting. In large group meetings, a co-facilitator role may be used to mediate the speaking order and possibly to keep an eye on the time so that the facilitator can focus on the discussion and reaching consensus. Like the facilitator, these roles can be rotated throughout the meeting and are voluntary. Self-management is an underlying principle in meetings, in keeping with the principles of non-hierarchy and self-organisation, where all participants are responsible for facilitating the 
meeting by keeping themselves in check and for pointing out any oppressive behaviour. The facilitator and participants in the meeting are guided by hand signals as a form of communication.

\subsubsection{Hand signals for communication in the consensus process}

In Camp for Climate Action meetings, including at the Climate Camp event, hand signals are used as tools to facilitate discussion and decision-making processes.

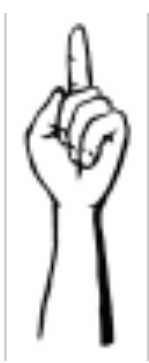

Raised hand or finger is used to contribute to the discussion.
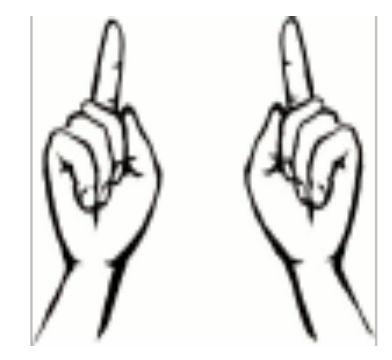

'Direct response' to the question or point - this takes priority over raised hands.
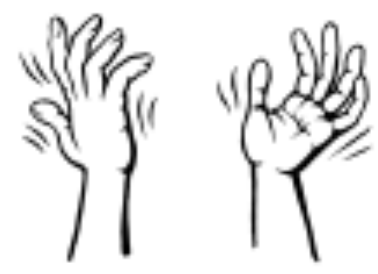

Showing agreement or support by silent clapping or 'twinkling' (shaking both hands or wiggling fingers up into the air). This avoids the need for participants to voice their agreement individually, which would slow down the process. 


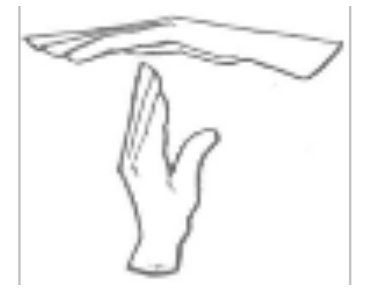

Technical point indicates a point outside of the discussion, which could relate to process (e.g. to keep discussion on track - time, agenda - or for an announcement outside of the discussion). This takes priority over the discussion and thus any raised hands or direct responses.

Another less common hand signal used in meetings is one indicating a 'point of clarification' (one hand curled into a C- shape), which takes priority over raised hands. This has been used to clarify a point (e.g. to correct something) or often to request clarification. The 'direct response' hand signal was usually used to clarify the point in question. The raised finger has also been used instead of the 'point of clarification' hand signal as a point of question to clarify, in which case it is usually responded to by a 'direct response'.

At the decision-making process stage in meetings, a facilitator tests for consensus on a proposal. This may be an emerging proposal through a growing sense of agreement from the discussion or a proposal being presented to the group.

A hand signal for 'stand aside', showing reservations or disagreement, was not used in any Climate Camp meetings that I attended, although the Handbook from the Upper Hutt Climate Camp (2009f) shows a palm up which also means a point for discussion. However, a stand aside is used during the decision-making process when testing for consensus, and not during the discussion process (although the discussion process is used to reach consensus on a proposal).

During a large meeting at the Climate Camp when a test for consensus on a proposal for the site of direct action was sought, the facilitator asked the group to show dissent with another hand signal of hands down 'twinkling' fingers. ${ }^{17}$ The facilitator then asked for any other issues to be raised, which were discussed and attempted to be resolved (e.g. by amendments to the proposal), and again tested

\footnotetext{
${ }^{17}$ This demonstrates the diversity of hand signals and how important it is to be clear on the signals and their meanings to avoid confusion and potential disempowerment or exclusion from the decision-making process.
} 
for consensus. To stand aside or stand down means that the person still has reservations which may or not mean that they cannot participate in carrying out the proposal but that they will allow the group to go ahead with the proposal anyway. An important point to understand in the consensus process is that disagreements as differing points of view are recognised as a healthy sign of diversity and as adding to discussion and to depth of understanding in decisionmaking.

A raised fist is unusual and did not once appear in any meetings that I attended. This hand signal indicates a block or veto and symbolises strong resistance to the proposal, to the point of stopping it/ blocking it from going ahead ${ }^{18}$. This is most likely to occur where participants feel that the proposal goes against the principles of the group. If this occurs, the issue is raised and discussed. If the block cannot be overcome, a new proposal may need to be sought and the blocked proposal dropped or put aside to be revisited later.

\subsection{Organising and decision-making structures (and processes)}

The horizontal organising structures, like the consensus decision-making processes, are at the centre of Camp for Climate Action as a movement for social justice and change and at the Climate Camp event itself as an example of a sustainable community.

The organising structure of Climate Camp used in Aotearoa was based on the one used in previous Climate Camps. In anarchic style, the objective is to form a non-hierarchical and participatory decision-making process by consensus using the principle of direct democracy. The basic structures consist of local groups, working groups, spokes councils and national meetings.

\subsubsection{Local groups}

In the planning of the Camp, local groups ${ }^{19}$ are based on regions, cities or towns and make up the basic decision-making element in the network. Active and nonactive local groups included Wellington, Auckland, Whangarei, Taranaki,

\footnotetext{
${ }^{18}$ Direct action in blockades and protests is a physical form of this decision to resist proceedings.

${ }^{19}$ And at the camp neighbourhoods, as will be discussed below.
} 
Hamilton, and Christchurch, as well as a 'Floaters and Drifters' local group for travellers (see Figure 4.3).

Local groups are autonomous and make decisions by consensus on local issues. Broader decisions affecting the organising of the Camp and the group as a whole on a national scale are discussed as proposals. Minutes from the local group meetings are taken and emailed to the other local (and possibly working) groups. Having local groups based in geographic locations builds the movement and shows the importance of community in Camp for Climate Action values.

At the Parihaka Gathering, we formed the Climate Camp Wellington Local Group and met shortly thereafter for the first time in Wellington. Reflecting the Climate Action Camp process at Parihaka, on our first agenda we discussed and agreed on ground rules at meetings and our principles and objectives, except this time as an autonomous collective involved with the organising of the first Climate Camp in Aotearoa. The Wellington local group met on average every two weeks throughout the year with our core active numbers varying between three and six and, in agreement with Climate Camp, we practiced working in a consensus based manner. Our key functions as a local group were to research, propose and discuss potential sites for the Camp and direct action and to engage in various forms of outreach and local fund raising. Although with our lack of experience, it took time to figure out the processes and our roles and function as a group. The formal consensus process was also not always followed due to inexperience and small numbers. 


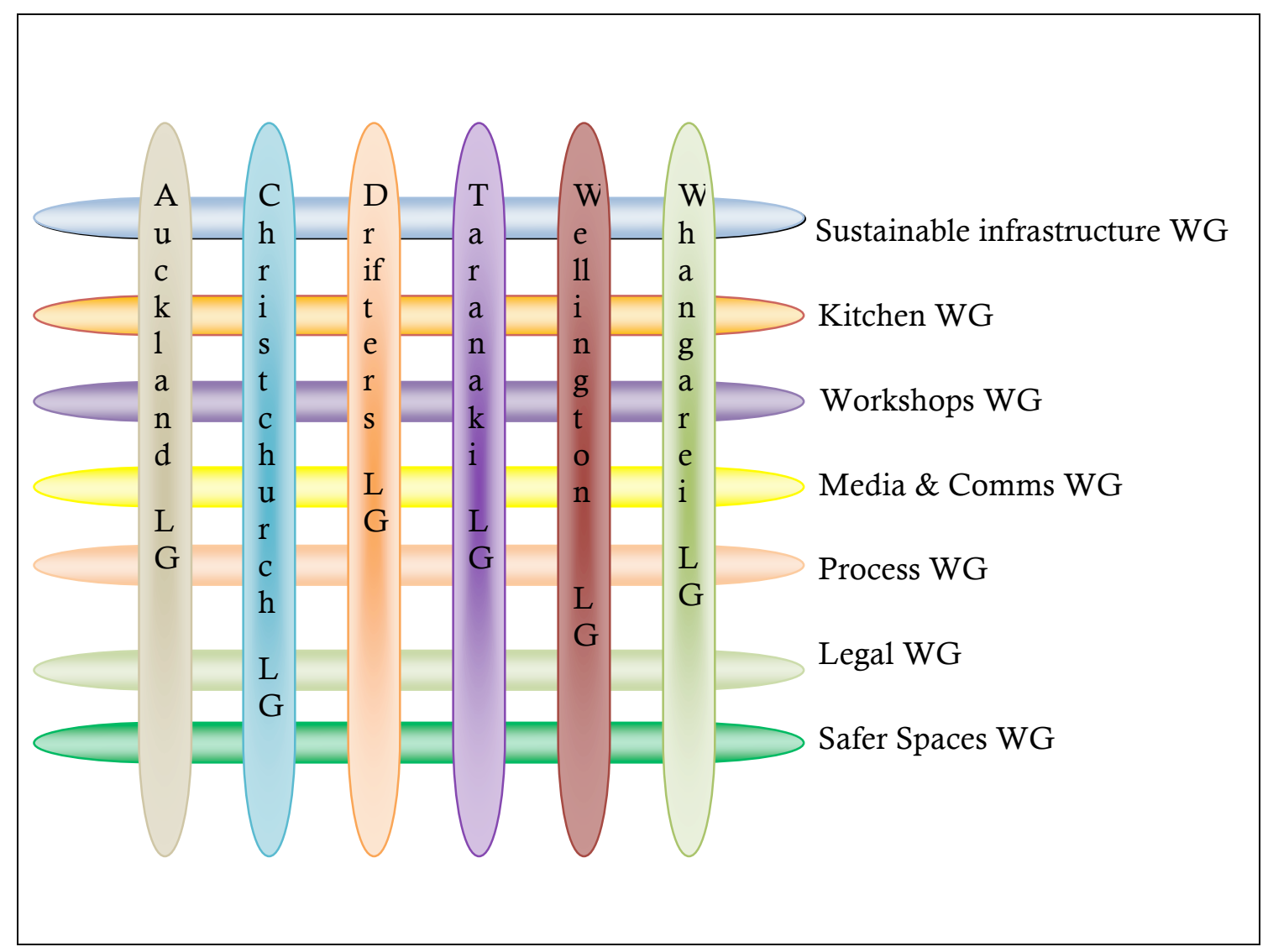

Figure 4.3. Diagram showing the relationship between local groups (LG) on the vertical axis and working groups (WG) on the horizontal axis from whiteboard (Source: Camp for Climate Action Gathering April 2009)

\subsubsection{Working groups}

Working groups were divided into functions of the Camp and were made up of individuals in local groups. Their function is to work on specific tasks or functions of the Camp. In the planning of the Camp working groups included process $^{20}$, sustainable infrastructure, kitchen, media and communication, workshops, finance, legal, safer spaces/ health and safety (see Figure 4.3 and Figure 4.4).

As it was the first time a Climate Camp was being organised in New Zealand, and with the limited numbers of participants involved and distances across the country, some working groups changed and amalgamated both before and at the Climate Camp.

\footnotetext{
${ }^{20}$ This working group functioned initially to set up various communication etc. processes and then dissolved.
} 
Although participation in a working group is voluntary, what occurred was that in the planning of Climate Camp, local groups tended more strongly towards certain tasks as seen in the diagram below (Figure 4.4). This was partially due to some degree or combination of interest, experience, skills and geographic location and the amalgamation of some working groups reflected this. However, there were still individuals in other geographical locations involved in other working groups and there was no obligation to be in the focal working groups of that local group. That would be against the voluntary nature of Camp for Climate Action and anarchist free association. One could also be involved in multiple working groups. So, for instance, I was in the sustainable infrastructure, process and workshops working groups. Technically these working groups have their own meetings. In the Wellington local group this did not occur however, although with more people and experience this could change.

A working group's participants communicated via email and Skype. Most national communication between participants in working groups occurred via email. The working groups and the local regional groups presented proposals via email to the other local regional groups. The proposals were discussed and decisions made by each of the local groups by consensus and brought back to the group via spokes councils (see Figure 4.4). 


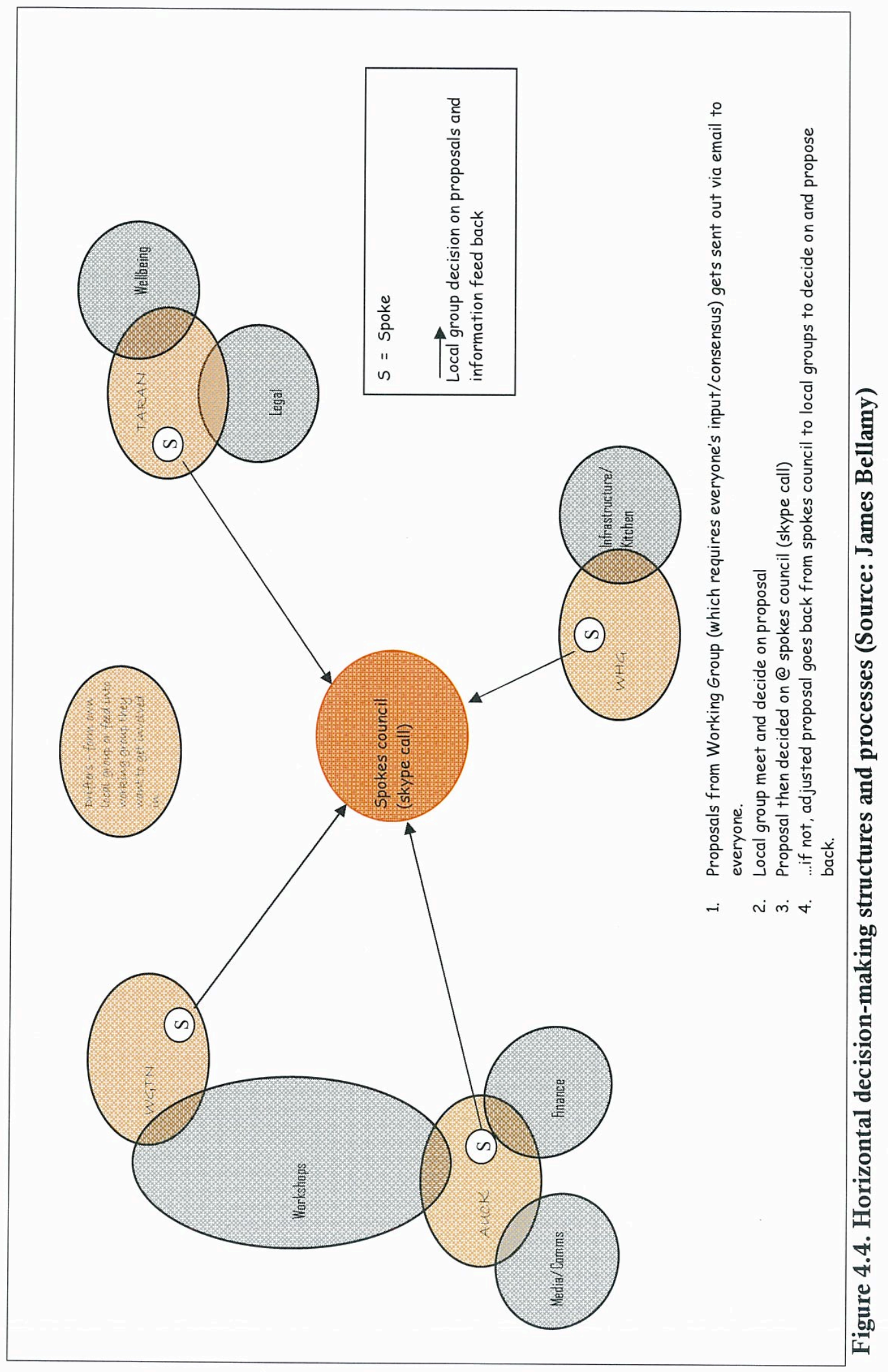




\subsubsection{Spokes council and spokes}

Local and working groups communicate with each other using the spokes council model and the consensus decision-making process (see Figure 4.5). "The role of the spokes council is to make decisions on a national level based on directives from their respective local groups" (Camp for Climate Action Aotearoa, 2009e). The spokes council consists of local group delegates or 'spokes', who are sent by their local group to feedback decisions, questions, uncertainties and such to the other local group spokes and then back to their local group.

Spokes do not have the autonomy to make decisions on behalf of their local group unless the local group gives them the authority to do so. Decisions must be based on what the local group has agreed upon with regard to a proposal prior to the spokes council. The spoke role is rotated within each local and working group to discourage hierarchies from forming and to up-skill participants. In practice, regular rotation of the spoke role is not necessarily possible with a small group and when some individuals have an advantage, such as more access to technology, confidence, experience, skills or time.

Camp for Climate Action Aotearoa spokes councils occurred through Skype conference calls. The consensus process was used in these meetings, with hand signals represented by keyboard symbols in the text section of Skype. At the next local meeting, the spoke reported back to their local group with feedback from the meeting and for any further decision-making (see Figure 4.4). Minutes of these meetings were usually noted and emailed to all local groups. In practice, spokes councils occurred as they were called for. 


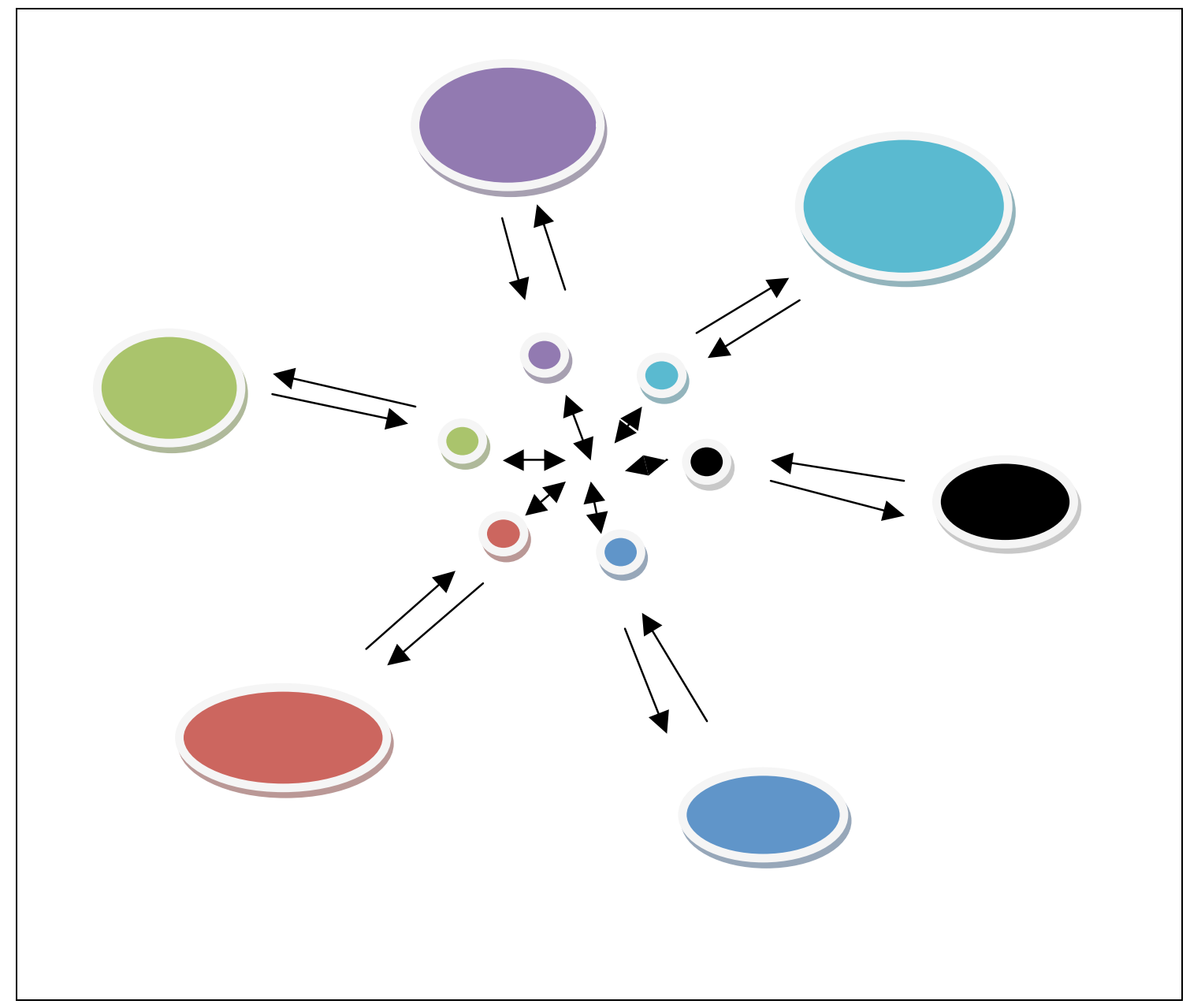

Figure 4.5. Diagram of the Spokes Council: showing spokes, local and working groups, and feedback flows. Local groups and working groups send a spoke to feedback their group's responses to proposals and issues for discussion. Outcomes and responses (such as new or adjusted proposals, agreements and concerns) from the spokes council are then fed back to the local group or working group via the spoke. This process functions as a line of communication between groups, for decision-making and discussion. The role of the spoke tends to rotate and meetings are conducted using the consensus process (Source: Author)

\subsubsection{National meetings}

In preparation for the Camp, there were national meetings to meet face-to-face and to discuss crucial issues including region and dates for the Camp. These occurred through the year in various locations in the north island including the ones I attended at Te Kauri Lodge in the Waikato, Tapu Te Ranga Marae, the Wellington Peoples Centre in Wellington and Kotare Trust in Wellsford. I was not able to attend all of the national meetings, however, the ones that I did attend all functioned using the consensus process. 
Techniques used in these meetings to assist discussion and decision making included 'go-rounds' to get a sense of where people were at in terms of ideas, opinions and feelings. This technique can ensure that everyone has the chance to speak. 'Go-arounds' worked well at the beginning of meetings for participants to introduce themselves or to share their thoughts at the end. Multiple 'go-arounds' during certain difficult decision-making enabled in-depth dialogue and understanding of differing perspectives to assist reaching consensus - such as deciding on dates for the Camp. Other techniques used were 'pros and cons' and 'plus and minuses' for weighing up proposals and points, and the 'popcorn' technique where people shouted out their idea in a brainstorming session. These were very effective tools for discussion and to facilitate decision-making.

Different perspectives add to the discussion and can change one's point of view and position on an issue. I recall after a crucial national meeting in July 2009 to decide on the region and date of the Camp being completely amazed at how well the process worked despite differing views. At these meetings, facilitation is crucial and can be a very difficult task.

\subsubsection{Neighbourhoods at the Camp}

The decision-making process as a form of participatory democracy continued at the Climate Camp event from 16-21 December at Moonshine Park in Upper Hutt, Wellington with around 200 people participating. Local groups became three neighbourhoods, with local groups from the Central and Upper North Island combining to become one neighbourhood, the South Island and the 'Floaters and Drifters' local groups become another neighbourhood and the Wellington region as the third neighbourhood. These neighbourhoods were where participants pitched their tents and were defined geographically and physically to allow for participants to meet and network with others from their region as part of the Climate Camp movement-building objective.

Each neighbourhood was allocated an equally sized and signposted area, according to an estimated guess of numbers of participants from each region who 
would be present at the Camp. ${ }^{21}$ The arrangement was based on the larger UK Climate Camps where each neighbourhood had it's own kitchen and dining area, and where neighbourhood meetings took place in the neighbourhood area. However, the Upper Hutt Climate Camp differed in that there was one central kitchen and neighbourhood meetings took place in the workshop tents.

Neighbourhood meetings were held daily, after breakfast as a forum using the consensus process to discuss and make decisions on any issues that had arisen, announce any jobs that needed volunteers for the running of the Camp and other community related issues and then later to assist the establishment of affinity groups for the direct action (discussed below). Discussions included issues such as, if and where the consumption of alcohol was acceptable, making transparent the financial issues through discussions such as whether to spend money on hiring another marquee and informing participants of the current financial situation on paying back incurred costs and personal loans, and whether or not to appoint a police liaison given the principles of the Camp. A difficult situation arose concerning the safer spaces policy and the identification of a past abuser, which led to emotional discussions about how we should or even if we could (in terms of time and capacity) deal with the issue at the Camp.

\subsubsection{Working groups at the Camp}

Working groups at the Camp were similar to those in the preparations of the Camp although with a focus on the day-to-day running of the Camp and thus more specific tasks. The sustainable infrastructure group, kitchen, safer spaces, security, legal, tamariki/ kids' zone, media had initial meetings in the first day or two days of the Camp for helpers to join. Jobs lists were set up in the Welcome Tent with rosters for any participants to volunteer to add their names to help out. Jobs included building infrastructure, cleaning toilets, looking after children, welcoming new people to the Camp, security watch and helping out in the kitchen with food preparation and washing up. This is a clear example of the anarchist principles of self-organisation, voluntary association and mutual aid.

\footnotetext{
${ }^{21}$ Interestingly, the combination of South Island with travellers proved to be problematic due to the large size of the group in meetings and also with some travellers or 'drifters' feeling that they did not share an affinity with the South Island but rather with other regions. They proposed to split up their meetings into two separate neighbourhoods or join the one they felt an affinity with.
} 


\subsubsection{Spokes meetings at the Camp}

For the spokes council, a spoke volunteered from each neighbourhood to feedback to the hub spoke meeting after the neighbourhood meeting. In addition, there was also a 'shadow' that volunteered at the neighbourhood meeting to be present at the spokes meeting. Their role was to gain knowledge of the spokes meeting process and to assist the spoke with feedback to the local group. The shadow would then take on the role of neighbourhood spoke the following day with another shadow attending the hub meeting.

In the Wellington neighbourhood we had two shadows, which facilitated more participants learning the process and also when shadows or spokes left the Climate Camp before the next neighbourhood meeting. I volunteered to be the Wellington neighbourhood spoke on the first day. In practice, the process was not as smooth as in theory. In the first spokes meeting, a spoke attempted to influence the decision with his personal opinion and was corrected for overstepping his role. Experience and a clear focus on the collective decisions are so important and it is not impossible in a position of 'power' to misuse that position.

In practice, working groups were not represented at the spokes meeting unless they were specifically needed. Instances included a safer spaces representative being present when dealing with the abuse dilemma and an infrastructure representative being called for on the issue of the marquee.

Minutes on the spokes council outcome were fed back to the neighbourhoods at their local regional meetings the following day by the spoke and the shadows. This was felt by our neighbourhood to be too slow for certain issues and decisions to be feedback and thus enacted so minutes were displayed in the tent after the spokes council.

\subsection{Non-Violent Direct Action (NVDA) ${ }^{22}$}

At both Climate Camp gatherings in April and December, Non-Violent Direct Action (NVDA) was explained as both a principle and as a tactic.

\footnotetext{
${ }^{22}$ Unless otherwise stated, quotes and information in this section have been recorded from workshops at the Camp for Climate Action Parihaka Gathering and the Climate Camp at Moonshine Park.
} 


\subsubsection{Direct action}

"Direct action is an outbreak of democratic expression, directly challenging the injustices we see in the world and the laws that perpetuate them" (Camp for Climate Action Aotearoa, 2009f, p. 24). A Climate Camp facilitator explained that direct action, as a principle, is "practicing political will" by "engaging in the decision-making process" because "we are empowered most when we do things ourselves." 'Doing it ourselves' means making decisions collectively and implementing those decisions. This is practiced through utilising the consensus process, by "speaking truth to power" and displaying resistance.

"We live in a world that assumes we need leaders and laws to keep us in check; that we're incapable of making hard decisions and implementing them without being told how. Direct action is direct democracy. It's one way of challenging this myth and collectively re-asserting control over our destinies" (Camp for Climate Action Aotearoa, 2009c).

The chapter on direct action in Do It Yourself: A Handbook for Social Change begins with the statement that "Direct action is an important part of political activism. But its exact definition is quite elusive, meaning to act directly to address an issue of concern. It stands in contrast to indirect or political action where elected representatives are asked to provide a remedy on our behalf ... it can be a philosophy for life which impacts on the way that we organise our health, our education, or the way we organise and communicate." (Cutler \& Bryan, 2007, p. 262)

As a tactic, direct action can be a tool within an individual campaign where it may act as a symbolic and 'cost and delay' tactic. At the Climate Camp in Wellington, the 'day of direct action', we used NVDA as a tactic to disrupt business-as-usual and to raise awareness of the profiteers and false solutions of climate change. The New Zealand stock exchange (NZX) profits from the Emissions Trading Scheme (ETS) as a market-based false solution, while the Ministry of Foreign Affairs and Trade (MFAT) promotes the polluting ecologically destructive New Zealand agricultural industry, monopolised by Fonterra, as clean and green. 
These NVDA actions also served the wider campaign to build a people's movement for those who want to take action to address what they see as the root causes of climate change. The direct action aspect of the Camp aligned with the objective "to radicalise and normalise direct action of climate change in Aotearoa" and "to identify the problem areas in Aotearoa and the root causes of Aotearoa's emissions" (Camp for Climate Action Aotearoa, 2009a).

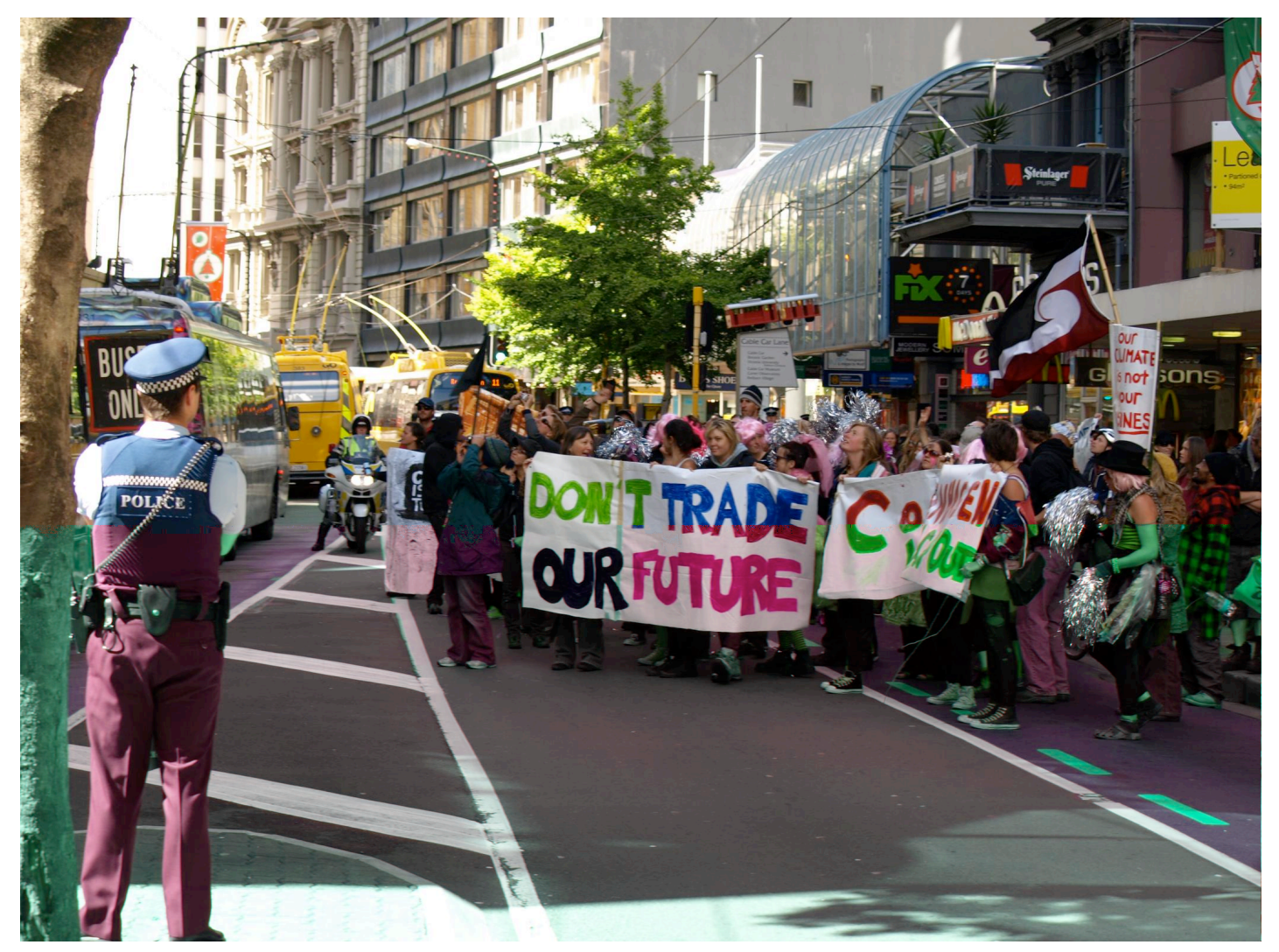

Figure 4.6. Climate Campers march along Lambton Quay in Reclaim the Streets style from the NZX building to the MFAT building to show solidarity and support for the climbers who scaled the building for a banner drop during the Climate Camp Aotearoa Day of Direct Action on 21 December 2009 in Wellington (Source: www.scoop.co.nz accessed 21/12/2009)

Soon after the Climate Camp Gathering, I attended a NVDA workshop at the Radical Social Centre in Wellington facilitated by a visiting activist. The speaker defined direct action as two different but not necessarily exclusive activities. Firstly, it can be defined as "interfering with the operations of injustices" such as blockades and sabotage, which is by its nature reactive and short-term action. Secondly direct action can be "embodying an alternative", which is more sustainable, pro-active and long term as well as being non-confrontational. An example of this would be a community centre. There are some overlaps, for 
example Food Not Bombs and Reclaiming the Streets. Similarly, direct action was defined at the Climate Camp workshops as both stopping something (a destructive process) and starting something (for instance guerrilla gardening).

A facilitator at the Parihaka Gathering summed up direct action and its significance as "creating change by going straight to the source" or "action that makes a change in the physical world." This relates to the primary purpose of the Camp for Climate Action to actively "address the root causes of climate change" and the DIY approach.

"We have to get together and create moments of resistance and celebration that break through this grey, complacent slide towards catastrophe. Direct action means knowing that it's up to us: that if we don't make the change, it will not happen. Taking action against the root causes of climate change, we shut things down to build things up, refusing to trust markets, money or governments. Instead we have faith in each other and the innumerable strength of hope in the midst of struggle" (Camp for Climate Action Aotearoa, 2009f, p. 19).

At the Parihaka Gathering, a small debate occurred during the NVDA discussion on whether permaculture was a form of direct action or not. One participant commented that permaculture was not direct action because it was not confrontational. However, the facilitator disagreed and explained that permaculture is direct action because it "looks at root causes" and is anticapitalist. It was generally agreed that it is direct action because it deals with the root cause of the problem.

Direct action was generally understood as more an action which attempts to stop the problem rather than being an action which creates a solution, although it is also that. The initial comment about permaculture not being a direct action was based on the belief that direct action means confrontation. However, direct action is not necessarily confrontational.

At the NVDA workshop at the Radical Social Centre, permaculture was also agreed to be a form of direct action. Activism was explained as having an earth 
perspective and a way of giving back what you take from the earth, which is reflected in permaculture design where input equals output.

\subsubsection{Non-violence}

Non-violence as a tactic was defined at the Radical Social Centre NVDA workshop as "not responding to violence with violence", which may be in the form of non-cooperation. Non-Violent Direct Action is also a moral and intentional stance that reflects a rejection of patterns of violence, control and injustice; and promotes the principle of the means being consistent with the ends and creating the change we want to see.

At the Parihaka Gathering in April 2009, we discussed what is or is not considered violent or non-violent and under what circumstances. For instance, is damage to property violent? We questioned ourselves as to how violent we thought we were by standing on a continuum. In a conversation after the workshop, a participant explained to me that our whole society is based on systems and processes of violence. So how can we say that we are non-violent? The systems and processes of industrial production are violent from the destruction of ecology in the extraction of fossil fuels to the treatment of animals and so on. The anarchistic Climate Camp views violence as systemic and the centralised processes and structures as the root of injustice.

To illustrate this point further: at the Climate Camp, a complicated situation arose where a participant involved in the planning of the Camp had been named as an abuser by an anarcha-feminist affinity group. A few weeks prior to the Camp, this affinity group had asked for the abuser to be excluded from the Camp days before it began. They used direct action as a tactic to disrupt the opening meeting of the Climate Camp, strategically during the safer spaces policy briefing, to draw attention to the past abuse and to demand the person's exclusion from the event. I did not understand why they would take action against an open network with which they shared similar principles. I voiced my concern to a safer spaces helper who explained that, for many people, climate change is a symptom of oppression and in order to stop climate change we need to deal with issues of abuse in all its forms. This view reflects the anarchist rejection of all forms of domination and is supported by the Camp for Climate Action principle "As a 
Climate Justice focused initiative, we must address class divisions, oppression and how they are intertwined with the problems and possible solutions to the issues at hand" (see Figure 4.1).

\subsubsection{Affinity groups ${ }^{23}$ for NVDA}

The basic entity of anarchist organising is that of the affinity group. This decentralised model has its roots in anarchist organising in Spain in the $19^{\text {th }}$ and $20^{\text {th }}$ centuries and is now practiced by environmental and social change networks around the world. Affinity groups or 'action groups' function in a non-hierarchal structure, using the consensus process, and are autonomous entities used for direct actions and other projects.

Essentially, the local group, neighbourhood and working group structures are forms of affinity groups with different functions other than taking direct action. "Affinity groups challenge top-down decision-making and organising, and empower those involved to take creative action" (Camp for Climate Action Aotearoa, 2009c, p. 4).

Central to this autonomous organising is the principle of equality and 'living how you want the world to be', as well as being an empowering activity. Importantly, affinity groups consist of individuals who share similar ideas, such as the same political background and shared tactics, (i.e. an affinity) and are based on trust.

There are also usually a variety of skills within an affinity group. The benefits of affinity groups are communication and effectiveness, solidarity and security. The effectiveness is partially due to their small size (between three and twenty people) as well as having a clear role and shared boundaries. Trust within the affinity group allows a sense of security and confidentiality. A group with shared and agreed upon ideas also means that decisions can be made quickly during an action.

Direct Action is challenging and emotional and the affinity group is about looking after each other. The 'buddy system' is a means of ensuring safety of the group during a Direct Action. Here, two or three individuals within the same

\footnotetext{
${ }^{23}$ Information in this section was collected at a workshop on affinity groups at Climate Camp at Moonshine Park.
} 
affinity group team up and keep an eye out for each other. Affinity groups may support each other in an action by forming 'clusters'.

Decision-making between affinity groups is practiced using the spokes council model. For the day of action, the affinity group decides on their spoke prior to the action. The spoke may be granted permission from the affinity group to make decisions on behalf of the group on that day to enable quick decision-making.

For the Day of Direct Action, a group of eight of us at Climate Camp formed an affinity group called the 'radical cheerleaders'. Our role was to support other affinity groups by keeping up morale, being distractive and calling the spokes council meeting through song. We were agreed to participate in 'non-arrestable' activities only. We formed clusters with other affinity groups, including the samba band affinity group and affinity groups supporting the arrestees as they were released.

\subsection{Elements of the Camp reflecting permaculture}

"We hope the camp is an example of an alternative society; one with low emissions, sustainable practices and sustainable relationships" (Camp for Climate Action Aotearoa, 2009f, p. 3). Climate Camp was a free and non-commercial event, demonstrating alternatives to market-based 'false solutions'. A sliding scale koha (gift donation) was suggested to help pay for expenses and as many materials as possible collected for the Camp were from recycled sources. 


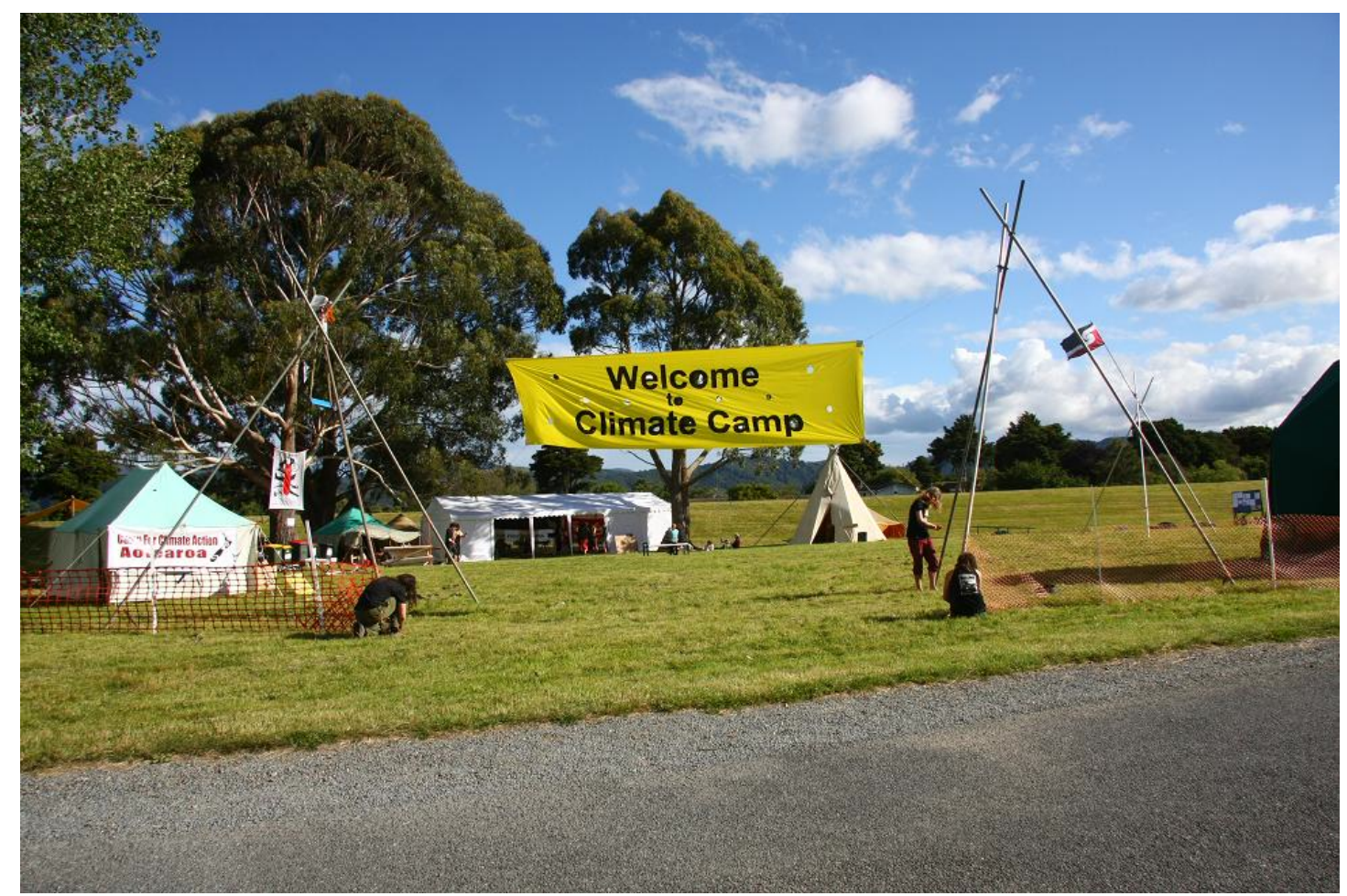

Figure 4.7. Setting up the entrance to the Climate Camp at Moonshine Park in Upper Hutt: with (from left to right) the Welcome Tent, Kitchen Tent, Marquee, Tamariki/Kids Tent (the tepee) and the Dome Workshop Tent in sight (Source: John Darroch)

The Climate Camp event consisted of four key elements, which reflect the objectives of Camp for Climate Action. These elements are sustainable living, education, direct action and movement building. They are important for the practice of community participation and DIY and to demonstrate just and sustainable solutions.

"Instead of trying to fix a destructive system, we are advancing alternatives that provide real and just solutions to the climate crisis: leaving fossil fuels in the ground; reasserting people's and community control over resources; relocalising food production; reducing over consumption, particularly in the North; recognising the ecological and climate debt owed to the peoples of the South and making reparations; and respecting indigenous and forest peoples' rights" (Camp for Climate Action Aotearoa, 2009f, p. 23). Direct action has already been discussed in depth and movement building has been mentioned above. The sustainable living and participatory education aspects of the Camp are discussed below. 


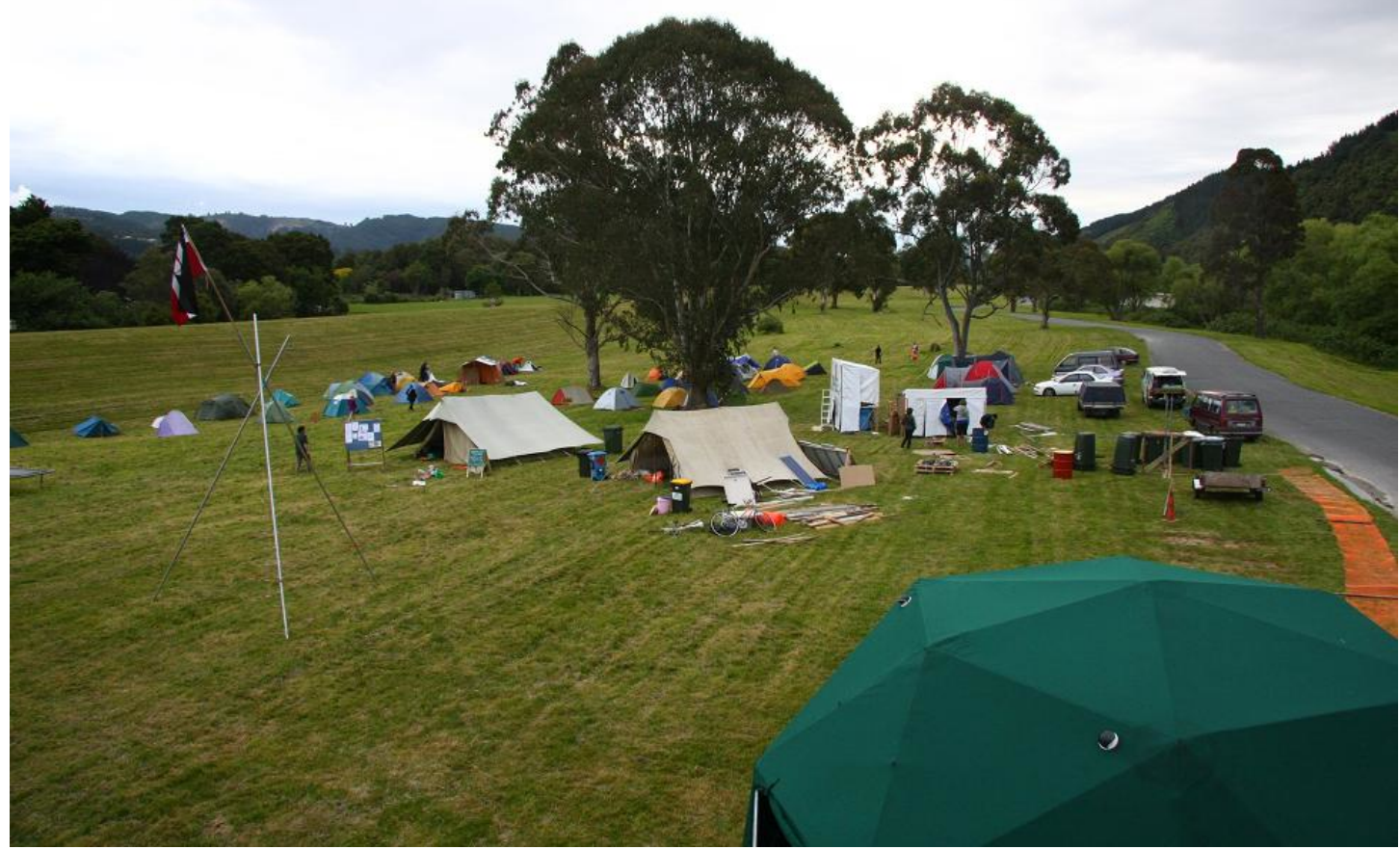

Figure 4.8. Setting up the site: (front to back) The Dome Tent, the Infrastructure Tent and Media Tent. The compost toilets are almost complete and the neighbourhoods have taken form (Source: John Darroch)

\subsubsection{Sustainable living}

Sustainable living reflects the objective "to create a Climate Camp which serves as an example of a sustainable community" (Camp for Climate Action Aotearoa, 2009a) or as a flyer explained "the camp is an example of a sustainable temporary eco village using a horizontal organising structure". Participatory democracy is a vital element of sustainable living in creating a just and sustainable community. "Sustainability isn't about the 'environment' as some abstract concern. It's about life and society" (Camp for Climate Action Aotearoa, 2009f, p. 18).

The Camp was set up using basic examples of sustainable living. Infrastructure included a grey water system made with two baths and sawdust, rocket stoves, solar showers, photovoltaic panels for power and two types of compost toilets. There was also a bicycle blender and a music-playing wheelie bin. Cooking was communal and used gas rings. Water was accessed by a pipe connection to the main system with DIY plumbing. 
Fourteen $^{24}$ or so tents were used for the functioning of the Camp. The Welcome Tent was where whiteboards with jobs lists and workshops updates and information including booklets were held. There were three workshop tents that also doubled up as neighbourhood and spokes council meeting rooms; a media tent with laptops and internet access; an infrastructure tent housing tools and batteries, a children's tent in the kids' zone (plus a trampoline borrowed from a 'dump shop'); a kitchen tent for cooking; two food storage tents; a tent for washing up; a medic tent for first aid and a mediation tent for conflict resolution and 'chill out' (which became the serving tent when the marquee blew down in the wind). The marquee functioned as a workshop space, the spokes council and large meeting place and the serving/ dining hall. All bought food was vegan. The whole Camp ate communally and was run by the participants.

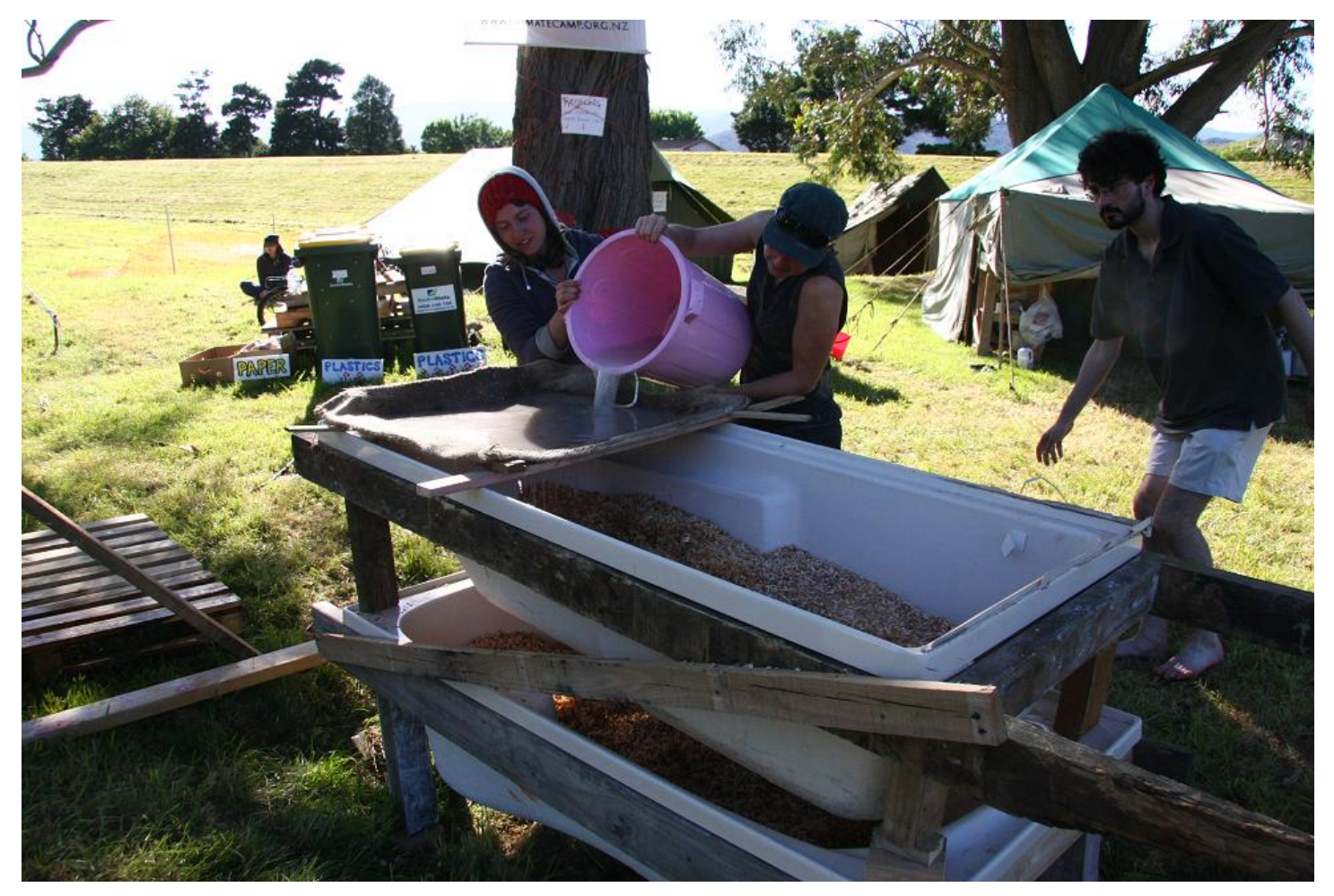

Figure 4.9. 'Doing it ourselves' sustainability: Participants emptying waste water into the grey water system (Source: John Darroch)

\footnotetext{
${ }^{24}$ This varied since some tents blew down in the strong winds.
} 


\subsubsection{Participatory education}

The element of participatory education serves most of the objectives of the movement, from up-skilling and skill sharing to raising awareness, to present alternative viewpoints and engaging communities more broadly (see Figure 4.1).

In line with the DIY approach and that there are no experts, the workshops were generally participatory and interactive, often with the facilitator leading the workshop engaging with participants for their knowledge as a group and then building on that. There were four workshop spaces, with three workshops at a time planned all day over four days. Workshops included topics on campaigning and mass action, NVDA, affinity groups, wild foods, deep ecology, capitalism and ecology, guerrilla gardening, climate justice and Copenhagen, and a tour of the sustainable infrastructure of the Camp.

Besides the timetabled workshops, there was also an open space free for anyone to facilitate a workshop, with a tent dedicated to these. The workshop programme whiteboard sat beside the jobs lists in the Welcome Tent, showing changes to the workshops and for anyone to add their own workshop in the 'open space'.

\subsection{Permaculture hui participatory tools for learning}

For this secondary case study, I attended three permaculture hui - two regional lower North Island meetings, one held in May 2009 at the Tapu Te Ranga Marae in Wellington and the other in July at the old hospital grounds in Porirua, and the Permaculture in New Zealand Annual General Meeting/ Hui held at the Tu Teao Marae in Te Teko at the end of May/ beginning of June.

\subsubsection{Open Space Technology}

At all three permaculture hui I attended, a collective learning approach called Open Space Technology (OST) was used to structure discussions. This way of organising meetings is also in line with anarchist principles of self-organisation and that there are no real experts. As a facilitator explained at one hui, "The idea is to draw on the knowledge of the group. It is an opportunity for people to share their knowledge and to learn from one another." There is no prearranged agenda. Participants "create and manage their own agenda of parallel working sessions 
around a central theme of strategic importance" and take responsibility for their own experience (Herman, 1998).

The OST process starts with a broad purpose or intention. For the lower North Island 'get-togethers', the general purpose was to discuss issues related to permaculture. At the AGM in Te Teko, the intention was also connected to permaculture but more specifically to the Maori statement 'Titiro ki mua nga taonga, mo nga whakatipuranga' translated to 'Look to the future's past, revive the treasures for future growth'. A facilitator identifies the intention of the hui and explains the OST process to participants. The permaculture meetings that I attended using the OST method varied from one day with about 30 people, to two days with about 20 to 25 people to three days with over 200 people.

The basic process used at the permaculture hui was that participants attending discussed and wrote down what they could offer and/or what they would like to request for discussion on post-its. Everyone with a post-it then says their offer and/or request aloud and places it on a large piece of paper called the 'marketplace', preferably grouped near similar ideas. Then, depending on the size of the group, a few volunteers place the similar ideas together and decide on their positions on a pre-drawn up timetable. Participants then attend the discussions they are interested in, with the person initially requesting the discussion facilitating it (but not controlling the discussion) and possibly taking notes.

In the OST method, there are only four ground 'rules' and one 'law'. The four ground rules are 1) 'whoever comes is the right people', 2) 'whatever happens is the only thing that could have', 3) 'when it starts is the right time', and 4) 'when it's over ... it's over'. The 'Law of Two Feet' means that participants can go wherever they want to be. They are free to move from one discussion to another (the butterfly) or move to one discussion to share a group's ideas with another group (the pollinating bee). At the end of all the sessions of the day, participants from the different groups fed back their discussion to the larger group to share what they had learnt. 


\subsubsection{The World Café}

On the last evening of the annual permaculture hui at the end of May 2009, another collaborative learning process through conversation, the World Café, was utilised to explore 'questions that matter', to gain insight into shared collective knowledge and to enable the organisation and participants to "see new ways to make a difference" (The World Cafe, 2007). The group was invited by the facilitator to explore three questions one at a time through dialogue and with different people. The first question explored the collective vision of permaculture contributing to a sustainable future of healthy lifestyles in Aotearoa/ New Zealand, the second concerned the barriers to this vision being achieved and the third question pertained to solutions to overcome the barriers.

The hall at the marae was set up to create an air of informality, with tables, each with a candle, a large piece of butcher paper and markers, and six to eight chairs. At each table was a 'host' who stayed at that table for the whole session. Participants at each table contributed their views and used the paper and markers to record and explain ideas of the first question. After twenty minutes or so, participants were asked to move around the room to a different table. The host then shared the ideas from the previous conversation to the participants and then the second question was discussed. This was repeated for the third question and then participants moved back to the table they were at initially to feedback the insights.

By moving around the tables, a cross-pollination and network pattern of conversations as well as deeper collective knowledge and understanding coevolves (The World Cafe, 2007). This process values non-hierarchical process and structure, informal relationships, cooperation and collective intelligence. Shared collective views that emerged during the World Café included recognition of profiteering, ego, self-interest, competition and exponential growth as problems for ecological and social sustainability. The use of the World Café and OST reflects the anarchic Climate Camp Aotearoa support for participatory collective learning. The collective concerns stemming from the PiNZ 2009 AGM World Café session mirror those of Climate Camp Aotearoa. 


\subsection{Concluding comments}

In this chapter, we have explored ways of organising as decentralised and autonomous groups, and participatory processes of making decisions and learning practiced by the Camp for Climate Action and in permaculture hui. We have discussed the praxis of the alternative and anarchist philosophy of selforganisation as a 'do it ourselves' attitude and practice of direct democracy, direct action and a rejection of capitalism and domination. Connections between permaculture and anarchist philosophy have been demonstrated through case studies. In the next chapter continues the discussion of anarchism and permaculture ethics and philosophy. 


\section{Chapter 5: Discussion}

\subsection{Introduction}

In this chapter the ethics, principles and processes of permaculture practice are analysed and the relationship to anarchism is drawn. The chapter begins by outlining the core permaculture ethics and principles and some of the practical applications of tools utilised by permaculture in different aspects of culture. Permaculture design ideas and aspects of sustainable living of the Climate Camp Aotearoa site at Moonshine Park held in December 2009 are analysed to demonstrate both anarchist and permaculture practice.

While the bulk of the chapter discusses the complementary concepts in permaculture and anarchism by comparative analysis, some contentions in the practice of anarchic organising that arose in Climate Camp Aotearoa and elsewhere are described. The latter section of the chapter grapples with some of the dynamic contentions between permaculture and anarchism, particularly in terms of their politics and historical contexts, and concludes with how they can contribute to each other.

\subsection{Permaculture ethics and design principles}

At the core of permaculture are a universal set of three ethics of permaculture philosophy and twelve practical design principles.

The three ethics are:

\section{1. 'Care for the earth' (or earth-care);}

2. 'Care for the people' (or people-care); and

3. 'Set limits to consumption and reproduction, and distribute surplus' (or fair-share) (Holmgren, 2002, p. 1).

The universal set of permaculture ethics, its design principles and, to a large extent, their applications are the foundations of permaculture. Interpretations of these ethics and design principles can vary within permaculture philosophy and practice however. This chapter, and the thesis more broadly, focuses specifically on Holmgren's interpretations from Permaculture: Principles and Pathways Beyond 
Sustainability (2002). The discussion uses Holmgren's permaculture ethics and design principles as a framework for analysis as they relate to anarchistic philosophy and practice.

\section{Holmgren's Permaculture Design Principles:}

1. Observe and Interact

2. Catch and Store Energy

3. Obtain a Yield

4. Apply Self-regulation and Accept Feedback

5. Use and Value Renewable Resources and Services

6. Produce No Waste

7. Design from Patterns to Details

8. Integrate Rather than Segregate

9. Use Small and Slow Solutions

10. Use and Value Diversity

11. Use Edges and Value the Marginal

12. Creatively Use and Respond to Change

Figure 5.1. David Holmgren's Twelve Permaculture Design Principles used as a universal checklist for whole systems thinking (Holmgren, 2002, p. viii)

Holmgren's twelve design principles are shown in the figure above (Figure 5.1). In permaculture, these design principles are followed in designing any system. The goal of permaculture design is to create resilient and ecologically sustainable low energy systems by applying the twelve principles. Bill Mollison has emphasised slightly different aspects of these design principles but the overall concepts for design remain the same as those of Holmgren's.

\subsubsection{Permaculture design applications}

The 'permaculture flower' (Figure 5.2) illustrates the seven domains of the permaculture design system evolution and its applications. At the centre of the flower - as the centre of permaculture - are the core ethics and principles outlined above. The first 'petal' of the permaculture flower, as the original starting point for permaculture, is land and nature stewardship. 
The applications of permaculture design have extended to the built environment and tools and technology - the second and third petals or 'domains'. The next four petals - culture and education, health and spiritual wellbeing, finances and economics, and land tenure and community governance - in the permaculture flower are less widely recognised domains in permaculture but they are central to a sustainable and just society.

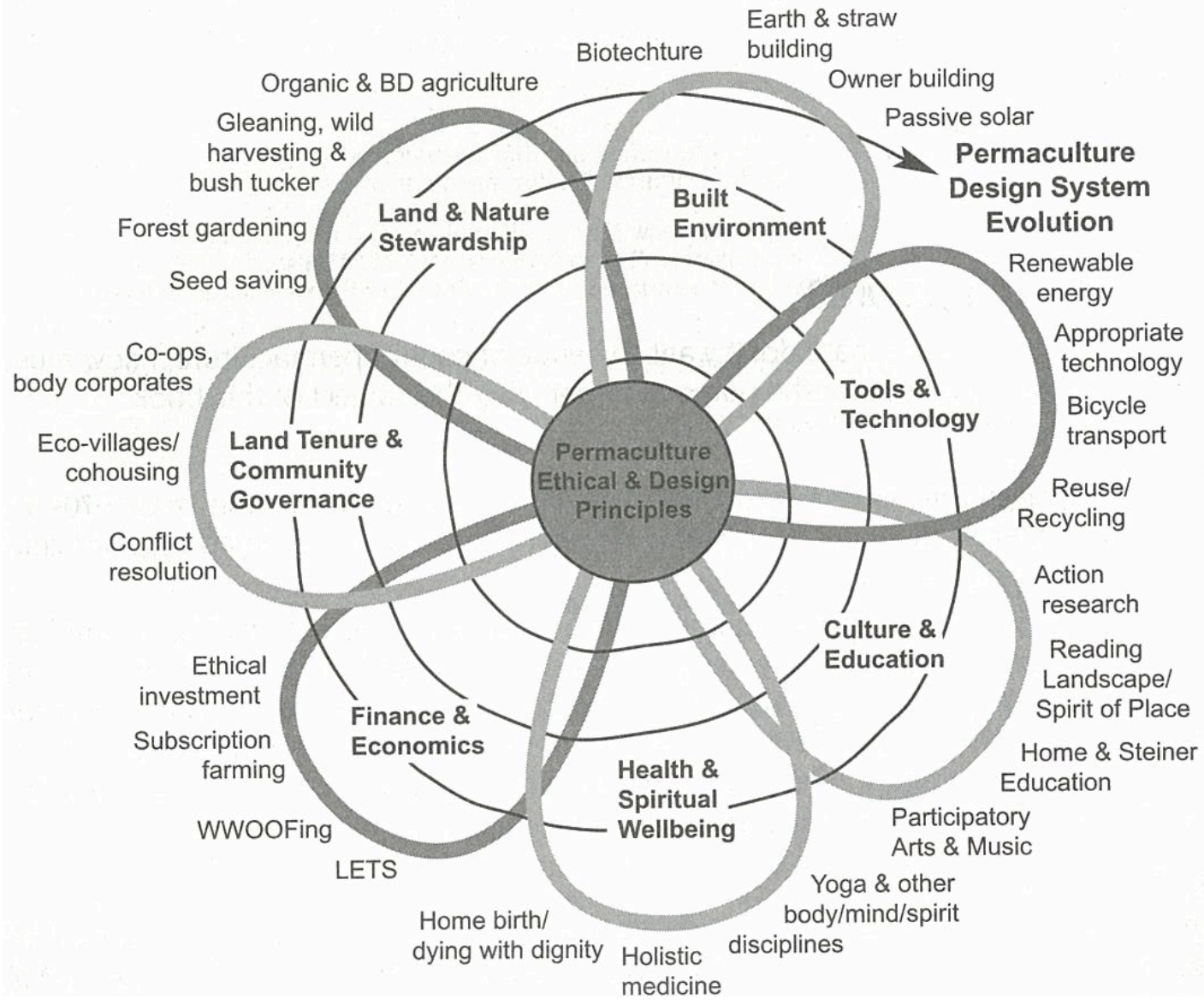

Figure 5.2. The Permaculture Flower: Starting with ethics and principles focused in the critical domain of land and nature stewardship, permaculture is evolving by progressive application of principles to the integration of all seven domains necessary to sustain humanity through energy descent (Holmgren, 2002, p. xx)

Permaculture demands a cultural (and educational) revolution that is participatory, with a more holistic application of health and wellbeing that integrates body and mind, and bottom up systemic economic and financial 
change (as opposed to reform). Lastly, new systems of land tenure (and other forms of ownership) and community governance are needed in the redesign out of what is perceived as our current dysfunctional cultural model, and towards an ethic of earth stewardship (Goldring, 2007; Holmgren, 2002; Korten, 2006; Seabrook, 2002).

It is the last 'petal' of the permaculture flower - the land tenure and community governance domain - that we are mostly concerned with, as it begins to deal with human organisation and decision-making. Consensus decision-making is one of the tools in this domain used by cooperatives and eco-villages. This holistic approach to creating a post-industrial low energy future requires systemic change, as indicated by the 'permaculture flower' (Figure 5.2).

Holmgren's permaculture design flower (Figure 5.2) also illustrates the idea that the individual is considered the primary agent of change in permaculture, as it is at the personal and local level that everyone has the most power to manage oneself and one's environment. From this standpoint stems the responsibility or 'care' for family and household - those immediately connected with the individual - and then outwards into broader community and society on the collective and global level. This is represented by the spidery spiralling line starting with the ethics and principles and the personal in the centre of the flower, moving through the domains on the design flower and impacting out onto the global level.

Anarchism is similarly concerned with whole system transformation of all aspects of culture. Decentralisation, autonomy, diversity, direct action, direct democracy and free association are anarchist principles $^{25}$ applied to the design of all aspects of any organisation. The previous chapter on the Climate Camp movement case study dealt primarily with the community governance domain in terms of democratic processes. This human organisation aspect is often referred as 'invisible structures' in permaculture teaching, and it is a relatively underexplored aspect in permaculture. It is these 'invisible structures' and the community governance domain that are of significance for anarchism. The thesis discussion is

\footnotetext{
${ }^{25}$ Like the permaculture principles, the exact categorising of defining anarchist principles differs but the underlying philosophy does not change.
} 
thus primarily concerned with the human organising and governance aspects of permaculture in light of anarchistic principles. The study is also interested in the permaculture principles utilised in the site design of the Climate Camp at Moonshine Park, discussed below.

\subsection{Sustainable living and design}

As the Climate Camp event itself was envisioned to demonstrate sustainable living, albeit temporarily for five days, other 'domains' were also present at the Moonshine Park site in December 2009. Using the permaculture design system flower (Figure 5.2), this included tools and technology (the third domain) such as renewable energy in solar panels and a wind turbine and composting toilets (which also relates to permaculture design principle 5 'use and value renewable resources and services', and principle 6 'produce no waste'), participatory education (the fourth domain) on topics exploring ideas of the first domain - land and nature stewardship (including deep ecology, guerrilla gardening and wild foods workshops), the second domain - economics and finance (including workshops on complementary currencies, the problem of neoliberalism and economic growth, and also being a non-commercial event based on voluntary association). In anarchism, domains can be divided into different strands or sectors: the workplace, environment, community and so on (different strands of anarchism). Many of the same DIY applications of these domains are advocated in both permaculture and anarchism.

The Climate Camp site at Moonshine Park was chosen for design-related reasons. The Wellington Region is very hilly. Terrain influences the possibilities for design of a site plan. The flat grassy layout of the park allowed more control and flexibility to design and establish a 'horizontal' or 'non-hierarchical' site plan. This was achieved by the geographic placement of neighbourhoods, communal tents and ablution areas for fair distribution and equal access to amenities, and to create a practical and welcoming communal space.

Permaculture design, as well as mimicking patterns in nature, is based on common sense ways of reducing energy use (e.g. principle 2 'catch and store energy' and principle 6 'produce no waste'). The concept of zoning in permaculture design deals with the placement of elements in relation to each 
other and their frequency of use in the system. For instance, at the Climate Camp Aotearoa Moonshine Park site, the composting toilets were placed between the common area and the neighbourhoods' camping area, in relatively close proximity to the tamariki / kids' zone and next to the road. From this position, they could be easily accessed by anyone from both areas and walking on the way from one area to the other. Children could access the toilets quickly and frequently and the road facilitated disabled access. Moonshine Park was also chosen for its proximity to regular public transport, therefore increasing participant accessibility to the site, decreasing the need for private vehicles and thus lowering the potential carbon emissions or energy use by attending Climate Camp (permaculture design principle 2, 'catch and store energy').

Sustainable living necessitates human organisation based on low energy systems. Within the framework of climate change, peak oil and the limits to growth, working collectively, practically and locally provide a foundation for the human scale necessary for the pathway to energy descent. "The most creative design involves the promiscuous hybridisation of possibilities from apparently disconnected, or even discordant sources to create a new harmony" (Holmgren, 2002, p. 14). Ethics and principles based on values that are concerned with transformation change from a social and environmental justice perspective are significant and worthy of consideration.

\subsection{Decentralisation and scale}

Decentralisation is a significant principle of anarchist practice. It is a necessary feature of non-hierarchical organising, as opposed to centralised dominant hierarchical systems. In anarchism, decentralisation also necessitates small-scale solutions to enable greater local community control of resources. This principle is inherent in both the principles of direct democracy and autonomy. Horizontal decision-making structures are decentralised and aim to decentralise power generally. Local and other affinity groups are decision-making entities in their own right and create a sense of community and ownership. The reasoning behind this is for people to make decisions for themselves - to have control of decisionmaking and the implementation of issues that affect them in their lives, and not have decisions and regulation imposed by an external authority. Centralised 
systems are rejected in anarchism as they are disempowering for communities by a lack of participation in decision-making processes and control over the means of production.

"We need to recognise that a high-energy society will inevitably develop a large number of hierarchical levels and then return to a low-energy base. This recognition may, in the long term, allow us to redevelop a flatter structure where elite functions and roles are not so inherently corrupting" (Holmgren, 2002, p. 79).

Decentralisation also relates to permaculture from a perspective of system stability (principles 7, 8 and 9). Distributed networks are favoured to centralised organisation. Total system collapse is less likely with a decentralised design due to a level of independence or self-reliant autonomy from other entities in the system. 'Use small and slow solutions' (principle 9) emphasises small human scale (in relation to large industrial scale) systems in order to create self-regulating systems that accept feedback (principle 4). Being responsive to feedback and thus tightening feedback loops is important in designing resilient communities (Holmgren, 2002; Hopkins, 2008; G. Williams, 2006). Smaller feedback mechanisms ensure awareness and responsiveness to the consequences of our actions. This design principle is true for all systems from decision-making to renewable energy and food production. Relocalisation is thus promoted in both permaculture and anarchism as a solution to ecological and social crises. "Human scale and capacity should be the yardstick for a humane, democratic and sustainable society" (Holmgren, 2002, p. 181).

The significance of the principle of decentralisation arose during the third Climate Camp Aotearoa national meeting after the Gathering at Parihaka, which was held in August 2009 in Wellington. The date of the Climate Camp was nearing and the pressure for us to focus on preparations was building. Due to the small number of active members in a few pockets around the country, a discussion arose on the structures of local and working groups, and the different local groups tending to focus more on certain functions. For instance, most active participants of the Auckland Local Group were involved in the Media and Communications and Finances Working Groups, most of the Whangarei Local Group participants 
were involved in the Sustainable Infrastructure and Kitchen Working Groups, and the Taranaki Local Group was working on the Legal and Safer Spaces Working Groups.

The issue was raised over whether or not to formalise this arrangement to assist with organising effectiveness. A decision was made to allocate certain local groups particular working group tasks after much debate within the group (and with some dismay). What this meant, as one participant pointed out, was that a more 'centralised' structure was temporarily adopted due to the circumstances. However, this did not mean that individuals from other local groups could not participate in assigned working groups or that those in a local group had to be in that working group. That would be against the (anarchist) principle of voluntary association. It was more of an exercise in formalising what had already been occurring (due to certain skills and locations) and to allow the organising for the camp to begin the next phase with more focus. The diagram of the decisionmaking structures and processes (Figure 4.3) in the previous chapter was designed during the national meeting to illustrate this structure.

This decision to adapt to circumstances also fits in with the permaculture design principle 'creatively use and respond to change' in terms of the significance of adaptive flexibility (Holmgren, 2002). The permaculture design principle 'integrate rather than segregate', in which each element (or person) performs many functions and each function is supported by many elements, had already been a factor in the local and working groups structure and adheres to the anarchist principles of decentralisation and diversity.

In permaculture, too much dependence within a system is as vulnerable as one that is monoculture. "[T]he globalised networks, often trumpeted as one of globalisation's great strengths, can in fact also be one of its great weaknesses. The over-networked nature of modern, highly connected systems allow shock to travel rapidly through them, with potentially disastrous effects" (Hopkins, 2008, p. 56). Thus, a local and more modular approach of sharing with the wider system and not mutual dependence is of preference. The Climate Camp structure of local groups, working groups and spokes council can be seen as an example of a 
modular structure where parts of the system can self-organise in the event of a shock.

\subsection{Autonomy and self-regulation}

Autonomy as an anarchist principle relates to the self-regulation design principle 4 - 'apply self-regulation and accept feedback', to decentralisation and to the concept of self-reliance in permaculture. Food sovereignty was the initial focus of self-reliance. Mimicking the diversity of natural systems/ecosystems in urban and rural agriculture to create self-maintaining low energy systems that required little to no external inputs (such as petro-chemical fertiliser) for production was key to design.

"Self-maintaining and regulating systems might be said to be the Holy Grail of permaculture: an ideal that we strive for but might never fully achieve ... Much of the ecologically dysfunctional aspects of our systems result from this denial of the need for self-regulation and feedback systems that control inappropriate behaviour by simply delivering the consequences of that behaviour back to us ... The speed of change and increasing connectivity of globalisation may be the realisation of this vision ... There is an inherent design tension between autonomy and higher order system control. Each cell, organism and population is as self-reliant as possible. This self-reliance at the smallest practical scale provides benefits to the large-scale system" (Holmgren, 2002, pp. 71-72).

Collective freedom to self-organise and self-manage is to be autonomous. "We can learn to work outside the framework of capitalism and organise for change we want to see without profit driven guidelines, centralised decision-making and hierarchical structures of power. It is indeed the power of ordinary people like you and me that grassroots organising is based on. It is about taking collective action on our behalf, empowering each other, working along the path of solidarity, mutual aid and cooperation" (Camp for Climate Action Aotearoa, 2009d, p. 1).

The anarchist principle of autonomy is reflected in the Climate Camp decisionmaking structures. Affinity groups in direct actions, local groups in regions and 
neighbourhoods, and (to a lesser degree) working groups, are autonomous entities. Linked to autonomy is decentralisation, which is reflected in the larger spokes council model's decision making devolving to local groups. An important aspect of autonomy is that of self-regulation or self-organisation, which has been discussed above as relating to the permaculture design principle (4) 'apply selfregulation and accept feedback'. Similarly, autonomy is about making decisions for ourselves and not being controlled or coerced by dominant forces, to decentralise that authoritative or centralised power to decide and take action.

The principle of autonomy or self-reliance applies both collectively and on an individual level. Accordingly, free or voluntary association is also principle of anarchism. It reflects the notion of not being controlled or coerced by other individuals or groups and the right to be able to leave a collective, join another or form a new group. The example of the discussion and decision at the August 2009 Climate Camp Aotearoa national meeting in Wellington - where local groups and working groups were aligned and the emphasis that individuals from any local group were still free to be part of any working group - has already been described above. Similarly, local groups and working groups are examples of voluntary associations.

With freedom of association and autonomy or self-reliance comes personal responsibility. Taking responsibility for the consequences of one's actions and regulating oneself is key to anti-authoritarian practice.

\subsection{Cooperation: mutual aid and fair-share}

For both anarchism and permaculture, cooperative relationships are key to the sustainability and resilience of systems. For anarchism, this is central to the principle of mutual aid. Patterns of violence are generated by domination and hierarchical relationships. Competition is not as common in nature and in human history as we have been led to believe by centralised systems of control (Knoll, 2009). As social beings we have survived by mostly looking after each other and not by taking advantage or profiteering from other people or the environment. Mutual support and solidarity are significant values in anarchist practice and played out in the principle of autonomy by valuing difference. 
The consensus process demonstrates the principles of cooperation and diversity in practice, where discussion and decision-making is a collective participatory process of exploring all points of view and agreeing on a decision together as a group. This view is shared by permaculture. "Awareness of difference is fundamental to life in a complex society, and the simple hierarchies of power must be replaced by a diversity of representation and delegation within the context of partnership relationships" (G. Williams, 2006, p. 203).

Relationships and patterns of behaviour are significant foci of both permaculture and anarchism. Both see domination as the foundation of all the crises facing humanity and the planet. For permaculture, this ecological domination reaches out into a way of thinking, a dualistic and reductionist paradigm that has created a modern logic of perceiving ourselves (humans) as separate from nature, the mind as separate from the body and so on. Thus "the development of more cooperative social patterns of behaviour and resource use is fundamental in a world of diminishing resources" (Holmgren, 2002, p. 176).

The anarchist perspective sees any form of domination as bad, including human domination over nature (e.g. Bookchin, 1971). The need to work together in mutual aid is, likewise, expressed in the three core permaculture ethics. The ethics of 'fair-share' and 'earth-care' reflect mutual aid in the design of systems that provide for the (energy) needs of all the elements (including other animals and plants) in an integrated manner and by avoiding excessive growth. (This is also evident in permaculture design principle 8 'integrate rather than segregate', and principle 10 'use small and slow solutions'.)

In permaculture, cooperative relationships in nature are mimicked through design tools such as companion planting, where a guild of diverse plants are placed together so that each type of plant provides for the others' needs, such as providing specific nutrients and protection from pests. Symbiotic interaction between a variety of flora and fauna and non-living elements is used in permaculture design, and is the antithesis of monoculture. 


\subsection{Diversity}

For a system to be self-reliant and resilient according to permaculture design and systems thinking, it is important for many elements (including persons) to support each function. For instance, in land use this would mean using wind, water and solar elements in the function of electricity generation. It is equally important for system stability that each element supports many functions in the system. The element of water is used for the multiple functions of electricity generation, drinking, washing and cooking. A diversity of sources of water is also important in a low energy and resilient system. Thus ponds, rain tanks, springs and possibly even council water mains are utilised as sources for water collection. Similarly, bio-diversity in any living system is valued for stability and variety. However, it is not how many elements or functions in a system that matter as much as the relationships between those elements (principle 8 'integrate rather than segregate').

In the anarchist horizontal decision-making structure used by Climate Camp Aotearoa, local groups consist of individuals (as elements) who are also in working groups and act as spokes (and thus have different functions/ roles). This design principle was also present in the multiple uses of some of the large tents at Moonshine Park Climate Camp in December 2009. For example, workshop tents were also used for neighbourhood and affinity group meetings. The marquee served as a space for workshops, spokes meetings and whole Camp meetings, a dining and food (self) service area and a place for socialising and drinking at night in bad weather.

Diversity of tactics, roles and skills in direct action and points of view in the consensus decision-making process are valued in anarchism and allow for creativity and adaptability. At the day of direct action, each affinity group provided a different function that supported other affinity groups. Additionally, diversity of opinions, ideas and cultures are valued in anarchism and permaculture for the creation of alternative possibilities to culturally dysfunctional modernity. This indicates unwillingness, by principle, of being prescriptive and advocating blueprints. 


\subsection{Taking action: direct action and self-reliance}

In principle 1: 'Observe and interact', Holmgren explores the importance of observation (and experience) through all our senses in order to find the patterns in nature and culture, so that we can recognise what is useful for adaption and to assist in the design of more self-organising systems. "But unless we get out there, and open our eyes and use our hands and our hearts, all the ideas of the world will not save us" (Holmgren, 2002, p. 24). Similarly, in anarchism, practical action is a significant principle.

Self-reliance in permaculture relates not only to material needs but also, importantly, to taking personal responsibility for one's actions. This means doing it for ourselves, and not relying on or giving power to others to make the changes for us. "Taking personal responsibility naturally moves us to be more self-reliant and less dependent on centralised sources of needs and responsibility. In the process, we discover that governments and corporations, while preaching selfreliance, actually need our dependence" (Holmgren, 2002, p. 87). For permaculture, self-reliance is political action, albeit 'under the radar'. For Holmgren, this invisibility and the movement's seeming disorganisation is a strong point for subverting the system. In anarchism, this relates to the principle of direct action.

The principle of direct action has been described in more detail in the previous chapter. The more confrontational approach to this principle of doing-it-yourself (or ourselves) is given emphasis within Climate Camp and the global justice movement in general; and what exactly constitutes 'direct action' is always a point of debate. The discussion arose around whether or not permaculture is a form of direct action at the Climate Camp Gathering at Parihaka because it is non-confrontational. It was generally agreed that permaculture deals with the root causes of the problem of climate change - including capitalism - and that direct action, as a principle, does not necessarily entail confrontational tactics. The implication of 'the end is the means' or 'the means is the end' as a central anarchistic principle is a respect for life and thus non-violence. This principle is also found in the permaculture earth-care ethic. 
At the anarchist conference on organising and also in Climate Camp workshops, 'the end is the means' was emphasised as a significant foundation of the movement's philosophy. Put simply, the end is non-hierarchy and the means is to work in the way you want to live - non-hierarchically. Thus, process is of more concern than the end (see also The Trapese Collective, 2007, p. 6). So, for instance, community currencies as alternative means of exchange are advocated by both permaculture and anarchism. How they are organised is of particular interest to both philosophies. Decentralisation, democracy based on values, localisation, not-for-profit, mutual exchange, reciprocity, participation, ownership, freedom of association are all principles on which community currencies are based and thus they are utilised as alternatives to the current dominant and dysfunctional economic system.

'Propaganda of the deed' means taking direct action to change the world and inspire others to act (Cutler \& Bryan, 2007, p. 263). In Gandhian terms this is 'being the change you want to see'. Taking direct action is a political stance and relates to the principles of autonomy and direct democracy. For many anarchists and other social change activists, choosing to act directly is often combined with the belief that campaigning for change through representative democracy is ultimately futile since all elected governments exist in a system which is made up of entrenched positions of power and influence (Cutler \& Bryan, 2007; The Seeds for Change Collective, 2007b).

\subsection{Direct democracy, community governance and invisible structures}

As we have seen from the previous chapter, direct democracy is self-organisation as self-governance. This means a DIY approach for communities and collectives having the autonomy or freedom to organise and make decisions directly. In order to do this equitably, it is important that everyone is involved in the decision-making process to be empowered to participate and take direct practical action. Decentralisation is key to creating the small-scale, human-sized and cooperative relationships that mutually support and allow for empowerment and participation of community.

Network democracy and consensus decision-making are advocated by permaculture as self-reliant, autonomous, self-organising living systems. 
Participatory whole-system decision-making involves cooperative patterns and networks of relationships. Self-organisation or complex adaptive systems in nature are a kind of democratic process. "Thus, if we can think of 'democracy' as meaning a system through which members of communities organise themselves, rather than a system for controlling them, our democratic systems would be getting closer to being complex, adaptive and self-organising" (Madron \& Jopling, 2003, p. 16). From this systems theory perspective, information processing and decision-making should be devolved as widely as possible. The global justice movement as a non-hierarchical, resilient and responsive network model with valued participatory learning and collective knowledge described in the case studies chapter fits into systems thinking of holistic social and political human systems.

The participatory democratic structure and consensus decision-making process used by Climate Camp Aotearoa is the practice of anarchist direct democracy, and opposed to hierarchy and centralisation. A crucial understanding in Climate Camp Aotearoa of the root cause of climate change is that it is based on hierarchical systems and relationships. Capitalism is seen as the systemic manifestation of these unequal relationships, tied in with the state as a coercive and authoritative institution. The consensus process and the spokes council model are considered to be 'horizontal' or 'non-hierarchical' structures due to the decentralised power structure and means of organisation.

The spokes council model demonstrates some diversions both between anarchist and permaculture perspectives as well as some potential differing views within permaculture. Horizontal decision-making structure or direct democracy is opposed to hierarchical patterns of organisation and behaviour. This illustrates a dualistic thinking of horizontal /good vs. vertical/ bad. A permaculture activist and teacher from the Wellington Region, Gary Williams (pers. comm. 22-24 May 2009) explained that, from a permacultural perspective, this falls into the same binary logic that has got us into the ecological (and social) crisis in the first place. He argued that Cartesian logic has separated humans from nature and it is this dualistic thinking that has led to relationships of domination and oppression. 
From this perspective it is more useful to view the design of the consensus decision-making process and the spokes council structure not as 'horizontal' or as the opposite of hierarchy but as one resembling a double helix or 'holarchies' ${ }^{26}$ and based on feedback loops of communication in spiral formation, where information flows reciprocally up and down the vortex. In his book Out of the Helix (2006), Gary Williams writes more on this holistic way of thinking. He advocates the need for cooperative relationships and consensus decision-making. "A complex world needs complex relationships understood in complex ways. Decision-making processes must have a more involved and inter-weaving dynamic, based around consensus and with a continual feedback of monitoring and response" (G. Williams, 2006, p. 213). Holmgren (2002) also emphasises the importance of establishing "direct feedback mechanisms" and the need to redevelop "flatter structures" to mitigate the inherent corruption of power in the design principle 'apply self-regulation and accept feedback'.

Whether or not definitions of hierarchy or non-hierarchy are agreed upon, I see the underlying principle in permaculture and anarchism as the same - a rejection of all forms of domination, systemic or behavioural, and a support for fairly distributed or decentralised power in relationships in order to form more 'balanced', 'integrated', 'responsive' or 'horizontal' social and ecological patterns of organisation. Creating holistic systems as ethical practice emphasises establishing mutually beneficial relationships within the organisation or design. As in living systems, the behaviour of these balanced systems is not controlled by an external agency. These high degrees of order are necessarily self-managing and in keeping with anarchist principles of autonomy, decentralisation and direct democracy.

\footnotetext{
${ }^{26}$ The term 'holarchy' was coined by Koestler and relates to natural hierarchies, where 'holons' (as individual whole elements) organise to create holarchies or a higher/ more complex wholes of organisation -"natural hierarchy is simply an order of increasing wholeness [or holism]... The whole of one level becomes a part of the whole of the next" (Wilber, 2000, p. 24). The problem of 'dominator hierarchies' develop when a holon "usurps its position and attempts to dominate the whole" (Wilber, 2000, p. 25). Accordingly, anti-hierarchy is to create another form of ranking system that favours linking. Ewoldt (2006) writes that this dominator paradigm, "best explained as force-based ranking hierarchies that exercise control through fear and force", is the foundation of collapse (triumvirate of peak oil, global warming and global economic growth).
} 


\subsubsection{Inequalities, conflict and informal hierarchies}

Taking personal responsibility and collective action against what New Zealand permaculture pioneer, Haikai Tane, calls "dysfunctional cultural intelligence" (Tane, 30 May 2009) is not an easy task. From my experience with Climate Camp Aotearoa, it requires high energy levels and optimism. The potential for burn out is high. Dealing with "internalized forms of oppression" (Graeber, 2009, p. 352), inequalities and conflict are highly emotional and time consuming. The amount of participation necessary to resolve these internal issues can seem frustrating, particularly when there are larger problems, such as climate change at stake. However, from the perspective of valuing respect for difference, the end being the means, and the means and the end being non-hierarchy or freedom from inequality, the internal inequality is from the same fundamental problem as the global inequalities just on a smaller scale.

This belief was demonstrated by an independent anarcha-feminist victim support affinity group at the Climate Camp in Moonshine Park in December 2009 who, ironically, took direct action at the opening meeting of the Camp to name an abuser and have the person excluded from being at the Camp. Consequently, much time and energy in meetings was spent through most of the duration of Climate Camp trying to deal with this scenario.

At a Climate Camp Aotearoa national meeting in the Waikato I attended in July 2009, a participant accused the group of patriarchy and colonialism, which shut down the meeting for hours and became an emotional detraction from the national meeting agenda. However, both of these examples highlight issues of inclusion and exclusion, the potential for agenda hijacking and the difficulty of addressing internalised forms of oppression. They also demonstrate the anarchist principle of confronting and addressing inequality as it arises and attempting to resolve conflicts in a cooperative manner.

The subject of 'informal hierarchies' was vocalised in both the Anarchist Wildcat Wellington Conference in mid-April 2009 and the Climate Camp Aotearoa Gathering held on the Parihaka Marae at the end of April 2009. It seems to be a common concern in organising non-hierarchically, namely how to overcome informal hierarchies (e.g. Graeber, 2009; Routledge, 2009). This also points to a 
major difference between libertarian socialism and other forms of socialisms and relates to the question of whether "if certain people tend to dominate, does that justify giving them the power to dominate formally". In other words, as I noted in my journal at the time: "if certain people tend to dominate, is that a good (enough) reason to set up a system (of decision-making) which legitimates their tendency to dominate?" (April 2009). The logic behind other socialist reasoning is that if hierarchies tend to form anyway, then they are best to be formalised so that they can be dealt with explicitly. Not all hierarchies are forms of domination from this perspective.

One manifestation I perceived of informal hierarchies developing relates to participation through having access and not having access to technology. Those individuals with access would tend to be the spoke for the local group (thus not rotating roles) and had more ability to participate, and thus also gained more responsibility (which, in my experience, seemed to be the case). This not only applied to individuals, but also to local groups. The groups with most time, experience and technology were most active and able to participate. These were issues raised by our Wellington group, which was a small, inexperienced, geographically isolated (in relation to other North Island local groups) and less technologically equipped group of individuals with other time commitments. This example also illustrates the diversity of each of the groups and the need for mutual aid, particularly in terms of skill and resource sharing.

In addition, core groups developed for decision-making and organising within the network. Individuals and groups with more experience and skills played more active roles in organising and were informally acknowledged for their leadership. This form of 'hierarchy' is not necessarily seen as 'good' or 'bad' in permaculture. 'Leadership' is not frowned upon in the same way as in anarchism. Or at least it is understood differently in that it does not connote a form of domination or authoritarianism.

Informal hierarchies may also be manifested in meetings through dominant voices who are strongly opinionated, want to be heard and are quicker to talk. This leaves less vocal, shy thinkers more likely to go unheard. This is an area where the role of facilitator is so vital and can help overcome the problem. Setting 
ground rules in meetings were also useful in fostering respect and creating a safer space. I noted: "Of all the meetings and conferences I attended for my fieldwork, I found Climate Camp huis most enjoyable because it was a space where I knew I did not have to compete to get a word in" (August 2009).

One of the objectives of Climate Camp Aotearoa is "to upskill the grassroots Climate Change movement and share our existing skills" (Camp for Climate Action Aotearoa, 2009a). As autonomous groups, the local groups were responsible for their own activities, including building skills such as facilitation and conflict resolution. There were, however, also national Climate Camp Aotearoa workshops on various issues at Kotare Trust. Although unintentional informal hierarchies exist, there is a conscious drive to eliminate these barriers and inequalities through conflict resolution and skill sharing, and a willingness to adapt.

\subsubsection{Obstacles to participation}

Participation is crucial to directly democratic processes. Collective learning and decision-making in the process of rebuilding community and transitioning to a caring low carbon human scale necessitates participation. There are difficulties in establishing such relationships. As Climate Camp Aotearoa participants have pointed out, in reaching consensus, we need to learn to cooperate with others and think of what is in the best interest of the group and not just ourselves. Our culture at present promotes individualism and competition. We need to learn to resolve conflict and allow for diversity. Discrimination against certain peoples, animals and plants over others has led to major imbalances in relationships and power. Both anarchism and permaculture are well aware of this and seek to create harmonious relationships within humanity by how we interact with each other and our environment.

As a principle in anarchism and permaculture, taking action directly and practically means participating in transformative change. There are practical issues to grapple with in the day-to-day practice of such projects. Communication in Climate Camp Aotearoa was one of these difficulties. As one participant observed, the organising structure used by Climate Camp Aotearoa had been designed for large numbers of people, and did not function as effectively 
with small and geographically distant regional local groups in comparison to the UK. Technology was heavily relied upon for communication, particularly Internet, Email, Skype and phone access. This created some difficulty in terms of practicing the Camp's principle of inclusivity and for participation of those without access to these communications. Reliance on technology broke down communications on a number of occasions due to technical faults and lack of access, which made participation and coordination difficult on a national level. In terms of feedback mechanisms, this slowed down responsiveness to changes.

\subsection{Counterculture and edges}

'Use the edges and value the marginal' is a permaculture design principle but it also applies to anarchism. The phrase refers not only to the edges between two ecosystems or other physical margins but also the marginal edges of mainstream culture of human systems. "The thinking implies that those on the edges will be the most able to adapt, develop and progress with appropriate sustainability when radical change is imposed by further collapse of decaying systems" (Ball, 2007). Counterculture is valued as a dynamic margin and as the place where creativity and transformational change stems. Solidarity with those at the margins and in the struggle for social and ecological justice, such as indigenous peoples, women and the poor, are central to the anarchist project. Anarchism in itself is a marginalised political philosophy and, as previously noted, its focus on the practice of self-reliant autonomy empowers participants to be less vulnerable to large system disturbance and more resilient in the face of disaster.

Holmgren $(2002,2006)$ writes that action is at the edge, and innovations in the mainstream have their roots in the counterculture:

"For me these invisible successes in reinvigoration of the mainstream represent both an endorsement of radical ideas and sobering lessons on how radical ideas are absorbed and digested by the cultural mainstream. The absorption has involved compromise of cherished values and the shedding of foolish or impractical notions. Most significantly it shows how establishment power never acknowledges that it is the fringe rather than the centre which is the source of inspiration in the modern world. While that maybe a cause for bitterness on the part of crusading radicals who are never 
acknowledged, it is also a lesson of how anarchistic experimentation and apparently directionless movements can be successful in changing society through invisible infiltration and subversion of the mainstream" (Holmgren, 2006, pp. 228-229).

\subsection{Politics, power and activism}

Holmgren mentions anarchy a number of times in his writings. The above quote is from an article 'Counter Culture as Dynamic Margin', and is the closest he comes to a political manifesto. Holmgren spoke on the same topic at the Permaculture in New Zealand (PiNZ) 2009 AGM in Te Teko that I attended (pers. comm. 30 May - 1 June 2009). He emphasised permaculture as part of the counterculture and referred to permaculture as activism. Scepticism of the ability of governments to make the necessary changes is a foundation of permaculture philosophy. Bill Mollison stopped protesting and began permaculture as a DIY approach based on self-reliance and regional self-sufficiency because he realised that the government was not listening or taking action.

Permaculture holds a vision separate from the political economic systems (Starr \& Adams, 2003, p. 28). Holmgren (2002) writes that centralised power in hierarchical institutions corrupts absolutely and that top-down management systems are unfit to deal with large disasters. The current global capitalist economy based on infinite growth, profit and the idea of endless fossil fuel supply is bound to collapse. Therefore, "the task is to create the alternative possibilities rather than battering at the ramparts demanding change ... The quality of that [mainstream] revolution will be determined by the diversity of living and working models that we have the energy and vision to create" (Holmgren, 2006, p. 230).

Permaculture activists advocate community democracy and a diversity of ownership and exchange mechanisms as the basis of a cooperative society. "The primary unit of society would be neither the individual nor the nation state" (G. Williams, 2006, p. 173). The process of facilitating individuals, households and local communities towards self-reliance and self-regulation in order to change our consumption-production patterns and thus lower our impact on the environment and improve social relations, as opposed to lobbying government or influencing 
policy, is reflected in the permaculture design principle 4 'apply self-regulation and accept feedback' in the permaculture strategy (Holmgren, 2002, p. 80).

What is so interesting about permaculture is that it is implicitly and inherently political (Ball, 2007; see also Trainer, 2000 on eco-villages) and, as shown above, shares complementary ethics and principles with anarchism (see Polk, 2008). An implication of these shared values is shared politics and "delinking" strategies. Permaculture and anarchism share interest in many of the same applications for their philosophy, including cooperatives and collectives, community currencies, collectively managed gardens and DIY renewable energy sources. Similarly, an important principle for both philosophies is that of living by example through practical action. Many community activists are involved in these activities in their everyday lives, including Climate Campers.

However, permaculture runs the risk of ignoring the political implications of its implementation as a practice. Permaculture's ability to complement many topdown approaches in the broad environmental movement (Holmgren, 2002) and its general reputation as seemingly apolitical or as just some weird type of gardening, makes it malleable to mainstream politics but at the expense of its implicit radical politics. The 'below the radar' strategy and thus invisibility of permaculture subversion to the mainstream also makes its effectiveness difficult to follow. To illustrate this strategy, a permaculture activist at a community currencies workshop in Wellington in August 2009 advised, "it is better to ask forgiveness than to ask permission" when dealing with government on the topic of complementary economic and financial systems. The implication of this attitude is that breaking the law cannot be ruled out in permaculture. This is where anarchism adds an explicitly political dimension of human organisation, which seeks out issues of power, into the permaculture principle and ethics.

The 'new anarchism' or 'post-ideological' or small 'a' anarchism' (Curran, 2006; Graeber, 2002; Starr, 2005), however, also runs the risk of seeming apolitical. In a recent publication, 'Criticism without Critique' (Shift Magazine/ Dysophia, 2010), from the Camp for Climate Action in the UK where the movement emerged, the contributors in the editorial write that although the aims and principles of Climate Camp are strongly anarchistic in origin, they did not make 
this fact explicit from the start due and as a result the movement has suffered cooptation by mainstream political views. Fear of a bad image of seeming too radical has threatened to destabilise the Climate Camp roots in the anarchist and radical movements, which are its politics (ibid). Climate Camp's principles of inclusion and participation require a constant balancing. By being too inclusive, its anti-political stance can get watered down, and being exclusive is not desirable.

\subsection{Variation between permaculture and anarchism}

Although permaculture and anarchism share much in common, their relationship to each other needs to be understood. Anarchism and permaculture ethics overlap but with different emphasis (and are closer or further away depending on emphasis of the author). Both anarchism and permaculture share a worldview of environmentalism and values. Both advocate the same methods of application based on mutual benefit, cooperation and reciprocity.

Perhaps a useful initial approach to assist our understanding of the variation between permaculture and anarchism is by surveying their histories. Permaculture began as an ethical land-based systems design philosophy in response to high energy, intensive, environmentally destructive, large-scale agriculture. This is reflected in the origin of its name from 'permanent agriculture' and its first ethic of earth care. Permaculture has since been incorporated into all design aspects of human organisation (reflected in Holmgren's permaculture flower and the teaching of invisible structures) and the name has been extended to mean 'permanent culture'. Across a Permaculture in New Zealand (PiNZ) sticker is written the text 'Cultivating communities', which illustrates this extension and its original meaning. Permaculture is still essentially a practical design philosophy. Its main concern is designing a low energy system with appropriate technology (with what we already know and technology we have as opposed to relying on future innovations to save us from collapse) primarily for environmental reasons. As one permaculture activist and Climate Camp participant explained, permaculture is not socially focused like anarchism. Collective organising is a less explored aspect of permaculture practice and philosophy but with growing interest. 
Unlike anarchism, politics is only a part of permaculture, as implicitly indicated in the last petal of Holmgren's permaculture flower labelled 'land tenure and community governance', in the 'invisible structures' of human organisation, and in the second ethic of people care (which is part of earth care) and third ethic of fair share. 'Care for the people' does allow permaculture to be people-centred, since it is about how we interact with and manage our environment, and organise ourselves collectively.

People-care as a central ethic means that looking after each other as a collective is an important value, while the earth-care ethic and fair share ensures that we include and provide for other species, not just humans, in our design systems. "The stewardship concept demands that we constantly ask the question: Will the resource be in better shape after my stewardship? One cannot go far in this process without challenging the ethical validity of the ownership of land and natural resources that lies at the heart of our legal system" (Holmgren, 2002, p. 5). Thus, issues of ownership and resource management and distribution (i.e. politics) can be argued as being central to permaculture design.

Anarchism is explicitly a political philosophy and has its history in resistance to centralised power hierarchies, as a response to large-scale industrial capitalism and the rise of, what it regards as, the corrupt nation state. Anarchism seeks to create an egalitarian society out of the wreck of capitalism, which it seeks to weaken and destroy. ${ }^{27}$ Anarchism's prime focus is socially based - and its intent is fair distribution (in decision-making, of resources etc.). Thus process becomes important. Perhaps if one were to rearrange permaculture ethics into prioritised anarchist ethics they would be reversed to fair-share, people-care, earth-care.

Unlike permaculture, the environmental ethic is only part of anarchism and this is understood in terms of domination, exploitation and profit. Of course, this is from the perspective of anarchism as a whole, with all its strands and from a historical perspective. Eco-anarchism, however, views the environmental crisis as ultimately part of the social crisis as it is an issue of justice in terms of social relationships and interactions. How we treat each other is extended to how we

\footnotetext{
${ }^{27}$ (As Climate Camp Aotearoa participants sang on the day of direct action, "Resist, resist. Fight the Capitalist ... We're gonna tear it down.")
} 
treat the environment. Permaculture views the basis of the environmental, energy, economic and social crises as a paradigm of Cartesian logic where we have mentally separated ourselves from nature and thus do not consider its needs and exploit it for our own purposes. This dualistic thinking has also created a separation of the individual from society, which relates to issues surrounding the question of what constitutes freedom and autonomy.

Thus, although both permaculture and anarchism are both concerned with systemic change and share the same ethics, permaculture focuses primarily on an ecological design strategy while anarchism focuses primarily on political process strategy. Both realise the major significance of ownership and control of resources and the means of production. Historically, anarchism is a much older philosophy and permaculture has drawn from its tradition and incorporated it into its ecological perspective (evident in the influence of Bookchin and Kropotkin); whereas anarchism has incorporated the modern issues of limits to growth, energy crisis, global warming and other environmental issues into its critique of capitalism, the nation state and other dominator hierarchies.

In view of the similarities of permaculture and anarchist ethics, principles and epistemology, their politics should be shared by implication. However, many permaculturalists do not perceive the state and parliamentary politics as inherently corrupt, and capitalism is not completely disregarded as all bad. These are part of political debate in permaculture whereas in anarchism the rejection of the state and capitalism are in its foundations.

\subsection{Tactics: confrontation and 'under the radar'}

Perhaps the most obvious tension, in general, between permaculture and anarchism is lies in their tactics, in particular with direct action as a 'cost and delay' tactic. Permaculture is less concerned with confrontational resistance and tearing down the system.

For permaculture (and anarchism), economic system collapse is inevitable, since infinite growth on a finite planet is impossible. Global economic growth relies on an endless supply of cheap fossil fuels, which resource depletion and "peak oil" is proving to be unsustainable and unrealistic, and thus 'powering down' or 'energy 
descent' is necessary. Additionally, if we do not transition to a low carbon future, the chance of runaway climate change increases dramatically.

Permaculture seeks solutions to this crisis and does not dwell on the problems. Anarchism also seeks solutions but it is more concerned with confronting the problem and stopping it. Climate Camps in the UK and Australia have involved shutting down coal-fired power stations and disrupting production of business-asusual so that profits are lost and thus hurting the capitalist bottom-line. In a longterm campaign, this may cause the business to be economically unviable. Keeping fossil fuels in the ground is one of the principles of climate justice, which also complies with a "peak oil" strategy.

From an anarchist perspective, permaculture does not explicitly confront the problem of capitalism. Capitalism is all encompassing and does not allow space to create alternatives to it. Therefore direct action - by exposing, confronting and tearing it down to open up spaces for alternatives to capitalism - is important for change. Working 'under the radar' is not enough and neither is individuals working on their little space on their own. There needs to be a reckoning force against it. So although permaculture through many of its ideas implies anarchism, it is not willing as a movement to confront the system by way of explicit resistance and critique, from an anarchist perspective. Of course this is not to say that individuals working within the permaculture network do not critique the system or are oblivious to issues of power and politics, but this is has not been a focus for permaculture because criticism focuses on the problems and not their solutions.

Since permaculture began as a land-based practice, 'invisible structures' were not taken into account. However, as permaculture has broadened to encompass all aspects of culture, it needs to take account of its relationship with the state. David Holmgren at the PiNZ AGM last year called for a more radically activist stance (pers. comm. 30 May - 1 June 2009).

Although there is some difference between anarchist and permaculture tactics, this is not to say that they are incompatible or exclusive to each. As philosophies (and in practice), anarchism is interested in both resisting and decentralising power and in creating alternatives, while permaculture is primarily concerned 
with living cooperatively with the land and people, as manifested through design application. Although solutions are the primary focus of permaculture rather than confrontation, however, practicing permaculture can and has run into problems with laws and authorities. It is here that the tactics of permaculture and anarchism converge. Guerrilla gardening is a prime example of radical permaculture and eco-anarchism in action. Embodying an alternative is a form of direct action by definition, although it may seem apolitical at first glance.

Many permaculture activists are not anarchists (or at least not explicitly) and although most agree on the problems with the current system, how to go about changing it, in terms of strategy, is debated. Although permaculture may be compatible with anarchism, the term 'anarchy' does not conjure up an image of a cooperative utopian society for most people and thus may not be all that useful as a term. On the other hand, as already mentioned from the Climate Camp UK example, by not making one's politics explicit, one runs the risk of political cooptation. However, being explicitly anti-authoritarian also runs the risk of being marginalised and co-opted. According to permaculture, surely this is not necessarily a bad idea since in the design of any system it is favourable to increase the edges of the system.

\subsection{Alternative systemic principles and solutions}

In terms of alternatives, both permaculture and anarchism advocate DIY, equitable relationships (although neither now completely disregard all competition as unhealthy). Both advocate small-scale decentralised systems based on cooperative relationships. By anarchist definition, national governments are centralised systems based on coercion and profit seeking (through rents, resource extraction etc.) as well as other capitalist values, and this is becoming more so as they lose power to the wealthy corporations, which hold no direct accountability to citizens (Starr, 2005).

Capitalism is based on the values of individualism, profit seeking, exponential economic growth (in production and consumption), private ownership, wealth accumulation, externalising costs, industrialisation and cheap labour and thus exploitative relationships or inequality. Therefore, although permaculture does not explicitly confront and resist government or corporations, as does anarchism, 
its principles and ethics are incompatible with the capitalist-consumerist system and the solutions promoted by permaculture are alternative to the current largescale extractive system. For anarchism, the capitalist system corrodes real democratic rights and thus control over decision-making and the use of resources and fate of the earth. However, permaculture does not necessarily view capitalism completely negatively since it may be seen as freeing up resources that will be necessary in a post-carbon society.

System resilience is emphasised by permaculture as the reason for the necessary systemic changes to how we organise ourselves and our environment, and use and control resources. Anarchism on the other hand emphasises the centralisation of power and the inherent corruption in these hierarchical systems and relationships. Anarchism is concerned with issues of justice, which are incorporated into the fair-share ethic of permaculture.

Self-reliance, direct action, autonomy, decentralisation, small scale, localisation, cooperation, collective decision making and ownership all point to a shared politics - one that rejects large scale centralised systems, expertism and authoritarianism and thus the nation state and party politics. Local autonomy is not about seizing power from the centre but it is about building local selfmanaging political systems. Both permaculture and anarchism seek to 'embody an alternative' as much as is possible in the present tense and to reduce reliance on the global economic industrial system. This is a 'prefigurative' politics (Graeber, 2002; Starr, 2005). The direct democratic processes practiced by Climate Camp Aotearoa, other climate justice networks and the global justice network in general, (the new anarchists) with the consensus method and nonhierarchical structures of decision-making is a prime example of this. Eco-villages or intentional communities also use the consensus process and tools such as facilitation and conflict resolution.

\subsection{Conclusion: anarchism and permaculture in mutual solidarity}

Not all anarchists are permaculturalists and not all permaculturalists are anarchists. However, anarchism as a politically focused social philosophy and permaculture as an ecologically focused design philosophy are mutually beneficial to each other. They share converging central ethics and principles and 
struggles of praxis. Both recognise that transformative social change is necessary. Whether it is called a cultural revolution, transition or system collapse, the underlying recognition is that we need to live more harmoniously with each other and the natural environment by creating diverse post-industrial societies. They both look to indigenous and pre-industrial societies and the natural world for their praxis.

Permaculture and anarchism are both concerned with how we organise and in finding practical ways to organise equitably and for the benefit of everything. Both wish to create a post-capitalist society, away from the ravages of industrialisation and modernity. Permaculture as a whole systems design tool can be utilised by anarchism in creating an egalitarian society that is ecologically sustainable. "Permaculture principles provide one lens for helping to identify the useful pieces of modernity and combine them with those from nature and from pre-modern cultures in a new designed synthesis" (Holmgren, 2002, p. 23).

Anarchism adds to permaculture through its contribution of consensus decisionmaking processes and decentralised organising structures as local political alternatives to globalisation and an explicitly political stance. Climate Camp epitomises the symbiosis of these philosophical practices. The values and solutions advocated by this perspective calls for a new paradigm of holistic thinking based on cooperative, small-scale systems and a respect for life, the right to self-organise and fair distribution. 


\section{Chapter 6: Conclusion}

\subsection{Introduction}

The aim of this thesis has been to answer the question of whether the ethics, principles and practice of anarchism and permaculture can provide an alternative to development framework. Answering this has been aided by firstly using case studies to show these principles in practice, and secondly by comparative analysis of anarchist and permaculture ethics and principles. This concluding chapter considers the implications of these practical philosophies for post-development praxis and development practice.

\subsection{Summary of the thesis}

In Chapter Two, the literature on post-development, anarchism and permaculture was explored. The post-development school critiques the development agenda as an interventionist and hegemonic strategy of the West to exploit the "Third World'. It has called for a paradigm shift and for alternatives to development. A key area of interest shared by post-development authors in the search for alternatives to development is the global justice movement. This network has been described by authors such as Curran (2006) and Graeber (2002) as anarchistic in principle and practice, even though it does not call itself such. Anarchist organisational principles reflect values of radical participatory (direct) democracy and direct action, mutual aid and solidarity. The new anarchism (Graeber, 2002) or post-ideological anarchism (Curran, 2006) rejects the notion that there is no alternative to the neoliberal paradigm and seeks to create alternatives to it. It extends its critique to, and rejects, all forms of domination and oppression.

Permaculture is an ethical philosophy that seeks to design low energy systems that mimic patterns and relationships found in nature. Permaculture originated in the 1970s as a response to the 'Limits to Growth' Report, the threat of global warming and the energy crises at the time. It grew with and as part of the rise of the environmental justice movement. Like post-development and anarchism, it rejects the notion of limitless economic growth as ecologically sustainable and calls for a paradigm shift towards cooperative relationships. Although the term 
permaculture began as meaning 'permanent agriculture', its definition has been extended to the much broader meaning of 'permanent culture' to encompass all aspects of human organisation. Its core ethics of earth-care, people-care and fairshare and its twelve design principles are applied to all whole system design.

Chapter Three discussed the research approach and justifications of the thesis project. The theoretical perspective was in line with post-development and a constructionist epistemology was adopted. Constructionism is the view that all knowledge, and therefore meaningful reality, is constructed and transmitted within an essentially social context dependent on interaction between human beings and their world, and contingent on human practice (Crotty, 1998, p. 42). The implications are two-fold. Firstly, to find meaning and understanding, the researcher needs to experience the activities of the community directly. Secondly, the researcher cannot be a neutral passive observer and thus needs to make her position explicit. Thus action research and the ethnographic approach were undertaken as holistic means of researching the ways different groups were organising and practicing their principles. This was achieved through case studies.

The research method utilised was qualitative participant observation in the form of full immersion, particularly in the primary case study, Camp for Climate Action Aotearoa. This approach reflected the anarchist principle of direct action and the permaculture principle of 'observe and interact'. The research approach sought to mitigate the extractive process of data gathering by building relationships with participants and giving back by playing an active role in the community.

The case studies were Wellington-based, in line with the post-development view that the West needs to look at itself, its own problems and stop interfering with the rest (Latouche, 1993). This approach also supported building local networks and lessened the ecological impact of long distance travel, in line with permaculture, post-development and anarchism. I gathered information mostly through conversation and at meetings. Secondary texts were also utilised and a journal was kept. Climate Camp Aotearoa and permaculture meetings were the main case studies although there were others, including community currencies, 
community gardens and community-supported agriculture. There were difficulties with the immersion approach that pertain to the cultural insider/ outsider dichotomy. I kept the identities of participants anonymous and did not include any confidential information to avoid potential harm to individuals and groups in these transformative and radical projects.

Chapter Four focused on Camp for Climate Action Aotearoa as the main case study, a climate justice event and a network that originated in the United Kingdom with anarchist and radical movement principles. The chapter sought to show the anarchist principles and practice of this organisation. Direct democracy and direct action are central to Climate Camp's praxis. The horizontal organising and decision-making structures and processes described in the chapter reflect the anarchist principles of decentralisation, non-hierarchy, social and ecological justice, autonomy, diversity, direct action, radical direct democracy and participatory education. The decentralised spokes council model, local and working groups, neighbourhoods and direct action affinity groups with consensus decision-making processes are these principles in practice. These were described in detail in this chapter.

The Climate Camp event at Moonshine Park in December 2009 was a demonstration of sustainable living with recycled infrastructure, renewable tools and technology, as well as its collective decision-making and implementation. The Camp was a non-commercial and participatory event with participants also involved in the day-to-day running of the camp. This included processes of decision-making by consensus using the same local groups, working groups and spokes council model utilised in organising for the event, as alternatives to the representative democracy of capitalism. Other alternatives to the centralised expert-led mainstream culture in education and learning were utilised at Climate Camp. Similarly, techniques used in permaculture displayed this participatory self-organising principle in learning through Open Space Technology (OST) and the World Café.

Although anarchism, an anti-authoritarian political philosophy, and permaculture, an ecological design philosophy, are seemingly quite different concepts, they share similar ethics and principles. Both philosophies point to 
practical alternatives to the top-down managerial approaches to decision-making and knowledge as well as ways of creating human and ecological systems based on relationships of symbiotic interaction.

Chapter Five discussed the ethics and principles of anarchism and permaculture in some depth and how they relate to each other conceptually as well as some of the implications. Holmgren's twelve principles of permaculture design and the three central ethics were discussed in relation to the community governance and 'invisible structures' of human organisation, which are Climate Camp Aoteoroa's anarchist practice and principles. The permaculture design principles utilised in the design of the Camp at Moonshine Park were discussed to show the practical compatibility in demonstrating alternatives of these two ethical philosophies.

Ethical concerns of mutual aid align with earth-care, people-care and fair-share. These are ultimately concerned with looking after each other for the benefit of all, in other words, creating more harmonious cooperative relationships based on social and ecological justice. In nature, ecosystems create these relationships through self-organisation. Similarly, anarchism values autonomy and freedom to self-manage while centralised systems are seen as authoritarian, dominating and oppressive. These centralised systems are rejected in permaculture as unstable and susceptible to disruption whereas decentralised systems are considered to be more resilient and self-reliant. Anarchism practices non-hierarchical, decentralised, or horizontal organising structures.

Scale is important to both philosophies in terms of community control and effectiveness. Small or human-scale systems are advocated in permaculture as size affects feedback responsiveness to change and the ability of a system to selfregulate. Thus localisation is valued. Likewise, decentralised small-scale organisation is significant for practicing direct democracy and local autonomy in anarchism. With the freedom to self-organise and form voluntary associations comes personal responsibility for one's own actions.

Direct action as 'doing it ourselves' and taking practical action is an important principle in anarchism and permaculture. Direct action in anarchism can mean embodying an alternative or taking action to stop something directly. Permaculture can be seen as a non-confrontational philosophy and strategy that 
seeks to subvert the system by example 'below the radar'. Anarchism and permaculture are primarily ethical practices. The means is the end, as embodying your principles in action and organisation, is a key concept in anarchism. Nonhierarchy and justice, respect for life and thus non-violence are its philosophy and practice, and the process is more important than the end. This is in opposition to 'the means justifies the ends' that anarchists see in other socialist forms and even more so in capitalism. Dealing directly with dominator hierarchies, what are seen as the root causes of ecological and social crises, is direct action and highly political.

Diversity is celebrated by both philosophies. For permaculture, this relates to the stability of a system to destructive forces. In whole systems design, it is important that each element supports many functions and that each function is supported by many elements. In anarchist practice, diversity of views in decision-making and tactics, roles and skills in direct action are valued. Diversity of culture is important to both practical philosophies for imagining and creating alternative possibilities to the current dominant and dysfunctional system. Thus a prescriptive approach must be avoided. In the Climate Camp Aotearoa Moonshine Park Handbook 2009 is written "We are not a blueprint - the camp is a small demonstration of what might be possible" (Camp for Climate Action Aotearoa, 2009f, p. 18).

There are many similarities between the philosophies and the implications of these would point to permaculture being almost completely synonymous with anarchism. However, permaculture's general 'under the radar' strategy and practice de-politicises its inherent political nature in terms of critique. Its nonconfrontational approach to politics allows it to infiltrate mainstream culture, but its focus on solutions, of embodying an alternative, is not necessarily seen as enough for anarchism, which seeks to quicken the demise of the global capitalist system and widen the cracks to create space for alternatives.

Bill Mollison described permaculture as "anti-political. There is no room for politicians or administrators or priests. There are no laws either. The only ethics we obey are: care of the earth, care of the people, and reinvestment in those ends" (London, 2005). Similarly, for Holmgren, dependence on centralised systems and 
power-corrupted officials is dangerous and thus a flatter structure is preferred for system resilience. Anarchism, as exemplified by Climate Camp, rejects mainstream politics. Control and ownership and thus collective decision-making are seen as significant for cultural change.

Permaculture is a significant systems thinking design tool that can be utilised by anarchist practice, while anarchism adds a more social element to permaculture systems and an explicit political critique of power and domination. In summary, I have argued that permaculture in principle and practice is anarchic and that permaculture's anti-political or apolitical stance tends to seemingly ignore its implicit political nature and thus de-politicises it. This strategy is also used in anarchist practice although generally a more explicit alternative political approach is evident, such as in the praxis of Camp for Climate Action Aotearoa.

Direct action as a tactic of resistance versus the 'under the radar' tactic for transformation is a point of contention that remains unresolved for some radical social change movements and individuals. Whether to use subversion from within or resistance from without shows a dynamic tension in the debate of tactical effectiveness. In other words, do we confront 'the system' openly or make changes quietly and unseen to break it down and to build alternatives? Does 'the system' need to be engaged with in order for alternatives to exist and survive?

\subsection{An alternative to development framework}

If the post-development/ anti-development/ alternative to development approaches were to be put into practice, what would it look like? I argue that it would be anarchic. The ethical principles of anarchism have been implemented by the now large and established movements of resistance such as the Zapatistas in Mexico, Peoples Global Action and World Social Forum. These have been cited extensively including post-development writing as examples of alternative imaginings and practices (e.g. Aguiton, 2005; Boron, 2005; Bullard, 2005; De Sousa Santos, 2005; Guttal, 2005; Rahnema \& Bawtree, 1997; Rosset, MartínezTorres, \& Hernández-Navarro, 2005) even if they have not been recognised explicitly as anarchist. 
The alternative to development principles and case studies cited by postdevelopment authors include many of the practices used by anarchist (and permaculture) collectives. Post-development as a critique of power and discourse, of domination and oppression, of which poverty is a form, parallels that of anarchism. The view of development as a hegemonic project of domination of the West for power and control through a strategy of intervention and the inherent ecological and social exploitation within the exponential economic growth agenda are equally argued.

The rejection of prescribing a universal blueprint is shared by post-development, permaculture and anarchism. The notion of knowing what's best for others and intervening on their behalf as 'trusteeship' (Cowen \& Shenton, 1996), 'vanguardism' (Graeber, 2004), or authoritarianism is also rejected by postdevelopment and anarchism alike. Permaculture's notion of stewardship in terms of earth-care is a useful conceptual tool for a cooperative way of thinking and practice. In terms of human relationships, the concept of solidarity in anarchism is a significant practice of mutual aid and respect for autonomy.

"Charity is not mutual aid. It is a way of giving from someone who has to someone who doesn't have, thereby creating a situation of dependency. Charity does not empower people, it does not help them to get back on their own feet, to try to help themselves" (Knoll, 2009, p. 11).

Self-mobilisation and direct action - taking responsibility and not relying on experts or leaders - are thus principles for alternatives to development. Autonomous self-organisation, as being without the influence of an external authority, is significant for the practice of post-development theory. The notion of expertism or professionalism - of experts coming to do development on the 'underdeveloped' and knowing what's best or even assuming that development is desirable (U. Kothari, 2005) - is rejected as domination and intervention by the post-development school.

Development as modern industrial capitalism or globalisation - practiced and measured by economic growth and profits, consumption and production - is seen 
as detrimental to social and ecological systems by post-development authors (and anarchism and permaculture alike). This materialism is a high-energy system that relies on fossil fuels to continue its exponential growth. The 'ravages of affluence' (Holmgren, 2002), the 'ravages of development' (Escobar, 1995) and the 'ravages of globalisation' (Seabrook, 2002) all point to the same destructive unjust system and monoculture that has spread with the rise of industrialisation and the nation state. This large centralised system is seen as reductionist, individualistic, competitive and exploitative, suffering from binary logic (Crush, 1999a; Holmgren, 2002) that separates us from nature and distances us from the impacts we have on our surroundings. Holistic systems thinking, tightening feedback loops, reducing the scale and creating decentralised local systems, assists the solution to this dysfunctional paradigm, according to permaculture design and anarchist practice.

The call for a paradigm shift in post-development, for a cultural revolution based on holistic thinking and values in permaculture, and for the practice of mutually supportive relationships in anarchism are essentially the same concepts. Pluralism in post-development or diversity in permaculture and anarchism, a rejection of dualistic thinking in permaculture or binary logic in post-development, looking to pre-industrial or indigenous ways of being (ontology) and understanding (epistemology) for alternatives to modernity or development are, likewise, all shared aspects.

Although this shared perspective has been criticised as utopian, is it not unrealistic. By perceiving the means as being the end and thus the process being the goal, and the goal being the elimination of domination by practicing principles of care and support, there is no end to the process. As a facilitator explained at the Climate Camp Gathering at Parihaka in April 2009, "we do not expect everyone to be holding hands singing Kumbaya into the sunset". There will always be disagreement. In imagining a peaceful, sustainable and truly democratic world, living those ideals as much as possible under the constraints of the current neoliberal paradigm and using those means to gather momentum to build up other systems is important. 
Post-development was a response to the failure of the old styles of left and right politics and an attempt to move beyond the impasse. For anarchism, the centralised power of the state in decision-making processes serves the interests and positions of the wealthy power holders - the winners - in representative democracy. Direct democratic processes such as consensus decision-making used by Climate Camp Aotearoa demonstrate a participatory and empowering collective process of self-governance through dialogue and understanding. This form of radical politics is considered as an example that points towards alternatives to development by post-development authors (e.g. Escobar, 1999; Ziai, 2004).

In a pure sense, no alternatives to development as completely independent systems or bounded wholes currently exist. Development is an all-encompassing and powerful large-scale cultural and geographical system of global economics, centralised governments and powerful corporations by which we are all, to varying degrees, affected. However, there are efforts to delink from the dominant paradigm and economic system towards alternatives to development (e.g. Gibson-Graham, 2005; 2006 ).

Consensus decision-making processes, the spokes council model, community currencies, CSA and so on are all tools that complement the principles and ethics of alternative systems to development. However, these tools are not alternatives to development in and of themselves. They can be used with the economic development goals of growth and profit, for example. The combination of principles and ethics described in this thesis form the basis for an alternative to development framework, and when used systemically with these sorts of tools, processes shadowing potential alternative to development systems can be seen. ${ }^{28}$

No one is completely outside of the dominator/ hierarchy relationship of the development paradigm (Ball, 2007). Post-development theory sits at the fringes of the system, with the status quo at the centre. What post-development asks is to imagine alternatives to development - to imagine other systems and relationships

\footnotetext{
${ }^{28}$ Particularly when the tools are used in whole system design processes so that they mutually support each other (integrate rather than segregate) and are decentralised and diverse (multiple elements support each function and each element supports multiple functions).
} 
outside of the existing one. It is through imagination that we can begin to create a more harmonious existence and bring into being new paradigms. Anarchism and permaculture are practical philosophies that address the root causes of systemic problems, not just the emergent symptoms, and seek to create spaces for and examples of alternatives in the present.

\subsection{Alternative development and development intent}

Since no pure 'alternative to development' exists, we are left with various forms of alternative development. The contentious questions of practice - what Graeber (2004) calls "Low Theory" - around issues of participation, inclusion, capacity and access, as well as democracy, empowerment, distribution, accountability and transparency, are shared concerns (e.g. Friedmann, 1992) that have been shown from the Climate Camp Aotearoa case study.

Alternative development works with the system and in dialectic with it (Zepeda, 2006) - in permaculture terms, the 'dynamic margin' between development and the imagined alternatives to development. Working from within the system often necessitates a process of including the excluded into the current system and thus improving it (e.g. Cooke \& Kothari, 2001). Many tools, principles and processes advocated by alternative development and post-development are the same. However, the combination of these tools, principles and processes, and how they are designed and applied in relation to each other systemically, are significant in determining whether or not the intent is that of an alternative to development or that of hegemonic development.

Alternative development is a creative and dynamic field of diversity and inclusivity, and thus risks (and has suffered) cooptation. To be exclusive or purist equally risks stagnation through a protectionist approach. Although postdevelopment rejects reductionist and binary logic, it similarly suffers from the same dualistic thinking at times. However, the whole system critique that anarchism and post-development provide are significant for a more politically engaged approach to the root causes of global crises and thus serve as warnings and indicators for choosing appropriate solutions to development. 


\subsection{Conclusion}

Post-development calls for direct democracy, a paradigm shift, holistic thinking, self-organisation, and diversity. This and its rejection of economic growth, intervention and hegemony, monocultures and binary logic, are consistent with both anarchism and permaculture.

Solidarity and stewardship, decentralisation and autonomy, tight multiple feedback mechanisms and a whole system design approach are some of the alternative people-focused solutions to the global crises of development proposed by anarchism and permaculture. From this perspective, development is a systemic problem and needs systemic solutions. Although alternatives to development do not exist in the pure sense of the term, it is necessary to imagine and to create multiple possibilities of organisation based on principles of mutual aid, direct action and self-management - and in opposition to the universal development approach of managing others. Anarchism and permaculture are ethical philosophies that are creatively putting this alternative to development framework into practice. 


\section{References}

Aguiton, C. (2005). Mapping the Movement. Development: The Movement of Movements, 48(2), 10-14.

Arvanitakis, J., \& Healy, S. (2000). S11 Protests Mark the Birth of "Third Wave Environmentalism". [commentary and creative action]. Ecopolitics: Thought \& Action, 1(1), 24-29.

Ball, C. (2007). Permaculture Politics - New Pythagorean Links. Retrieved from http://www.permacultureinternational.org/Members/pacificedge/perma culture-politics-new-pythagorean-links

Bey, H. (1991). T.A.Z.: The Temporary Autonomous Zone, Ontological Anarchy, Poetic Terrorism Available from http://www.hermetic.com/bey/taz cont.html

Blomberg, J., Giacomi, J., Mosher, A., \& Swenton-Wall, P. (1993). Ethnographic Field Methods and Their Relation to Design. In D. Schuler \& A. Namioka (Eds.), Participatory Design: Principles and Practices (pp. 123-156). Hillsdale, New Jersey: Lawrence Erlbaum Associates.

Bookchin, M. (1971). Post-Scarcity Anarchism. Berkeley: Ramparts Press.

Bookchin, M. (1995). Social Anarchism or Lifestyle Anarchism: An Unbridgeable Chasm. Edinburgh: AK Press.

Boron, A. (2005). Civil Society and Democracy: The Zapatista Experience. Development: The Movement of Movements, 48(2), 29-34.

Brydon-Miller, M. (2009). Covenantal Ethics and Action Research: Exploring a Common Foundation for Social Research. In D. M. Mertens \& P. E. Ginsberg (Eds.), The Handbook of Social Research Ethics (pp. 243-258). Los Angeles: Sage Publications.

Bullard, N. (2005). Guest Editorial Where is the Movement Moving? Development: The Movement of Movements, 48(2), 4-7.

Butz, D., \& Besio, K. (2009). Autoethnography. Geography Compass, 3(5), 1660 1674.

Camp for Climate Action Aotearoa (2009a). Our Principles and Objectives Retrieved 21 January 2010, from http://www.climatecamp.org.nz 
Camp for Climate Action Aotearoa (2009b). What is Climate Camp? Retrieved

21 January 2009, from http://www.climatecamp.org.nz

Camp for Climate Action Aotearoa (2009c). Camp for Climate Action Aotearoa:

An Introduction.

Camp for Climate Action Aotearoa (2009d). Climate Camp Aotearoa Reader.

Camp for Climate Action Aotearoa (2009e). Camp for Climate Action Aotearoa:

Organising Structure and Working Process Document.

Camp for Climate Action Aotearoa (2009f). Camp for Climate Action Aotearoa Handbook.

Carter, A. (2000). Analytical Anarchism: Some Conceptual Foundations. Political Theory, 28(2), 230-253.

Cavanagh, J., \& Mander, J. (Eds.). (2004). Alternatives to Economic Globalization: A Better World is Possible (A Report of the International Forum on Globalization) (2nd ed.). San Francisco: Berrett-Koehler Publishers, Inc.

Chomsky, N. (1999). Profit Over People: Neoliberalism and Global Order. Delhi: Madhyam Books.

Clegg, J. W., \& Slife, B. D. (2009). Research Ethics in the Postmodern Context. In D. M. Mertens \& P. E. Ginsberg (Eds.), The Handbook of Social Research Ethics (pp. 23-38). Los Angeles: Sage Publications.

Comim, F. (2008). Climate Injustice and Development: A Capacity Perspective. Development: Climate Justice and Development, 51(3), 344-349.

Cooke, B., \& Kothari, U. (2001). The Case for Participation as Tyranny. In B. Cooke \& U. Kothari (Eds.), Participation: The New Tyranny? (pp. 1-15). London: Zed Books.

Corbridge, S. (1998). 'Beneath the Pavement Only Soil': The Poverty of PostDevelopment. Journal of Development Studies, 34(6), 138-148.

Cowen, M. P., \& Shenton, R. W. (1996). Doctrines of Development. London \& New York: Routledge.

Crotty, M. (1998). The Foundations of the Social World: Meaning and Perspective in the Research Process. Crows Nest NSW: Allen \& Unwin.

Crush, J. (1999a). Introduction: Imagining Development. In J. Crush (Ed.), Power of Development (3rd ed., pp. 1-23). London: Routledge.

Crush, J. (Ed.). (1999b). Power of Development (3rd ed.). London: Routledge. 
Curran, G. (2006). 21st Century Dissent: Anarchism, Anti-Globalization and Environmentalism. New York: Palgrave Macmillan.

Cutler, A., \& Bryan, K. (2007). Why We Need to Take Direct Action. In The Trapese Collective (Ed.), Do It Yourself: A Handbook for Changing Our World (pp. 262-276). London: Pluto Press.

De Angelis, M. (2005). The New Commons in Practice: Strategy, Process and Alternatives. Development: The Movement of Movements, 48(2), 48-52.

De Sousa Santos, B. (2005). The Future of the World Social Forum: The Work of Translation. Development: The Movements of Movements, 48(2), 15-22.

Escobar, A. (1991). Anthropology and the Development Encounter: The Making and Marketing of Development Anthropology. American Ethnologist, 18(4), 658-682.

Escobar, A. (1995). Encountering Development: The Making and Unmaking of the Third World. New Jersey: Princeton Universtiy Press.

Escobar, A. (1997). The Making and Unmaking of the Third World. In M. Rahnema \& V. Bawtree (Eds.), The Post-Development Reader (pp. 85-93). London \& New Jersey: Zed Books.

Escobar, A. (1999). Imagining a Post-Development Era. In J. Crush (Ed.), Power of Development (3rd ed., pp. 211-227). London: Routledge.

Esteva, G. (1995). Development. In W. Sachs (Ed.), The Development Dictionary: A Guide to Knowledge as Power (4th ed., pp. 6-25). Johannesburg: Witwatersrand University Press.

Esteva, G. (1997). Basta! Mexican Indians Say 'Enough!'. In M. Rahnema \& V. Bawtree (Eds.), The Post-Development Reader (pp. 302-305). London: Zed Books.

Esteva, G., \& Prakash, M. S. (1997). From Global Thinking to Local Thinking. In M. Rahnema \& V. Bawtree (Eds.), The Post-Development Reader (pp. 277-289). London: Zed Books.

Ewoldt, D. (2006). Natural Systems: Demonstrating the Interdependencies between Sustainability and Democracy. Paper presented at the Proceeding of the 50th Annual Meeting of the ISSS. Retrieved 20 March 2010, from http://journals.isss.org/index.php/proceedings50th/article/view/413 
Friedmann, J. (1992). Empowerment: The Politics of Alternative Development. Oxford: Blackwell.

Gandhi, M. (1997). The Quest for Simpicity: My Idea of Swaraj. In M. Rahnema \& V. Bawtree (Eds.), The Post-Development Reader (pp. 306-307).

Gibson-Graham, J. K. (2005). Surplus Possibilities: Postdevelopment and Community Economies. Singapore Journal of Tropical Geography, 26(1), 426.

Gibson-Graham, J. K. (2006). A Post-Capitalist Politics. Minneapolis: University of Minnesota Press

Goaman, K. (2004). The Anarchist Travelling Circus: Reflections on Contemporary Anarchism, Anti-Capitalism and the International Scene. In J. Purkis \& J. Bowen (Eds.), Changing Anarchism: Anarchist Theory and Practice in a Global Age (pp. 163-180). Manchester: Manchester University Press.

Goldring, A. (2007). Why We Need Holistic Solutions for a World in Crisis. In The Trapese Collective (Ed.), Do It Yourself: A Handbook for Changing Our World (pp. 11-27). London: Pluto Press.

Graeber, D. (2002). The New Anarchists. New Left Review, 13, 61-73.

Graeber, D. (2004). Fragments of an Anarchist Anthropology. Chicago: Prickly Press.

Graeber, D. (2009). Direct Action: An Ethnography. Oakland, CA: AK Press.

Guttal, S. M. (2005). Creating the Open Space: The WSF in India. Development: The Movement of Movements, 48(2), 84-87.

Herman, M. (1998). About Open Space Retrieved 9/02/2010, from http://www.openspaceworld.org

Heywood, A. (1992). Political Ideologies: An Introduction. London: Macmillan.

Highleyman, L. A. (1988). An Introduction to Anarchism Retrieved 10/04/09, from http://www.black-rose.com/articles-liz/intro-@.html

Holmgren, D. (30 May - 1 June 2009). Guest Speaking at the Permaculture in New Zealand (PiNZ) Annual Hui. Te Teko.

Holmgren, D. (2002). Permaculture: Principles and Pathways Beyond Sustainability. Hepburn: Holmgren Design Services. 
Holmgren, D. (2006). The Counter Culture as Dynamic Margin (2000) David Holmgren: Collected Writings and Presentations 1978-2006. Hepburn Springs, Victoria: Holmgren Design Services.

Homer-Dixon, T. (2007). The Upside of Down: Catastrophe, Creativity and the Renewal of Civilisation. London: Souvenir Press.

Hopkins, R. (2008). The Transition Handbook: From Oil Dependency to Local Resilience. Totnes, Devon: Green Books.

Hopkins, R. (2009). Responding to Ted Trainer's Friendly Criticism of Transition Retrieved $24 \quad$ July $2010, \quad$ from http://transitionculture.org/2009/09/08/responding-to-ted-trainersfriendly-criticism-of-transition/

Juris, J. S. (2007). Practicing Militant Ethnography with the Movement for Global Resistance in Barcelona. In S. Shukaitis, D. Graeber \& E. Biddle (Eds.), Constituent Imagination: Militant Investigations // Collective Theorization (pp. 164-176). Oakland // Edinburgh // West Virginia: AK Press.

Keesing, R. M., \& Strathern, A. J. (1998). Cultural Anthropology: A Contemporary Perspective (3rd ed.). Fort Worth: Harcourt Brace College Publishers.

Kent, D. (2005). Healthy Money Healthy Planet: Developing Sustainability Through New Money Systems. Nelson: Craig Potton Publishing.

Kiely, R. (1999). The Last Refuge of the Noble Savage? A Critical Assessment of Post-Development Theory. European Journal of Development Research, 2(1), 30-55.

Knoll, S. (2009). Mutual Aid: An Anarchist Concept At Work in Southern Africa. Zabalaza: A Journal of Southern African Revolutionary Anarchism (10), 11-13.

Korten, D. (2006). From Empire to Earth Community. Development, 49(3), 76-81.

Kothari, R. (1997). The Agony of the Modern State. In M. Rahnema \& V. Bawtree (Eds.), The Post-Development Reader (pp. 143-151). London: Zed Books.

Kothari, U. (2005). Authority and Expertise: The Professionalisation of International Development and the Ordering of Dissent. Antipode, 37(3), 425-446. 
Kropotkin, P. A. (1904). Mutual Aid: A Factor of Evolution. London: W.Heinemann.

Latouche, S. (1993). In the Wake of the Affluent Society: An Exploration of PostDevelopment. London: Zed Books.

Latouche, S. (1997). Paradoxical Growth. In M. Rahnema \& V. Bawtree (Eds.), The Post Development Reader (pp. 135-142). London: Zed Books.

London, S. (2005). Permaculture: A Quiet Revolution - An Interview with Bill Mollison $\quad$ Retrieved 11/02/2010, from http://www.scottlondon.com/interviews/mollison.html

Madron, R., \& Jopling, J. (2003). The Web of Democracy. New Internationalist (360), 16-18.

McGregor, A. (2009). New Possibilities? Shifts in Post-Development Theory and Practice. Geography Compass, 3(5), 1688-1702.

McKinnon, K. (2007). Postdevelopment, Professionalism, and the Politics of Participation. Annals of the Association of American Geographers, 97(4), 772785.

Meltzer, A. (1996). Anarchism: Arguments for and Against. Edinburgh: AK Press.

Mertens, D. M., Holmes, H. M., \& Harris, R. L. (2009). Transformative Research and Ethics. In D. M. Mertens \& P. E. Ginsberg (Eds.), The Handbook of Social Research Ethics (pp. 85-102). Los Angeles: Sage Publications.

Mollison, B. (1988). Permaculture: A Designers' Manual. Tyalgum, N.S.W.: Tagari Publications.

Mollison, B., \& Holmgren, D. (1987). Permaculture One: A Perennial Agriculture for Human Settlements. Tyalgum, N.S.W.: Tagari Publishers.

Mollison, B., \& Slay, R. M. (1994). Introduction to Permaculture (2nd ed.). Tyalgum, Australia: Tagari Publishers.

Morland, D. (2004). Anti-capitalism and Poststructuralist Anarchism. In J. Purkis \& J. Bowen (Eds.), Changing Anarchism: Anarchist Theory and Practice in a Global Age (pp. 23-38). Manchester: Manchester University Press.

Morse, V. (2007). Against Freedom: The War on Terrorism in Everyday New Zealand Life. Te Whanganui a Tara (Wellington): Rebel Press. 
Mueller, T. (2003). Empowering Anarchy: Power, Hegemony and Anarchist Strategy. Anarchist Studies, 11(2), 26-53.

Murphy, P. (2008). Plan C: Community Survival Strategies for Peak Oil and Climate Change. Gabriola Island, BC: New Society Publishers.

Nederveen Pieterse, J. (2001). Development Theory: Deconstructions/Reconstructions. London: Sage Publications.

Nolan, R. W. (2002). Development Anthropology: Encounters in the Real World. Boulder \& Oxford: Westview Press.

Nustad, K. G. (2001). Development: The Devil We Know? Third World Quarterly, 22(4), 479-489.

Pain, R. (2003). Social Geography: On Action-Orientated Research. Progress in Human Geography, 27(5), 649-657.

Polk, S. (2008). Neoliberal Urban Areas and an Anarchist Response: Community, Direct Democracy and Ecological Design. Paper presented at the APSA 2008 Annual Meeting, Hynes Convention Center, Boston, Massachusetts Online $<\mathrm{PDF}>$. Retrieved 20 August 2009, from http://www.allacademic.com//meta/p mla apa research citation/2/8/ 0/2/3/pages280230/p280230-1.php

Purkis, J., \& Bowen, J. (Eds.). (2004). Changing Anarchism: Anarchist Theory and Practice in a Global Age. Manchester: Manchester University Press.

Rahnema, M. (1997). Introduction. In M. Rahnema \& V. Bawtree (Eds.), The Post-Development Reader (pp. ix-xix). London: Zed Books.

Rahnema, M., \& Bawtree, V. (1997). The Post-Development Reader. London: Zed Books.

Rapley, J. (2004). Development Studies and the Post-Development Critique. Progress in Development Studies, 4(4), 350-354.

Rist, G. (1997). The History of Development: From Western Origins to Global Faith. London: Zed Books.

Rist, G. (2007). Development as a Buzzword. Development in Practice, 17(4-5), 485491.

Rosset, P., Martínez-Torres, M. E., \& Hernández-Navarro, L. (2005). Zapatismo in the Movement of Movements. Development: The Movement of Movements, 48(2), 35-41. 
Routledge, P. (1996). The Third Space as Critical Engagement. Antipode, 28(4), 399-419.

Routledge, P. (2009). Transnational Resistance: Global Justice Networks and Spaces of Convergence. Geography Compass, 3(5), 1881-1901.

Sachs, W. (1995). Introduction. In W. Sachs (Ed.), The Development Dictionary: A Guide to Knowledge as Power (4th ed., pp. 1-5). Johannesburg: Witwatersrand University Press.

Sachs, W. (1997). The Need for the Home Perspective. In M. Rahnema \& V. Bawtree (Eds.), The Post-Development Reader (pp. 290-300). London: Zed Books.

Scheper-Hughes, N. (1995). The Primacy of the Ethical: Propositons for a Militant Anthropology. Current Anthropology, 36(3), 409-420.

Scheyvens, R., Scheyvens, H., \& Murray, W. E. (2003). Working with Marginalised, Vulnerable or Privileged Groups. In R. Scheyvens \& D. Storey (Eds.), Development Fieldwork: A Practical Guide (1st ed., pp. 167193). London: Sage Publications.

Schumacher, E. F. (1973). Small is Beautiful: A Study of Economics as if People Mattered. London: Vintage.

Seabrook, J. (2002). Unchaining Captive Hearts. New Internationalist (342), 15-17.

Sen, A. K. (2002). Globalization, Inequality and Global Protest. Development, 45(2), 11-16.

Seyfang, G., \& Pearson, R. (2000). Time for Change: International Experience in Community Currencies. Development 43(4), 56-60.

Shi, D. E. (1997). The Searchers After the Simple Life. In M. Rahnema \& V. Bawtree (Eds.), The Post-Development Reader (pp. 308-310). London: Zed Books.

Shift Magazine/ Dysophia (2010). Criticism without Critique: A Climate Camp Reader: Shift Magazine/ Dysophia.

Sidaway, J. D. (2007). Spaces of Postdevelopment. Progress in Human Geography, 31(3), 345-361.

Simon, D. (2007). Beyond Antidevelopment: Discourses, Convergences, Practices. Singapore Journal of Tropical Geography, 28(2), 205-218. 
Starr, A. (2000). Naming the Enemy: Anti-Corporate Movements Confront Globalization. London \& New York: Zed Books.

Starr, A. (2005). Global Revolt: A Guide to the Movements Against Globalization. London \& New York: Zed Books.

Starr, A., \& Adams, J. (2003). Anti-globalization: The Global Fight for Local Autonomy. New Political Science, 25(1), 19-42.

Storey, A. (2000). Post-Development Theory: Romanticism and Pontius Pilate Politics. Development, 43(4), 40-46.

Tane, H. (30 May 2009). Guest Speaking at the Permaculture in New Zealand (PiNZ) Annual Hui. Te Teko.

Tedlock, B. (1991). From Participant Observation to the Observation of Participation: The Emergence of Narrative Ethnography. Journal of Anthropological Research, 47(1), 69-94.

The Seeds for Change Collective (2007a). How to Make Decisions by Consensus. In The Trapese Collective (Ed.), Do It Yourself: A Handbook for Changing Our World (pp. 63-77). London: Pluto Press.

The Seeds for Change Collective (2007b). Why Do It Without Leaders. In The Trapese Collective (Ed.), Do It Yourself: A Handbook for Changing Our World (pp. 50-62). London: Pluto Press.

The Trapese Collective (2007). Introduction: Do It Yourself. In The Trapese Collective (Ed.), Do It Yourself: A Handbook for Changing Our World (pp. 110). London: Pluto Press.

The World Cafe (2007). What is the World Cafe? Retrieved 9 February 2010, from http://www.theworldcafe.com

Trainer, T. (2000). Where Are We, Where Do We Want To Be, How Do We Get There? [Dialogue Section]. Democracy and Nature: The International Journal of Inclusive Democracy, 6(2).

Trainer, T. (2009a). The Transition Towns Movement; its Huge Significance and a Friendly Criticism Retrieved 24 July 2010, from http://candobetter.org/node/1439

Trainer, T. (2009b). Ted Trainer on Transition Towns Retrieved 24 July 2010, from http://yesterdaysfuture.net/blog/?p=413 
Valente, F. L. S. (2002). Food Security and Nutrition at the Heart of 'Another World'. Development, 43(2), 84-88.

Verson, J. (2007). Why We Need Cultural Activism. In The Trapese Collective (Ed.), Do It Yourself: A Handbook for Changing Our World (pp. 171-186). London: Pluto Press.

Waterman, P. (2005). The Old and the New: Dialectics around the Social Forum Process. Development: The Movement of Movements, 48(2), 42-47.

Wilber, K. (2000). A Brief History of Everything (2nd ed.). Boston: Shambhala Publications.

Williams, G. (22-24 May 2009). Lower North Island Permaculture Hui. Wellington.

Williams, G. (2006). Out of the Helix: A Cultural Mutation - Essays on Cultural Transformation. Horowhenua: Spiral Pulse Press.

Williams, L. (2007). Anarchism Revived. New Political Science, 29(3), 297-312.

Zepeda, C. (2006). Development Alternatives or Alternatives to Development: The Creative Whirlwinds of the Alternatives. In R. Alluri, S. D'Souza, C. Nunez, J. Peterson, T. V. Staveren \& C. Zepeda (Eds.), An Exercise in Worldmaking (pp. 127-139). The Hague: Institute of Social Studies.

Ziai, A. (2004). The Ambivalence of Post-Development: Between Reactionary Populism and Radical Democracy. Third World Quarterly, 25(3), 10451060. 